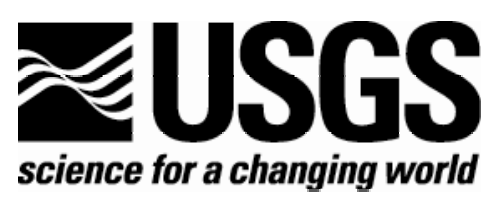

\title{
Two-Dimensional Magnetotelluric Model of Deep Resistivity Structure in the Bodie-Aurora District of California
}

By Jay A. Sampson

\section{Open-File Report 2006-1060}




\section{U.S. Department of the Interior \\ Gale A. Norton, Secretary}

\section{U.S. Geological Survey \\ P. Patrick Leahy, Acting Director}

U.S. Geological Survey, Reston, Virginia 2005

Revised and reprinted: 2005

For product and ordering information:

World Wide Web: http://www.usgs.gov/pubprod

Telephone: 1-888-ASK-USGS

For more information on the USGS - the Federal source for science about the Earth, its natural and living resources, natural hazards, and the environment:

World Wide Web: http://www.usgs.gov

Telephone: 1-888-ASK-USGS

Although this report is in the public domain, permission must be secured from the individual copyright owners to reproduce any copyrighted material contained within this report. 


\section{Contents}

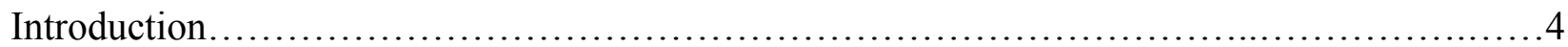

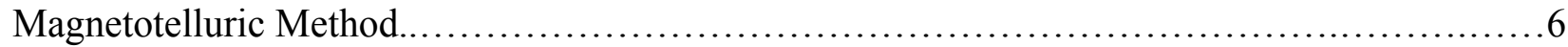

Bodie-Aurora Magnetotelluric Survey .................................................. 10

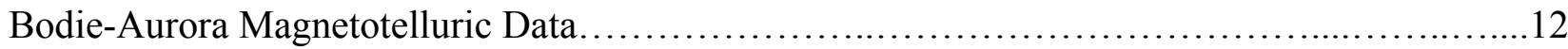

Bodie-Aurora Electrical Resistivity Cross Section..........................................16

Geologic Interpretation of the Bodie-Aurora Deep Resistivity Structure Based on the 2-D Inversion

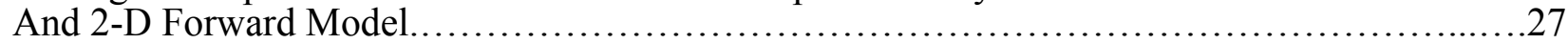

Conclusions and Recommendations for Future Work........................................30

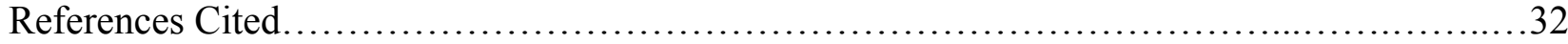

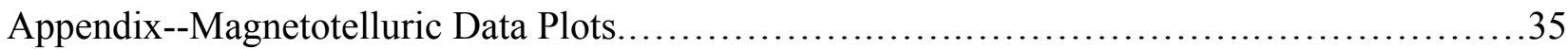

\section{Figures}

Figure 1. Bodie-Aurora magnetotelluric profile index map in eastern California...................5

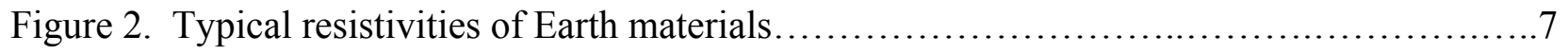

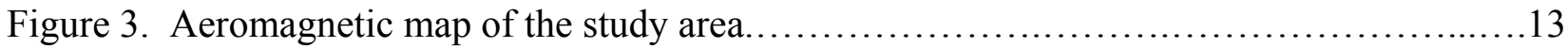

Figure 4. Two-dimensional resistivity inversion of the Bodie-Aurora magnetotelluric

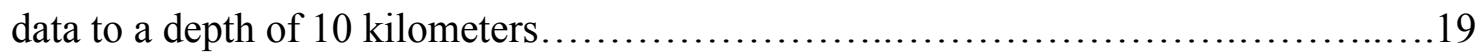

Figure 5. Two-dimensional resistivity inversion of the Bodie-Aurora magnetotelluric

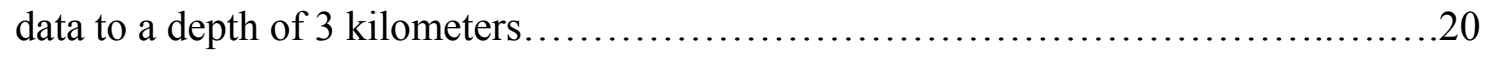

Figure 6. Observed and calculated data curves of the Bodie-Aurora magnetotelluric

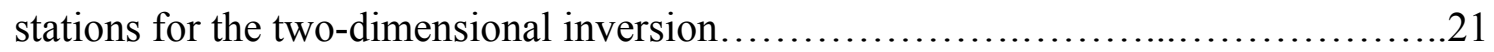

Figure 7. Tipper strike Frequency Section of the Bodie-Aurora magnetotelluric data..............23

Figure 8. Two-dimensional forward model of the Bodie-Aurora magnetotelluric data

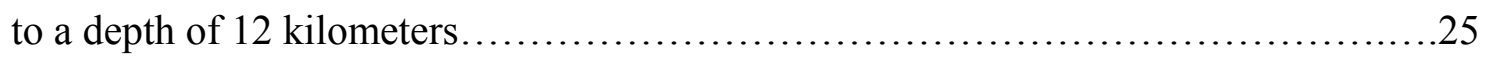

Figure 9. Observed and calculated data curves of the Bodie-Aurora magnetotelluric stations for the two-dimensional forward model....................................26

\section{Table}

Table 1. Location coordinates of the Bodie-Aurora magnetotelluric stations. 


\section{Introduction}

Magnetotelluric data were acquired during October 2001 by the U.S. Geological Survey (USGS) as part of a study to examine the structural nature of basins in the transition zone between the Sierra Nevada Mountains of California and the Basin and Range province of Nevada. Magnetotelluric (MT) geophysical studies assist the mapping of geologic structure and the inference of lithologic packages that are concealed beneath the Earth's surface. The MT method is a passive geophysical technique that utilizes the Earth's natural electromagnetic field as a source of signal to investigate the electrical resistivity structure of the subsurface to depths sometimes reaching tens of kilometers $(\mathrm{km})$. The MT data can be used to form electrical apparent resistivity profiles to complement regional or detailed geologic or geophysical studies.

The Basin and Range province has a complicated geologic history, which includes extension and compression of the Earth's crust to form the basins and ranges that blanket much of Nevada. The basins and ranges in the vicinity of this study trend northeastward and are bounded by steeply dipping strike slip faults. Interestingly, deep east-west magnetic trends occur in the aeromagnetic data of this study area indicating that the northeast-trending basins and ranges represent only thinskinned deformation at the surface with an underlying east-west structure. To investigate this issue, MT data were acquired at seven stations (fig. 1) in eastern California, $20 \mathrm{~km}$ east of Mono Lake. The purpose of this report is to present a two-dimensional apparent resistivity model of the MT data acquired for this study. The apparent resistivity model, in conjunction with existing geologic, magnetic, and gravity data, can be used to understand the structure and lithology of the concealed basins along the profile to depths reaching approximately $10 \mathrm{~km}$. 


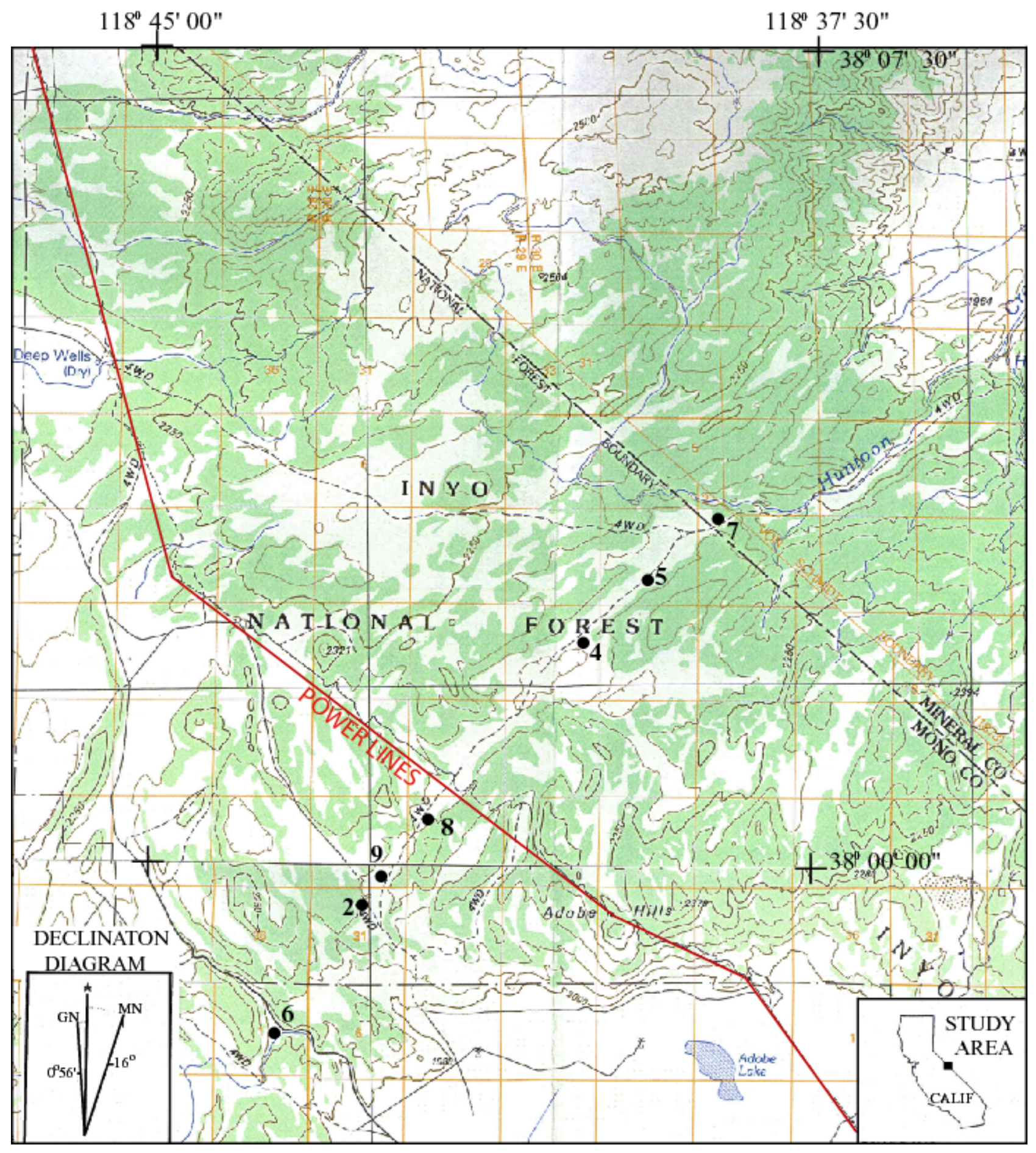

Figure 1. Location of the 11.4-kilometer Bodie-Aurora magnetotelluric (MT) profile in eastern California. The Bodie-Aurora profile is composed of the seven MT stations acquired during October of 2001. Base map is from California-Nevada 1:100,000 Benton Range and Excelsior Mountains U.S. Geological Survey topographic maps. 


\section{Magnetotelluric Method}

The MT method is a passive geophysical technique that uses the Earth's natural electromagnetic field as a source of signal to investigate the electrical resistivity structure of the subsurface. The resistivity of a geologic unit is largely dependent upon fluid content, porosity, degree of fracturing, temperature, and conductive mineral content (Keller, 1989). Saline fluids within pore spaces and fracture openings can reduce the resistivity of a rock matrix. Resistivity may also be lowered by the presence of conductive clay minerals, carbon, and metallic mineralization. Increased temperatures cause higher ionic mobility and mineral activation energy, reducing rock resistivities significantly. Unaltered, unfractured igneous rocks are normally very resistive, typically thousands of ohm-meters (ohm-m). Fault zones can appear as low apparent resistivity units of less than $100 \mathrm{ohm}-\mathrm{m}$ when they are composed of rocks fractured enough to have hosted fluid transport and consequent mineralogical alteration (Eberhart-Phillips and others, 1995). Carbonate rocks are moderately to highly resistive with values of hundreds to thousands of ohm-m depending upon their fluid content, porosity, fracturing, and impurities. Marine shales, mudstones, and clay-rich alluvium normally are very conductive with resistivities from a few to tens of ohmm. Unaltered, metamorphic, nongraphitic rocks are moderately to highly resistive (hundreds to thousands of ohm-m). Tables of electrical resistivity for a variety of rocks, minerals and geological environments are included in Keller (1987) and Palacky (1987). Figure 2 illustrates that a wide range of resistivities may exist for various Earth materials.

The MT method can be used to probe the Earth's crust from depths of a few hundred to tens of km (Vozoff, 1991). Natural variations of the Earth's magnetic and electric field are measured and recorded at each MT station. The MT signal in the frequency range of 10,000 to $1 \mathrm{Hertz}(\mathrm{Hz})$ is due to worldwide lightning activity, whereas the signal from 1 to $0.0001 \mathrm{~Hz}$ is the result of geomagnetic micropulsations. The low frequency micropulsations originate either from within the Earth or from solar disturbances. Natural electric and magnetic fields propagate vertically in the Earth because the very large resistivity contrast between the air and the Earth causes a vertical refraction of both fields as they are transmitted into the Earth (Vozoff, 1972). The ionosphere surrounding the Earth acts as a waveguide that allows the electrical energy from lighting strikes to travel large distances around the Earth. The electrical energy induces magnetic fields in the Earth's subsurface that are recorded by the MT system. 


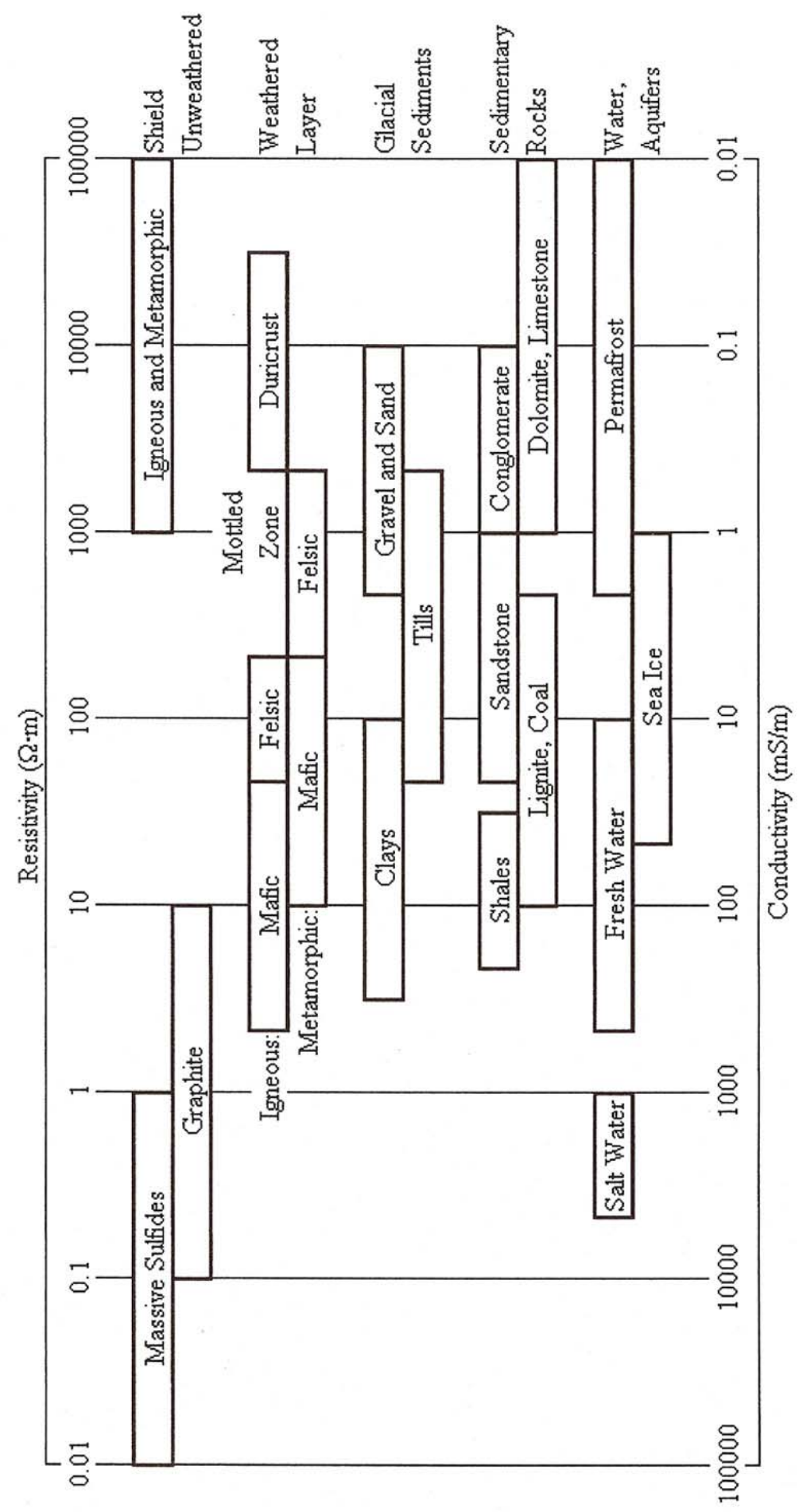

Figure 2. Typical ranges of resistivities of earth materials (Palacky, 1987). Resistivity units are given in Ohm meters. Conductivity units are given in millieSiemens per meter. 
The MT method records the natural electric and magnetic fields in two orthogonal, horizontal directions. The tensor impedance, parameterized as apparent resistivity and phase, are obtained from the recorded signals during post-acquisition processing of the data. Apparent resistivity is the ratio of one component of the electric field magnitude over the orthogonal component of the magnetic field magnitude, normalized by frequency and the magnetic susceptibilty for free space. The electrical resistivity of a rock specimen can be measured in the laboratory, whereas the apparent resistivity at a given frequency should be thought of as an average resistivity of a package of Earth materials at a given depth. The apparent resistivity curves for an MT station represent apparent resistivity values over a range of frequencies. As the frequencies decrease, the depth of investigation increases. MT surveys normally are planned so the profile of stations is perpendicular to geologic strike. Two apparent resistivity curves are calculated at each MT station, with one curve being the transverse electric (TE) mode (electric field parallel to geologic strike) and the other being the transverse magnetic (TM) mode (electric field perpendicular to geologic strike). The impedance phase is the arctangent of the un-normalized ratio of the orthogonal components of the electric field magnitude over the magnetic field magnitude. The apparent resistivity and phase are related through a Hilbert Transform; the phase is proportional to the slope of the apparent resistivity curve on a log-log plot, but from a baseline at 45 degrees (Vozoff, 1991). The phase data, like the apparent resistivity data, also can be modeled. Traditionally, signals from a single MT site are converted to complex cross-spectra using a FastFourier-Transform technique. A least-squares, cross-spectral analysis (Bendat and Piersol, 1971) then is used to solve for a transfer function (impedance) that relates the observed electric fields to the magnetic fields under the assumption that the Earth consists of a two-input, two-output, linear system with the magnetic fields as input and the electric fields as output.

If the vertical magnetic field is recorded at an MT station, a transfer function between the horizontal and vertical components of the magnetic field can be constructed that commonly is referred to as the "tipper". The tipper magnitude is a measure of the tipping of the magnetic field out of the horizontal plane (Vozoff, 1991). The magnitude is zero for the one-dimensional (1-D) case and typically increases to between 0.1 to 0.5 , but rarely as great as 1 , as it responds to vertical and subvertical two-dimensional (2-D) or three-dimensional (3-D) structures. The tipper strike, another parameter that can be calculated from these components, typically is used to help resolve the 90-degree ambiguity in the impedance rotation angle. The tipper strike, while not required in 
the data processing, is useful in modeling the MT data. The three-component magnetic field coherencies that are calculated provide a check on the signal-to-noise ratio of the measured values in the tipper magnitude and tipper strike data plots. The vertical magnetic field, unfortunately, typically is very small in magnitude and difficult to measure with induction coils in mountainous terrain. Because of the very small signals recorded, protection from all movement of the vertical coil is difficult but essential. A small breeze will buffet the vertical coil and result in noisy unuseable data at mid-range frequencies (typically 0.1 to $10 \mathrm{~Hz}$ ). Setup time at an MT station increases greatly when the vertical magnetic field is recorded because the vertical coil must be buried. The vertical magnetic field was recorded at all of the stations in this study.

Remote reference (RR) processing commonly is used to reduce noise and bias errors, due to instrumental or environmental noise, in the impedance determinations (Gamble and others, 1979a; Clarke and others, 1983). Horizontal magnetic or electric fields or both are recorded simultaneously at a separate, remote site and cross-correlated with the electromagnetic fields at the local site. The RR method is one of the simplest, yet most useful, ways in which MT measurements from two sites can be used to improve the quality of the local impedance estimates. In many cases, neither the natural signal nor the noise source can be adequately modeled as Gaussian, and thus, least-square techniques can fail even with remote referencing. Hence, robust processing techniques in which a weighting term is included in the RR impedance estimator are becoming popular (Egbert and Booker, 1986; Chave and Thompson, 1989). Lack of sufficient time and equipment did not permit the use of remote referencing for this study. Remote referencing may have improved the data quality in this study, as $60-\mathrm{Hz}$ interference was significant. In most cases, if visual inspection of the data acquired for this study indicated unusable noisy data at the time of acquisition in the field, those data were rejected and not recorded.

For a 2-D Earth, the diagonal terms of the impedance tensor are zero. The off-diagonal terms of the MT data are decoupled into TE and TM modes. When the geologic structure (without strong rock-grain anisotropy) satisfies the 2-D assumption, the MT data for the TE mode are for the electric field parallel to geologic strike, and the data for the TM mode are for the electric field across strike. The tipper, if available, is helpful in distinguishing the TE and TM modes. Normally, data are processed with a fixed rotation parallel and perpendicular to regional strike, as acquired in the field. The apparent resisitivity parameter can be distorted by near-surface resistivity 
inhomogeneities, called "static shifts", as described by Pellerin and Hohmann (1990). Because of static shift, the entire TE or TM (or both) curve, over its entire frequency range, will be shifted up or down making the curve appear to be more or less resistive than it really is. Data can be corrected with an independent or remote dataset. About 10 percent of any given dataset typically has significant static shift distortions.

The MT method is well suited for studying complicated geological environments because the electric and magnetic relations are sensitive to vertical and horizontal variations in resistivity. Large variations in rock resistivities (at least a factor of 3 ) on either side of a fault or between rock lithologies are successfully mapped by this geophysical technique. The MT method also is capable of establishing whether the electromagnetic fields are responding to subsurface terranes of effectively one, two, or three dimensions. An introduction to the MT method is given in Telford and others (1990), and a more advanced treatment is contained in Vozoff (1991).

\section{Bodie-Aurora Magnetotelluric Survey}

The Bodie-Aurora profile, as shown in figure 1, consists of seven MT soundings that were acquired by the U.S. Geological Survey during October 2001. The 11.4-km profile extends northeastward across the low Adobe Hills, which are located in the Inyo National Forest of eastcentral California. The southwest end of the profile is near the California-Nevada border $18 \mathrm{~km}$ due east of Mono Lake. The northeast end of the profile is located just inside Nevada about $5 \mathrm{~km}$ southwest of Huntoon Valley. MT stations were located about every $1.5 \mathrm{~km}$ along the profile. Station locations were selected to cross an east-west trending magnetic anomaly shown in figure 3. The MT data acquired for this study should result in a better understanding of that magnetic anomaly.

All sounding locations were road accessible. Access to the study area was by way of fairly well maintained county roads to within approximately $5 \mathrm{~km}$ of the work area. The final $5 \mathrm{~km}$ to the work sites required traversing a moderately difficult four-wheel-drive (4WD) jeep trail. The profile itself was located along a sandy 4WD trail that became increasingly difficult with daily trips to and from the work sites. The MT stations were located on sandy surficial deposits common alongside the trail. Exposed rock along the length of the profile appears to be an extensive basalt flow that 
blankets the area. Tertiary cinder cones are exposed between stations 6 and 8 with one being very near to station 7 (Gilbert and others, 1968, and Kleinhampl and others, 1975). The same authors map many small faults in the exposed basalt flow to the north and south of the MT profile. Those faults parallel the profile between stations 8 and 7 with one being very near, if not precisely beneath, the profile. That fault is mapped first near station 9 and continues on a northeasterly strike well beyond station 7 . Between stations 8 and 6 , the faults either terminate or rotate to a northwesterly strike.

All data were acquired by a portable EMI MT-1 system (EMI, 1996). The horizontal electric fields (Ex and Ey) were measured using copper-sulfate electrodes in an L-shaped array with dipole lengths of nominally 30 meters $(\mathrm{m})$. The orthogonal components of the magnetic field ( $\mathrm{Hx}$ and Hy), with horizontal components in the same direction as the electric-field array, were measured with permalloy-cored induction coils. The vertical component of the magnetic field $(\mathrm{Hz})$ also was collected. Frequencies sampled ranged from 23,000 to $0.009 \mathrm{~Hz}$. The magnetic declination on the compass was set to 14 degrees east to determine true north ( 0 degrees). The azimuths (in degrees) of the horizontal coils and electrodes for all stations were $\mathrm{Hx}=0, \mathrm{Hy}=90$, $E x=0, E y=90$. Six days of fieldwork were required to acquire the data for this study. Difficult terrain conditions and substantial driving distances over 4WD roads to field sites limited data acquisition to only one MT station per day.

Location information for the seven MT stations that comprise the Bodie-Aurora profile is listed in table 1. Station locations were plotted by hand on 1:24000 USGS topographic maps during field acquisition and also located by a hand-held GPS system. Latitudes and longitudes then were verified from the field maps and finally converted to Universal Transverse Mercator (UTM) coordinates. Coordinates are referenced to the 1866 Clarke spheroid and North American 1927 Western United States datum. Longitude and latitude format is in degrees, minutes, and seconds. UTM units and elevation above sea level are given in meters. 
Table 1. Location coordinates of the Bodie-Aurora magnetotelluric stations.

\begin{tabular}{|c|c|c|c|c|c||c|c|}
\hline Station ID & Field Station & Latitude & Longitude (-) & \multicolumn{2}{|c|}{ UTM Zone 11 } & \multicolumn{2}{|c|}{ Elevation } \\
\hline on 2-D Model & ID Number & degrees-minutes-seconds & x-coordinate & y-coordinate & meters & feet \\
\hline 6 & $\mathrm{ab} 6$ & $37-58-17$ & $118-43-20$ & 348729 & 4204040 & 2026 & 6647 \\
\hline 2 & $\mathrm{ab} 2$ & $37-59-23$ & $118-42-22$ & 350182 & 4206048 & 2109 & 6921 \\
\hline 9 & $\mathrm{ab} 9$ & $37-59-24$ & $118-42-16$ & 350329 & 4206076 & 2111 & 6926 \\
\hline 8 & $\mathrm{ab} 8$ & $38-00-15$ & $118-41-36$ & 351333 & 4207630 & 2174 & 7134 \\
\hline 4 & $\mathrm{ab} 4$ & $38-02-04$ & $118-40-07$ & 353564 & 4210950 & 2119 & 6952 \\
\hline 5 & $\mathrm{ab} 5$ & $38-02-25$ & $118-39-14$ & 354867 & 4211575 & 2179 & 7149 \\
\hline 7 & $\mathrm{ab} 7$ & $38-03-06$ & $118-38-20$ & 356206 & 4212815 & 2103 & 6898 \\
\hline
\end{tabular}

\section{Bodie-Aurora Magnetotelluric Data}

The Bodie-Aurora profile is located in a remote area of California away from most sources of cultural noise that would affect the quality of the data. Sources of noise, such as power lines, power generators, and moving vehicles and trains, can produce an incoherent noise mainly affecting frequencies above $1 \mathrm{~Hz}$. Other electrical noise, such as direct current electric trains and active cathodic protection of pipelines, produces coherent electromagnetic signals mainly affecting frequencies below $1 \mathrm{~Hz}$. No known pipelines or mining operations were in the study area. All stations for the profile were set up next to a 4WD road. Data collection was halted, and bad data were rejected when moving vehicles were in the area. Wind noise was minimized by burying the magnetic induction coils and by keeping the electric dipole wires flat on the ground. Interference from military air-traffic transmissions, radio repeater stations, or possibly a distant irrigation pump occasionally could be seen in the data, and those data were rejected and not retained in the data files. This survey was located in a very remote area with few sources of noise except for one. Unfortunately, two large northwest to southeast trending power lines cut through the center of the profile just $0.8 \mathrm{~km}$ to the northeast of station 8 . Those power lines follow a 4WD road shown in figure 1. They also can be seen in the aeromagnetic data as a lineament trending from the northwest to the southeast (fig. 3). The presence of those power lines was apparent in the data and had a negative effect on data quality. Normally a study area would have been located at least $3 \mathrm{~km}$ from power lines such as those encountered during this study. However, for this study, a suitable alternative location could not be found. Noisy data were identified and then rejected (the entire 


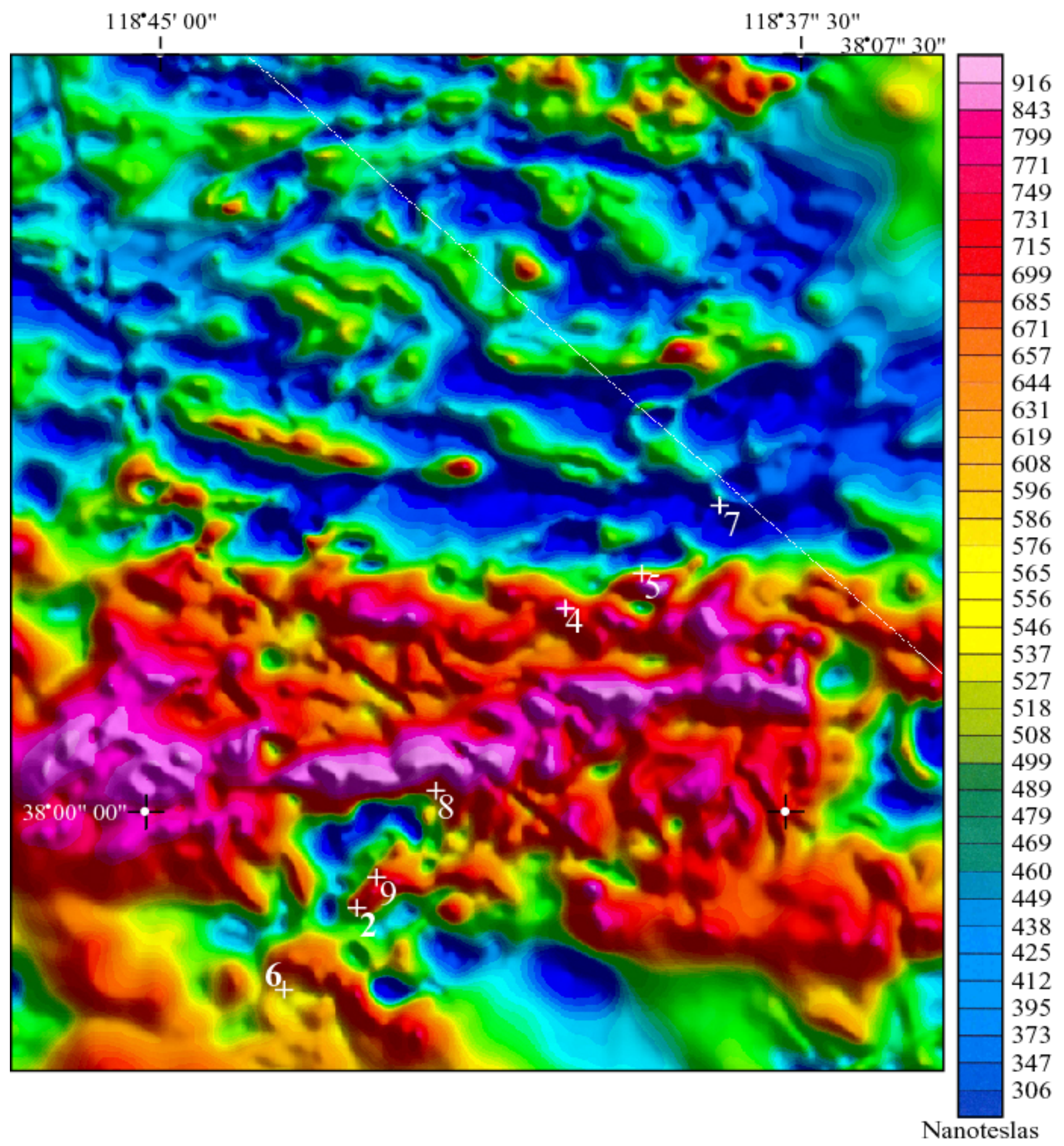

Figure 3. Aeromagnetic map of the study area (U.S. Geological Survey, 2001). Labeled white crosses are magnetotelluric stations. 
time-series) by visually inspecting and selecting the best signal-to-noise field data. The remaining data then were combined into the final data plots.

Initial processing of the recorded MT time-series data transformed the electrical and magnetic signals into the frequency domain. Time-series known to contain noise, caused by passing vehicles, excessive wind, or operator error, for example, were not included in the final cross-power files. Data were freely rotated and are presented as such in the appendix. The apparent resistivity and phase tensor values for each site then were calculated (detailed discussion in Magnetotelluric Method section above). For the apparent resistivity plots, the xy component (" $\mathrm{x}$ " symbol) is the nominal TE mode and the yx component ("o" symbol) is the TM mode. Error bars on the Apparent Resistivity, Impedance Phase, Skew, Tipper Magnitude, and Tipper Strike plots represent probable errors within one standard deviation of the sample variance (Gamble and others, 1979b).

For each station, nine separate plots are given in the Appendix:

1. APPARENT RESISTIVITY for the maximum TE (x symbol) and minimum TM (o symbol) modes with free rotation.

2. IMPEDANCE PHASE for the maximum TE (x symbol) and minimum TM (o symbol) rotation.

3. ROTATION ANGLE for the impedance tensor.

4. IMPEDANCE SKEW for the impedance tensor.

5. Multiple E-predicted coherency (E MULT Coh.) for the maximum (Ex-HxHy) (x symbol) and minimum (Ey-HxHy) (o symbol) modes of the electric field.

6. Impedance POLAR PLOTS.

7. TIPPER MAGNITUDE of the vertical magnetic field.

8. TIPPER STRIKE of the vertical magnetic field.

9. MULTIPLE COHERENCY FOR Hz-Hx (x symbol) and Hz-Hy (o symbol).

Apparent resistivity is the ratio of one component of the electric field magnitude over the orthogonal component of the magnetic field magnitude, normalized by frequency and the magnetic susceptibilty for free space. The impedance phase is the arctangent of the unnormalized ratio. The phase is proportional to the slope of the apparent resistivity curve. A negative slope in the phase 
curve will be seen as a positive slope in the apparent resistivity curve but at a lower frequency. The opposite relationship also applies. Static shift of the apparent resistivity curves, indicating nearsurface resistivity inhomogeneities, was apparent in the Bodie-Aurora apparent resistivity plots. No independent electromagnetic data were acquired specifically to correct for the small to moderate static shift present in all stations. The rotation angle for the impedance tensor corresponds to the direction of maximum apparent resistivity. A measure of the dimensionality for MT data is provided by the impedance skew of the impedance tensor. If the effective measured resistivity response to the geology beneath a MT station is truly 1-D or 2-D, then the skew will be zero. Both instrument and environmental sources of noise contribute to nonzero skew values, but typically are small (about 0.1) for relatively low noise-level recordings. Higher skews (above about 0.2) are an indication of either the resistivity response to 3-D geology or higher levels of noise (Vozoff, 1972). For this data, set all MT stations have skews of less than 0.2 in the frequency range of 10 to $100 \mathrm{~Hz}$. Between the frequencies of 0.1 and $10 \mathrm{~Hz}$, the skews for all stations are above 0.2. The increasing skews of stations 6, 7, and 9 may indicate 3-D geology or noise or both. It appears that the high random skews of stations 2 and 8 are the result of even higher levels of noise and possibly 3-D geology. Generally, data with high skews and low coherencies are noisy.

Predicted values of the electric field can be computed from the measured values of the magnetic field (Vozoff, 1991). The coherence of the predicted electric field with the measured electric field is a measure of the signal-to-noise ratio provided in the multiple E-predicted coherency plot (plots are labeled "E MULT Coh. in the appendix). Values are normalized between 0 and 1, where values at 0.5 signify signal levels equal to noise levels. For this data set, coherencies varied from station to station. All stations had acceptable coherency values above 10 Hz. Coherencies for station 7 are acceptable above $5 \mathrm{~Hz}$, for station 8 above $0.9 \mathrm{~Hz}$, for station 2 above $0.02 \mathrm{~Hz}$, and for station 6 above $0.01 \mathrm{~Hz}$. Stations 2 and 6 had very high coherencies in the dead band of 0.1 to $5 \mathrm{~Hz}$. Coherencies generally are lower in the "dead band" because of the lower levels of natural signal at those frequencies. The frequency range of 0.1 to $10 \mathrm{~Hz}$ is on the outer edges of the frequency range for thunderstorms and micropulsations. Either natural dead band signal was unusually high for stations 2 and 6 or a coherent noise problem occurred.

The impedance polar plots provide a measure of the MT data dimensionality (Reddy and others, 1977). The impedance is a scalar value for a 1-D Earth; the tensor diagonal elements are 
zero for a 2-D Earth, and a full 2 by 2 for a 3-D Earth. For 1-D resistivity structures, the principal impedance polar diagram (dashed line) is a circle. For 2-D or 3-D resistivity structures, the principal impedance polar diagram, determined from the off-diagonal elements, elongates either parallel or perpendicular to strike direction. Over resistors, the principal impedance polar diagram elongates perpendicular to strike direction, and over conductors, it elongates parallel to strike direction. For nearly 2-D resistivity structures, the polar diagram, determined from the diagonal elements, (solid line) attains the shape of a small symmetric cloverleaf. For 3-D resistivity structures, the two polar plots are of comparable amplitude. The polar diagrams of sites 8,9 , and to a lesser extent 2 and 6, taken into consideration with those stations' high coherencies, indicate 3-D effects.

The tipper is the transfer function between the vertical and horizontal components of the magnetic field. The tipper magnitude is a measure of the tipping of the magnetic field out of the horizontal plane (Vozoff, 1991). The magnitude is zero for the 1-D case and typically increases to between about 0.1 and 0.5 , and rarely as great as 1 , as it responds to vertical and subvertical structures. The tipper strike is the geologic strike determined from the $\mathrm{Hz}$ data. The tipper strike typically is used to help resolve the 90-degree ambiguity in the impedance rotation angle. The $\underline{\mathrm{Hz}-}$ $\underline{\mathrm{Hx}}$ and $\mathrm{Hz}-\mathrm{Hy}$ coherency plots provide a measure of the signal-to-noise ratio of the vertical magnetic field with respect to each of the orthogonal horizontal magnetic field directions. Values are normalized between 0 and 1, where values at 0.5 signify signal levels equal to noise levels. These three-components of magnetic-field coherence provide a check on the signal-to-noise ratio of the measured values in the tipper magnitude and tipper strike plots. The vertical magnetic field typically is small and difficult to measure with induction coils in mountainous terrain because it is usually hard to adequately bury them.

\section{Bodie-Aurora Electrical Resistivity Cross Section}

Wannamaker (1983) determined that MT responses in northern Basin and Range geologic settings are normally 3-D in nature. Wannamaker and others (1984) also have demonstrated in 3-D resistivity modeling of MT data that approximating 3-D structure with 2-D modeling is best achieved by fitting the TM curve at the expense of fitting the TE curve. A close fit to the TM curve produces the best approximate model in a 3-D situation using 2-D algorithms. During modeling, 
care must be taken not to make the model too conductive with respect to the TE mode on 3-D stations. Because TM data are quite insensitive to the depth extent of a subsurface body (EberhartPhillips and others, 1995), the depths to the base of the bodies in the resulting 2-D model are not well constrained by using this technique. To best define the lower limits of the structures in a 3-D setting, 3-D resistivity modeling is required.

Stations 8, 9, and to a lesser extent 2 and 6 of this study indicated 3-D effects necessitating 3-D modeling of the data. Available resources, however, made 3-D modeling of this data set impossible. As a result, the MT data acquired for this study were modeled using a 2-D software package commercially available from the Geotools ${ }^{\mathrm{TM}}$ Corporation (www.geotools.com). The RLM2DI inversion program written by Randall L. Mackie from that package was used to determine the resistivity values for the 2-D inversion presented in this report. The RLM2DI inversion is based on acquired data and represents the Earth as a finite element mesh, which is like a "stack of bricks", each with a resistivity assigned from a palette of available values. The customary way to enter MT data into the Geotools ${ }^{\mathrm{TM}}$ software package and the RLM2DI 2-D inversion program is by reading a file in the standard format adopted by the Society of Exploration Geophysicists (SEG). That format is referred to as the EDI (Electrical Data Interchange) format. The EDI format is rapidly becoming accepted worldwide. Stacked spectra, impedances, or computed MT parameters can be read from an EDI file. Spectra are preferable if they are available because they allow the most processing flexibility. When data are read from an EDI file, the sites are automatically created at the correct locations because the EDI format includes full spatial information.

Field data acquired by the EMI MT-1 (EMI, 1996) system for this study were first visually selected for highest signal-to-noise levels and then converted to the proper EDI format. The EDI file then was entered into the Geotools ${ }^{\mathrm{TM}}$ software package. Data for each station between the frequencies of $46 \mathrm{~Hz}$ and $0.015 \mathrm{~Hz}$ were edited again to selectively deactivate individual frequencies that had low coherencies, high skews, or phase values that were in the wrong quadrant, each of which indicate noise. The data were rotated to a fixed angle of -41 degrees, which is 90 degrees counterclockwise from the 49-degree azimuth of the Bodie-Aurora profile of stations. The TE mode for each station then was set to be the XY curve, which corresponds to the -41-degree azimuth. The Geotools ${ }^{\mathrm{TM}}$ software automatically created the beginning mesh to be used for the 2-D inversion of this study. The entire mesh consists of 67 columns and 59 rows and has a total width 
of more than $120 \mathrm{~km}$ and total depth of more than $90 \mathrm{~km}$. Column width and row thickness increases away from the finer (central) part of the mesh to minimize edge effects in the inversion. The inversion presented in this report shows only the finer part of the mesh, which includes 62 columns and 45 rows. Each of the 60 columns between the end-stations of the profile is scaled to represent about $190 \mathrm{~m}$, giving the inversion a total width between end-stations of about $11.4 \mathrm{~km}$. The thickness of the rows increases from $10 \mathrm{~m}$ at the surface to $1 \mathrm{~km}$ at the maximum mesh depth of $10 \mathrm{~km}$. The inversion program was run for 25 iterations to allow the program to fit the observed data. The resulting 2-D inversion is presented at the depths of 10 and $3 \mathrm{~km}$ (figs. 4 and 5 respectively). Figure 4 shows the inversion to a depth of $10 \mathrm{~km}$ and width of $11.4 \mathrm{~km}$ and is essentially true to scale, with width nearly equaling depth. Figure 5 better illustrates the surface apparent resistivities at a depth to $3 \mathrm{~km}$ but has a vertical exaggeration of approximately $4: 1$. The 2-D inversion was run only on the TM mode because some of the data indicates a 3-D response. Figure 6 displays the computed fit of the inversion to the TM mode data. The observed TM data and the calculated fit to those data are represented in that figure by red circles and red pluses respectively. The curves formed by black circles represent the observed TE curves. As can be seen from the observed field data curves (formed by circles in fig. 6), data quality is marginal to poor in the middle portion $(0.1$ to $5 \mathrm{~Hz})$ of the TE and TM curves for most stations of this study. Large gaps in observed data were caused by removal through editing of noisy data points. Several frequencies in stations 7 and 8 had large error bars. It would be reasonable to expect that the power lines between stations 8 and 4 (fig. 1) had negative effects, varying to some degree, on the data quality of all stations of this study. Stations 2, 6, 8, and 9 were affected more by the power lines than stations 4,5 , and 7 , because the power line signal is enhanced over the resistive material that is seen at depth in the observed apparent resistivity data and in the resulting inversion. 


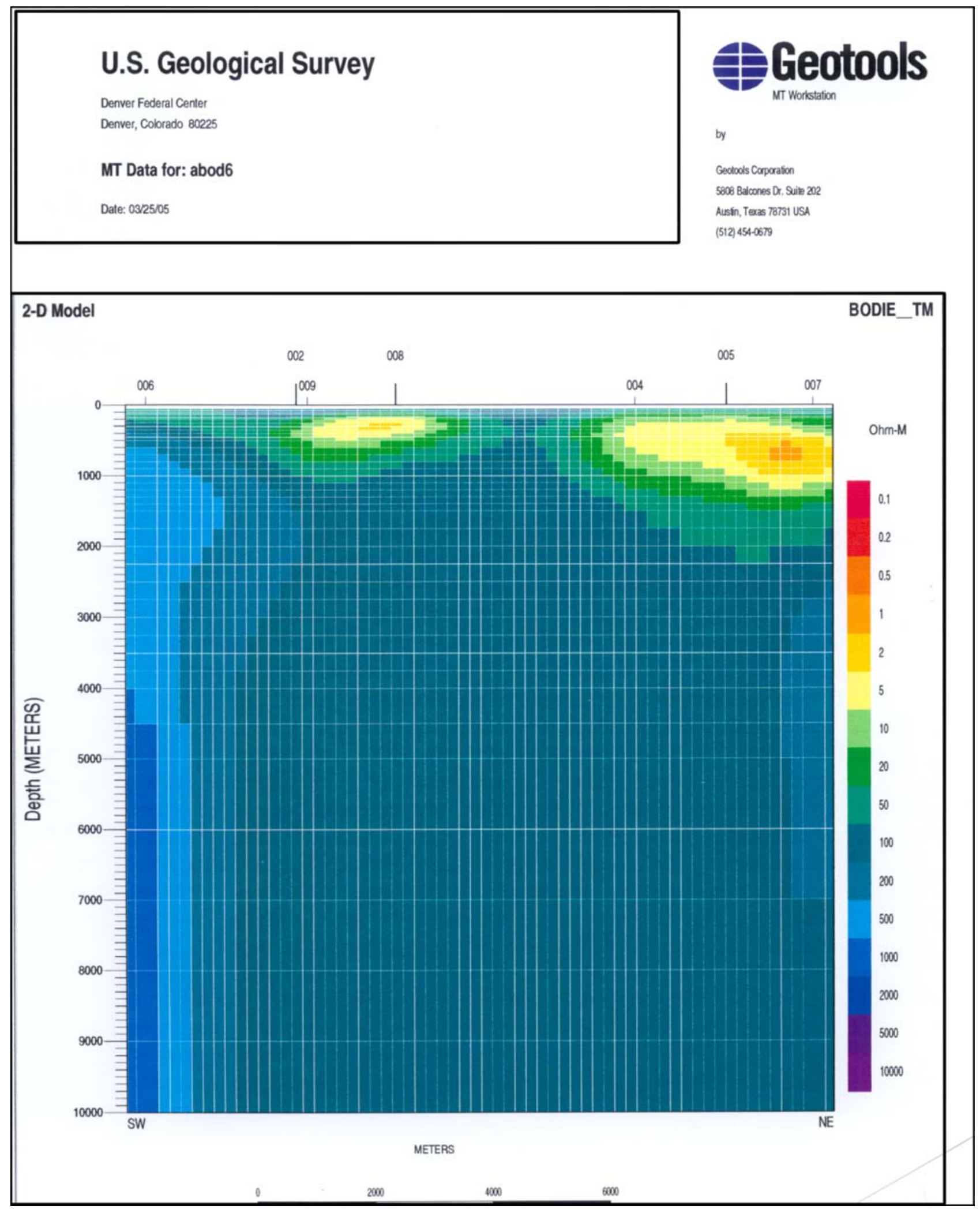

Figure 4. Two-dimensional resistivity inversion of the Bodie-Aurora magnetotelluric data to a depth of 10 kilometers. 


\section{U.S. Geological Survey}

Denver Federal Center

Denver, Colorado 80225

MT Data for: abod6

Geotods Corporation

5808 Baloones Dr. Sule 202

Date: 03/25/05

Ausin, Texas 78731 USA

(512) 454-0679

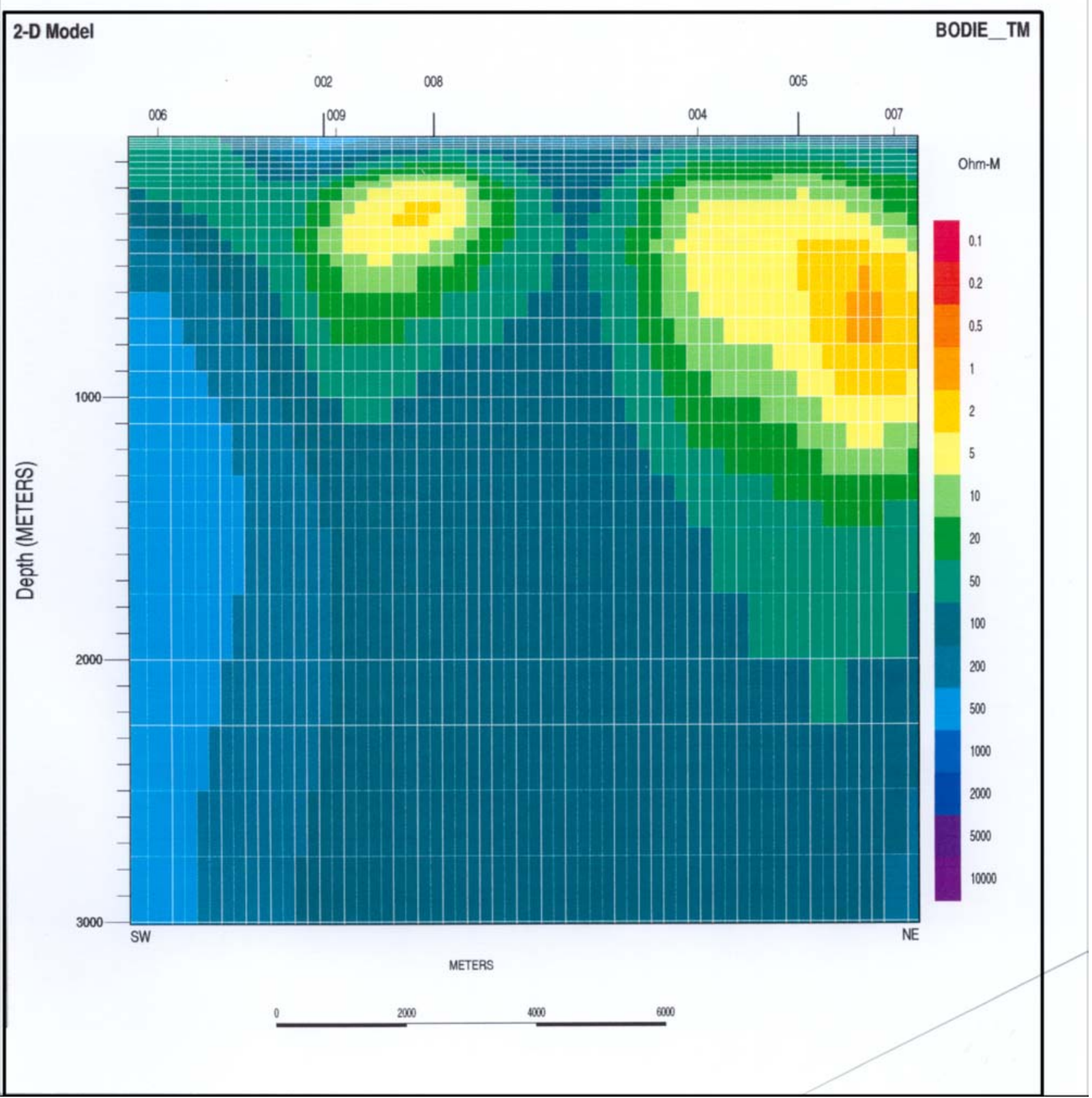

Figure 5. Two-dimensional resistivity inversion of the Bodie-Aurora magnetotelluric data to a depth of 3 kilometers. 


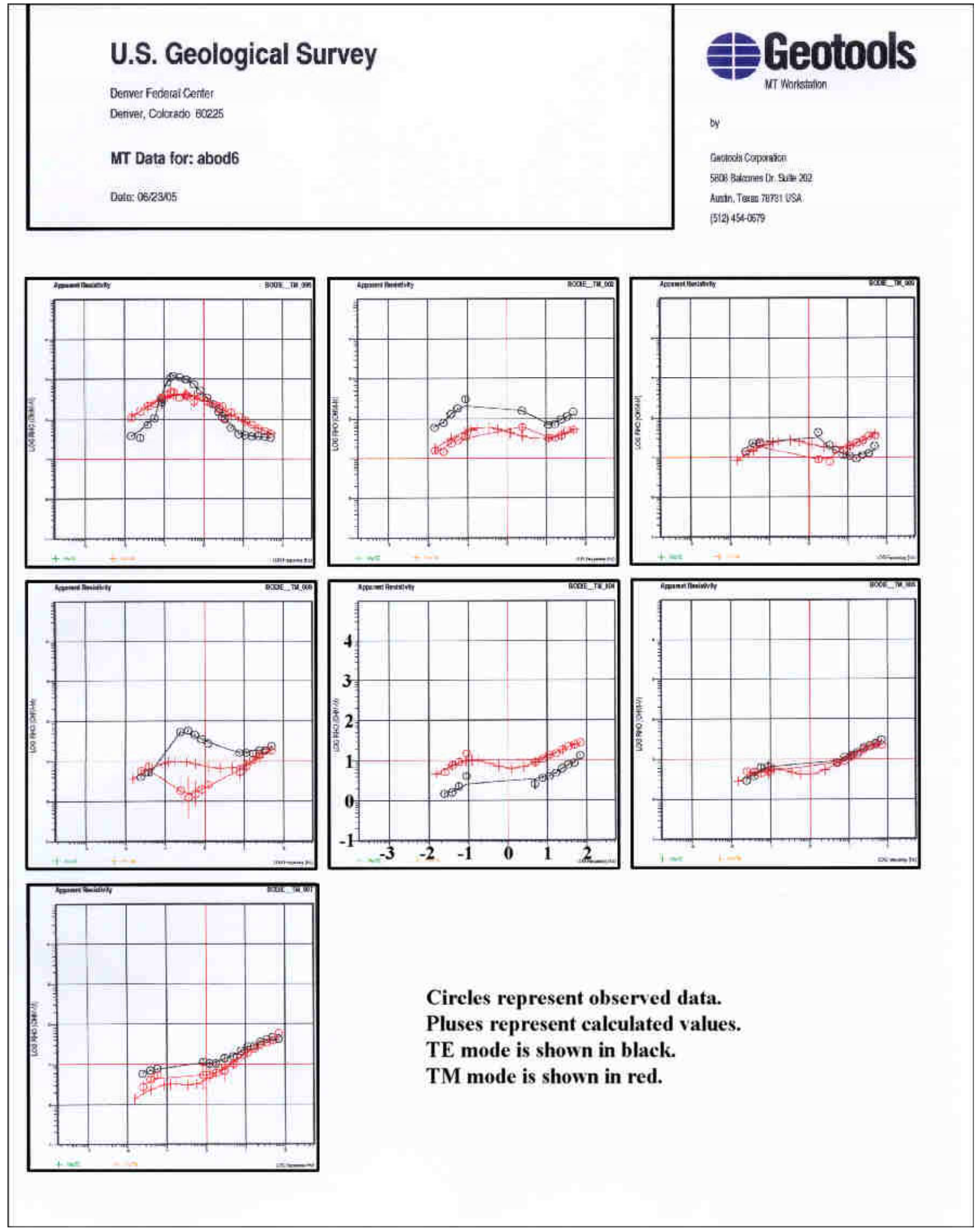

Figure 6. Observed and calculated data curves of the Bodie-Aurora magnetotelluric stations for the two-dimensional inversion. 
As can be seen in figure 6, the calculated fit (red pluses) to the TM data (red circles) by this inversion appears to be quite reasonable. Because data could not be collected too close to the power lines, a large gap is present between stations 8 and 4. If an MT station could have been collected midway between stations 8 and 4, the inversion probably would have resolved whether or not a continuous shallow conductor exists beneath stations 2 through 7 . The inversion began with a 100-ohm-m half-space and did not have adequate data to resolve a continuous shallow conductor between those stations. Please note that the terms "conductor" and "resistor" refer to an average apparent resistivity of a mass of material and may not necessarily refer to a single geologic unit. A "conductor" or "resistor" may be composed of many geologic units that have a wide variety of resistivities.

The tipper strike data, representing the geologic strike, can be calculated over a range of frequencies. Those values then can be contoured. The resulting tipper strike frequency section for the Bodie-Aurora MT data is included as figure 7. Generally, as frequency decreases in the section, depth increases. When looking at the strike frequency and apparent resistivity plots, one should remember that the depth of investigation at an MT station is directly proportional to the resistivity of the material beneath that station. Stations that are underlain by resistive material will have data to a greater depth than stations underlain by conductive material, because the natural signals that are recorded are attenuated more rapidly in conductive material. At very shallow depths between stations 6 and 8 tipper strike is calculated to be from -25 to -5 degrees, whereas beneath stations 4 and 5 the tipper strike has rotated to a value of about 85 degrees at similar depths. Also at shallow depth, the tipper strike is shown to be about 15 degrees beneath station 7 . At frequencies from 5 down to $0.5 \mathrm{~Hz}$, the tipper strike direction appears to be generally northeasterly for all but station 4 , which indicates a more easterly strike. Below a frequency of $0.1 \mathrm{~Hz}$, the tipper strike data indicate a persistent tipper strike direction of 90 degrees across the entire profile.

Locations of the MT stations collected for this study were positioned to cross the east-west trending magnetic anomaly shown in figure 3. That anomaly should have east-west (90-degree) tipper strike values. The tipper strike frequency section (fig. 7) indicates that the only persistent 90-degree tipper strike directions occur below $0.1 \mathrm{~Hz}$. The average apparent resistivity at $0.1 \mathrm{~Hz}$ can be measured from the observed data curves (fig. 6) to be approximately $50 \mathrm{ohm}$-m for stations 2 and 9 and about $10 \mathrm{ohm}-\mathrm{m}$ or less for stations 4, 5, and 7. Those average apparent resistivities continue 


\section{U.S. Geological Survey}

Denver Federal Center

Denver, Colorado 80225

MT Data for: abod6

Date: 03/25/05
平Geotools

by

Gectools Conporation

5008 Balcones Dr. Sutte 202

Ausin, Texas 78731 USA

(512) $454-0679$

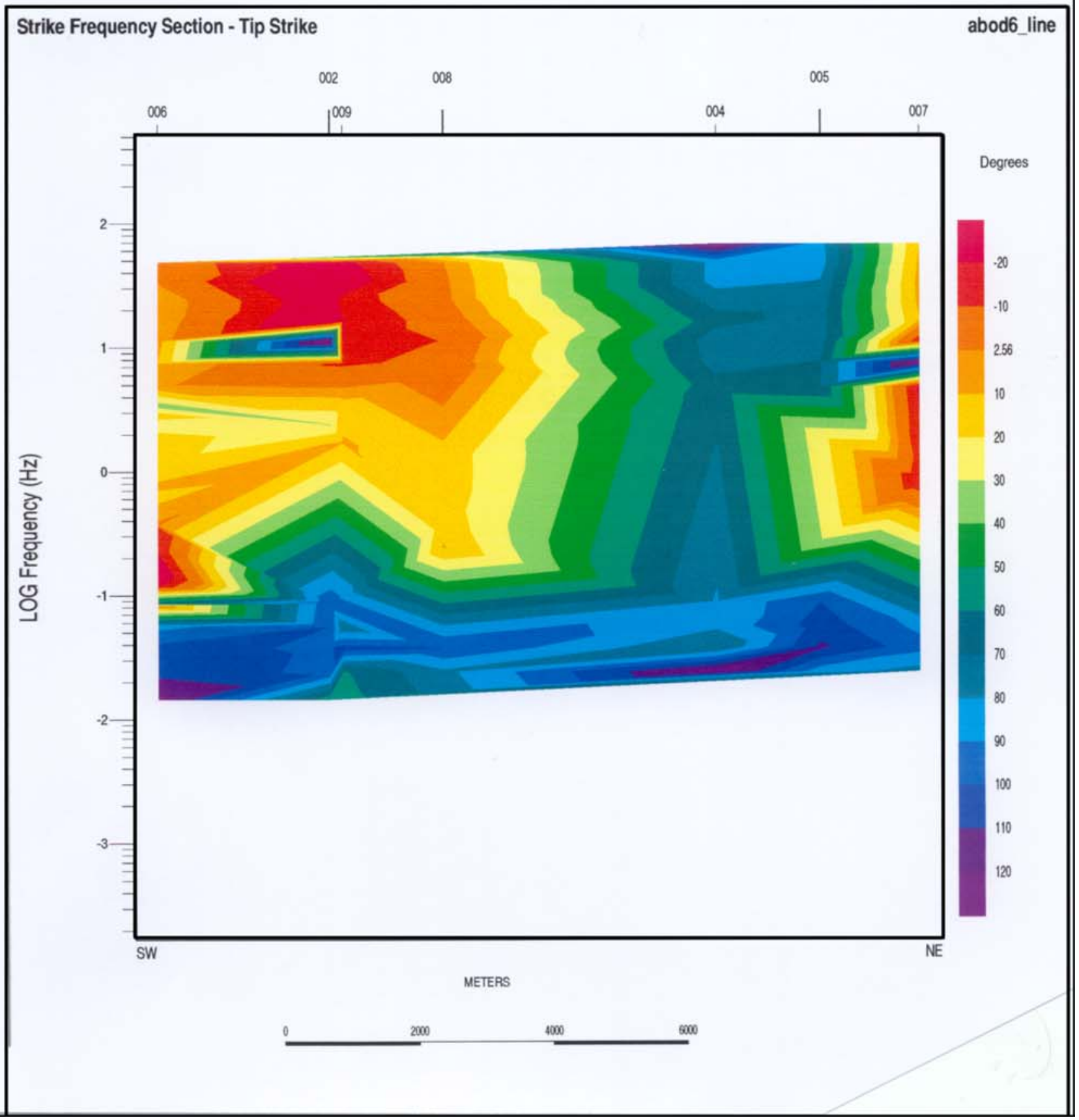

Figure 7. Tipper strike frequency section of the Bodie-Aurora magnetotelluric data. 
to decrease below $0.1 \mathrm{~Hz}$ on all of the MT data curves. As the material producing the 90-degree tipper strike values below stations 2 and 9 at a frequency of $0.1 \mathrm{~Hz}$ is more resistive, it will occur at a greater depth than the more conductive material that produces the same 90-degree tipper strike values seen beneath stations 4, 5, and 7 at $0.1 \mathrm{~Hz}$. Apparent resistivities at depth, beneath stations 4, 5, and 7, are greater than $10 \mathrm{ohm}-\mathrm{m}$, which means that the material producing the east-west tipper strike beneath stations 8 through 5 (the source of the east-west magnetic anomaly) is not shown on the 2-D inversion.

A 2-D inversion is often only a beginning step in the modeling of MT data. Additional 2-D forward models frequently are necessary to improve the calculated fit to the observed MT data or to explain certain geologic features. The PW2D modeling code written by Dr. Philip Wannamaker and included in the Geotools ${ }^{\mathrm{TM}}$ Corporation modeling package was used to construct the final 2-D model shown in figure 8. The computed response to that model is shown in figure 9. Forward modeling was necessary for this data set as the 2-D inversion did not show a conductor at depth that would explain the east-west trending magnetic anomaly seen beneath stations 8, 4, and 5. As stations 4 and 5 were 2-D, it was expected that a better fit to the TE and TM data could be obtained. Because stations 2, 6, 9, and 8 exhibited 3-D characteristics, a good match to the observed TE data was not anticipated.

The 2-D inversion matched the Bodie-Aurora observed data quite well to a depth of about $2 \mathrm{~km}$ and was used as a starting point for the forward modeling. The apparent resistivities of the 2-D inversion were not altered substantially above the depth of $2 \mathrm{~km}$ except for making the shallow conductor continuous between stations 2 and 7. Apparent resistivities were changed below a depth of $2 \mathrm{~km}$ during the forward modeling to obtain the best fit to the observed data. During successive forward models, the apparent resistivities beneath stations 4, 5, and 7 were decreased until a good match to the observed TE and TM data was obtained. The area of the model between the depths of $4 \mathrm{~km}$ and $11 \mathrm{~km}$ corresponds to the frequencies between 0.1 and $0.015 \mathrm{~Hz}$ of the observed data curves beneath stations 4,5 , and 7 . If apparent resistivities in the model were raised slightly above the depth of $11 \mathrm{~km}$, the lowest end of the calculated curves also would rise, giving a poorer fit to the observed data. Beneath stations 4, 5, and 7, at depths greater than $11 \mathrm{~km}$, apparent resistivities could be raised or lowered in the model with no apparent effect on the calculated curves. Additional data at lower frequencies would be necessary to extend the model below $11 \mathrm{~km}$ for data 


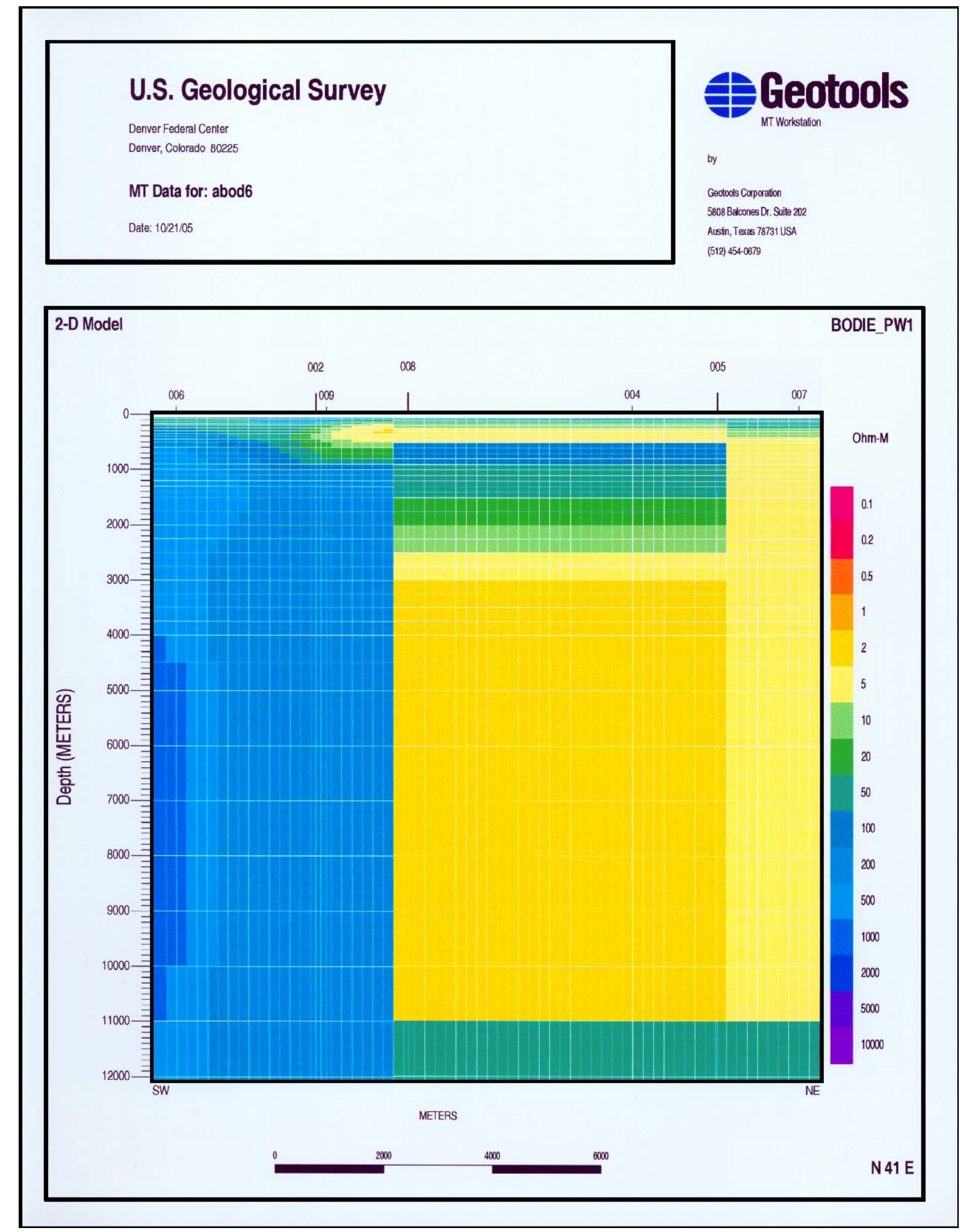

Figure 8. Two-dimensional forward model of the Bodie-Aurora magnetotelluric data to a depth of 12 kilometers. 


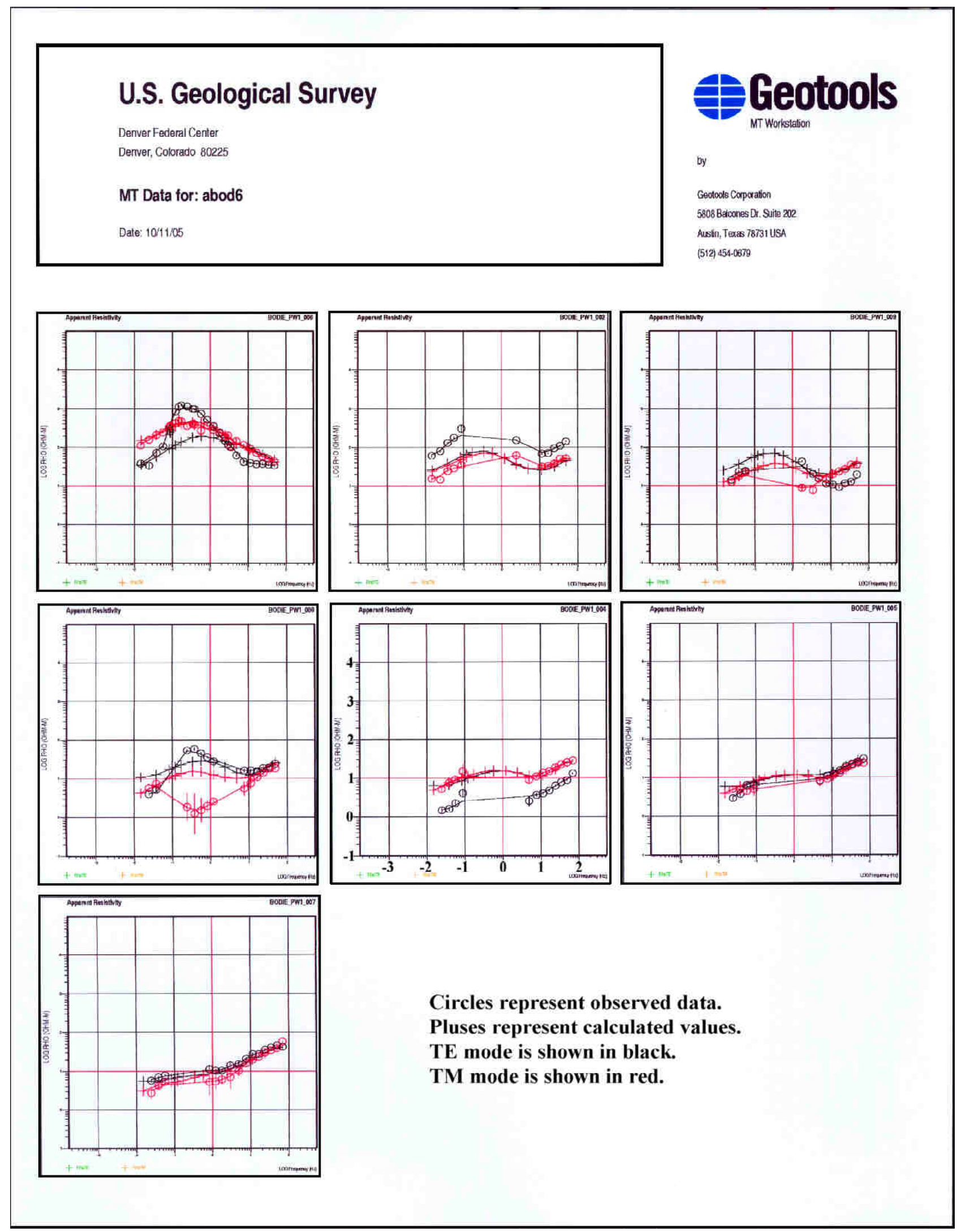

Figure 9. Observed and calculated data curves of the Bodie-Aurora magnetotelluric stations for the two-dimensional forward model. 
curves that are as conductive as stations 4, 5, and 7. The resistive curves of stations 6,2 , and 9 provided data to much greater depths. It was necessary to have 50-ohm-m apparent resistivities between the depths of 15 to $20 \mathrm{~km}$ to closely match those data curves at their lowest frequencies. Between the depths of $1 \mathrm{~km}$ and $15 \mathrm{~km}$, beneath stations 6, 2, and 9, resistivities as high as $1000 \mathrm{ohm}-\mathrm{m}$ were necessary to match the data curves. Moving the vertical boundary (beneath station 8) to the left or to the right between the resistive and conductive areas of the model seemed to have negative effects on the calculated fit to the observed data curves. The position of the vertical boundary between those resistive and conductive areas is uncertain because of the lack of data between stations 8 and 4 .

\section{Geologic Interpretation of the Bodie-Aurora Deep Resistivity Structure Based on the 2-D inversion and 2-D Forward Model}

The MT data curves for the Bodie-Aurora study have substantial apparent resistivity differences at their mid-range and lowest frequencies. The MT data curves of stations 6, 2, and 9 form a distinct southwestern segment of the profile, show a resistor in their mid-range frequencies, and have higher average apparent resistivities $(50 \mathrm{ohm}-\mathrm{m})$ at $0.1 \mathrm{~Hz}$ than stations 4, 5, and 7 . Showing no indication of a mid-range resistor, stations 4, 5, and 7 form a northeastern segment of the profile, and average $6 \mathrm{ohm}-\mathrm{m}$ at $0.1 \mathrm{~Hz}$. The observed data curve of station 8 is more conductive than those of stations 6,2, and 9 and shows a resistor. Station 8 seems to be a transition station between the two segments. A reason for the difference between the two segments of the profile may be found in Tosdal and others (2000). The subject of that paper is a detailed discussion of the breakup of the Neoproterozoic North American continental landmass and how that event relates to the location of mineral belts in Nevada. Briefly, the stable continental crust is underlain by Precambrian basement and is separated from the oceanic crust by a transition zone along the continental edge. The transition zone is composed of sedimentary rocks and is underlain by a thinned transitional continental crust. The transitional crust was thinned by extension during continental breakup and may contain local blocks of thicker crust or may even be underplated by mantle-derived mafic material. One would expect the transition zone to be fractured and contain included saline fluids, making it more conductive than the resistive oceanic or continental crust material. A step-like bend in the continental edge between the conductive transition zone and the 
resistive oceanic crust is called the Mina deflection and is mapped by Tosdal and others (2000) to be just to the south of the Bodie-Aurora MT profile. Additional sample data, if it were to be collected, could result in the repositioning of the Mina deflection more to the north or even farther to the south. The southwestern segment of the Bodie-Aurora profile is resistive at mid-crustal depths, whereas the northeastern segment of the profile is conductive at mid-crustal depths. It is unlikely that the MT profile is measuring the edge of the transition zone and oceanic crust, but the profile may be above a pull-apart basin related to the step-like echelon discontinuity in the Mina deflection at the Nevada-California border.

The 2-D inversion (figs. 4 and 5) indicates that 100- to 500-ohm-m material lies between stations 2 and 7 to a depth of about $150 \mathrm{~m}$. That material is interpreted to be a basalt flow that is thinly covered by sand and crops out frequently along most of the Bodie-Aurora profile. The northwesterly ( -25 to -5 degrees beneath stations 6 to 8 ) and easterly ( 85 degrees beneath stations 4 and 5) tipper strike azimuths seen in the highest frequencies of the strike frequency section seem to be related to faulting in that basalt flow. Below about $200 \mathrm{~m}$ in depth from station 2 northeastward to station 5 and then below $400 \mathrm{~m}$ beneath station 7 (from about $5 \mathrm{~Hz}$ to $.5 \mathrm{~Hz}$ ), the inversion indicates that lower resistivity material in the range of 5 to $20 \mathrm{ohm}-\mathrm{m}$ lies beneath the exposed basalt flow. Keeping in mind the large gap in the data between stations 8 and 4, that conductor is possibly continuous and is interpreted to be altered volcanic rock that increases in thickness from about $200 \mathrm{~m}$ beneath station 2 to possibly $700 \mathrm{~m}$ at the eastern edge of the model beneath station 7 and strikes north-northeast. As mentioned earlier, fitting only the TM mode of 3-D data does not always give accurate depths to the base of conductors in the resulting 2-D inversion. Because of that, the true thickness of the conductor actually may be more or less than shown in this inversion. The conductor indicated between stations 2 though 8 and 4 through 7 is not seen in the inversion beneath station 6. The apparent resistivities beneath the conductor rise to an electrically homogeneous block of 100-ohm-m material that extends to a depth of approximately $15 \mathrm{~km}$. Based on the inversion, those rocks could be interpreted as being a thick sequence of Paleozoic sediments. The inversion also indicates that apparent resistivities at mid-crustal depths of 10 to $15 \mathrm{~km}$ increase southwest of station 6. Increasing apparent resistivities to the southwest of the profile may be related to the rocks of Cowtrack Mountain, Granite Mountain, or resistive oceanic crust. Beneath stations $6,2,9,8$, and 7, at depths greater than $15 \mathrm{~km}$ (not shown in figs. 4 or 5), apparent 
resistivities decrease until a basement of $20 \mathrm{ohm}-\mathrm{m}$ or less is reached at a depth of approximately $20 \mathrm{~km}$. The conductive basement commonly is seen in the modeled MT data at their lowest frequencies (Wannamaker, 2000). Beneath stations 4 and 5, a conductive basement is not seen, as 50-ohm-m apparent resistivities are shown to the maximum vertical limit of the inversion. The MT data curves of stations 4 and 5 are highly conductive in their lowest frequencies and indicate the presence of a deep conductor that also is not shown in the inversion. The deep conductor is seen in the data curves of stations 4,5 , and 7 at and below $0.1 \mathrm{~Hz}$., has a tipper strike direction of about 90 degrees and is most likely the source of the east-west magnetic anomaly shown in figure 3.

The 2-D inversion shown in figures 4 and 5 presents a good picture of the electrical resistivity structure to a depth of only about $2 \mathrm{~km}$ on the northeastern conductive segment of the profile. For an improved model below a depth of $2 \mathrm{~km}, 2-\mathrm{D}$ forward modeling was used to gain a better fit to the observed 2-D data. The resulting 2-D model is included in this report as figure 8. The upper $2 \mathrm{~km}$ of figure 8 vary little from the upper $2 \mathrm{~km}$ of the 2-D inversion (figs. 4 and 5). For figure 8, the shallow conductor interpreted as being altered volcanic rocks was made to be continuous between stations 2 and 7. Doing so did not seem to improve or degrade the fit of the calculated curves to the observed data. Apparent resistivities beneath the 3-D stations 6, 2, 9, and 8 were increased and resulted in a somewhat improved fit to the observed data for those stations but did not alter the interpretation that those stations are over resistive oceanic crust or resistive rocks associated with Cowtrack or Granite Mountain. To approximate the 2-D observed data for stations 4, 5, and 7, apparent resistivities gradually were lowered to match the observed data curves. A slight resistor was required between the depths of 0.5 and $2.5 \mathrm{~km}$ the rocks of which are probably volcanic and have less alteration than those in the overlying conductor. Below $2.5 \mathrm{~km}$, apparent resistivities decrease until a depth of $11 \mathrm{~km}$ is reached, which is equivalent to a frequency of $0.015 \mathrm{~Hz}$ and the maximum depth to which data were collected for those stations. The conductive area of figure 8 between the depths of about 4 and $11 \mathrm{~km}$ corresponds to the frequencies of 0.1 to $0.015 \mathrm{~Hz}$ on the observed data curves and has a tipper strike of about 90 degrees as shown in figure 7. This conductive zone corresponds to the east-west magnetic anomaly shown in figure 3. It has been the objective of this study to identify the source of that magnetic anomaly. The rocks below stations $8,4,5$, and 7 at depths greater than $3 \mathrm{~km}$ become very conductive for at least $8 \mathrm{~km}$ and are magnetic. Normally, sedimentary rocks are nonmagnetic, whereas metamorphosed or 
igneous rocks are not very conductive. It would be difficult to make sedimentary rocks magnetic. The alternative explanation is to make igneous or metamorphic rocks conductive. Therefore, a possible source for the magnetic anomaly may be metamorphosed mafic or ultramafic oceanic crust that contains conductive saline fluids.

\section{Conclusions and Recommendations for Future Work}

The 2-D MT model (fig. 8) presented in this report, in conjunction with the initial 2-D inversion (figs. 4 and 5), and the tipper strike frequency section (fig. 7), makes possible a better understanding of the subsurface geology along the Aurora-Bodie profile. Interpretation of the 2-D model and inversion to the east of MT station 2 indicates that a thin surface layer of exposed resistive basalt overlies lower resistivity material that thickens to the east. The tipper strike indicates that the lower resistivity material strikes to the northeast, and is interpreted to be altered volcanic rocks. Beneath that lower resistivity material to a depth of about $2.5 \mathrm{~km}$, resistivities rise slightly in rocks that strike to the northeast and are most likely similar to those above but are not as greatly altered. At depths between 4 and $11 \mathrm{~km}$, resistivities decline and indicate very conductive material that strikes to the east (as does the magnetic anomaly), corresponds to the frequencies between 0.1 and $0.015 \mathrm{~Hz}$ of the observed data curves beneath MT stations 8, 4, and 5, and is interpreted to correspond to the magnetic anomaly. Resistivities to the east of MT station 5 are conductive, non-magnetic, and interpreted to be the result of the sedimentary rocks of Huntoon Valley. The model shows a boundary between the resistive material (probably oceanic crust) to the west of MT station 8 and the conductive material to the east of station 8 . A gap between MT stations 8 and 4 is due to the presence of powerlines, which prevented data acquisition. Because of that gap, and the poor data quality of station 8 , the positioning of the vertical boundary between the resistive material to the west and the conductive material is uncertain. Moving the vertical boundary to the east or to the west will alter the interpretation as to the source of the magnetic anomaly. Moving the boundary to the east leads one to the interpretation that the source of the anomaly is resistive oceanic crust. Moving the boundary to the west suggests that the unlikely source of the anomaly is magnetic basin fill or transition zone sediments.

Additional work for this study might include extending the MT profile several $\mathrm{km}$ in both directions to gain a better understanding of the resistivities of Cowtrack and Granite Mountains to 
the southwest and Huntoon Valley to the northeast. Addition of those stations should permit a better placement of the vertical boundary shown beneath MT station 8. Repeating the previously collected stations with an MT system capable of more effectively filtering $60-\mathrm{Hz}$ noise may also be beneficial. Placement of one or two MT stations between stations 8 and 4 might answer the question of whether or not the shallow conductor is indeed a continuous feature beneath stations 2 through 7. Collection of additional data below the frequency of $0.015 \mathrm{~Hz}$ might help to resolve the lower limits of the conductive zone beneath stations 4, 5, and 7. Detailed gravity and magnetic data along the Bodie-Aurora profile should be collected and modeled. Those data would help to better define the limits of the east-west trending magnetic anomaly. 


\section{References Cited}

Bendat, J.S., and Piersol, A.G., 1971, Random data: analysis and measurement procedures: New York, N.Y., Wiley Interscience, 407 p.

Chave, A.D., and Thompson, D.J., 1989, Some comments on magnetotelluric response function estimation: Journal of Geophysical Research, v. 94, no. B10, p. 14,215-14,225.

Clarke, J., Gamble, T.D., Goubau, W.M., Koch, R.H., and Miracky, R.F., 1983, Remote-reference magnetotellurics: equipment and procedures: Geophysical Prospecting, v. 31, p. 149-170.

Eberhart-Phillips, D., Stanley, W.D., Rodriguez, B.D., and Lutter, W.J., 1995, Surface seismic and electrical methods to detect fluids related to faulting: Journal of Geophysical Research, v. 100 , no. B7, p. 12,919-12,936.

Egbert, G.D., and Booker, J.R., 1986, Robust estimation of geomagnetic transfer functions: Geophysical Journal of the Royal Astronomical Society, v. 87, p. 173-194.

EMI, 1996, MT-1 Magnetotelluric system operation manual, version 3.2: Richmond, Calif., Electromagnetic Instruments, Inc., $220 \mathrm{p}$.

Gamble, T.D., Goubau, W.M., and Clarke, J., 1979a, Magnetotellurics with a remote magnetic reference: Geophysics, v. 44, no. 1, p. 53-68.

Gamble, T.D., Goubau, W.M., and Clarke, J., 1979b, Error analysis for remote reference magnetotellurics: Geophysics, v. 44, no. 5, p. 959-968.

Gilbert, C.M., Christensen, M.N., Al-Rawi, Yehya, and Lajoie, K.R., 1968, Structural and volcanic history of Mono Basin, California-Nevada, in Studies in volcanology - A memoir in honor of Howel Williams: Geological Society of America Memoir 116, p. 275-329.

Keller, G.V., 1987, Rock and mineral properties, in Nabighian, M.N., ed., Electromagnetic methods in applied geophysics theory: Society of Exploration Geophysicists, Tulsa, Okla., v. 1, p. $13-51$. 
Keller, G.V., 1989, Electrical properties, in Carmichael, R.S., ed., Practical handbook of physical properties of rocks and minerals: Boca Raton, Fla., CRC Press, p. 359-427.

Kleinhampl, F.J., Davis, W.E., Silberman, M.L., Chesterman, C.W., Chapman, R.H., and Gray Jr., C.H., 1975, Aeromagnetic and limited gravity studies and generalized geology of the Bodie Hills region, Nevada and California: United States Geological Survey Bulletin 1384, 38 p.

Palacky, G.J., 1987, Resistivity characteristics of geologic targets, in Nabighian, M.N., ed., Electromagnetic methods in applied geophysics theory: Society of Exploration Geophysicists, Tulsa, Okla., v. 1, p. 53-129.

Pellerin, L., and Hohmann, G.W., 1990, Transient Electromagnetic Inversion: A remedy for magnetotelluric static shifts: Geophysics, v. 55, no. 9, p. 1242-1250.

Reddy, I.K., Rankin, D., and Phillips, R.J., 1977, Three-dimensional modeling in magnetotelluric and magnetic variational sounding: Geophysics Journal of the Royal Astronomical Society, v. 51, p. 313-325.

Telford, W. M., Geldart, L.P., and Sheriff, R. E., 1990, Applied Geophysics (2 ${ }^{\text {nd }}$ Edition): New York, N.Y., Cambridge University Press, 770 p.

Tosdal, R.M., Wooden, J.L., and Kistler, R.W., 2000, Geometry of the neoproterozoic continental break-up, and implications for location of Nevadan mineral belts, in Cluer, J.K., Price, J.G., Struhsacker, E.M., Hardyman, R.F., and Morris, C.L., eds., Geology and ore deposits 2000: The Great Basin and beyond: Geological Society of Nevada Symposium Proceedings, May 15-18, 2000, p. 451-466.

U.S. Geological Survey, 2001, Six aeromagnetic Surveys in Nevada and California -- A web site for distribution of data: U.S. Geological Survey Open-File-Report 01-0145 [http://pubs.usgs.gov/of/2001/ofr-01-0145/].

Vozoff, K., 1972, The magnetotelluric method in the exploration of sedimentary basins: Geophysics, v. 37, p. 98-141. 
Vozoff, K., 1991, The magnetotelluric method, in Nabighian, M.N. ed., Electromagnetic methods in applied geophysics: Society of Exploration Geophysicists, Tulsa, Okla., v. 2, part B, p. 641711.

Wannamaker, P.E., 1983, Resistivity structure of the northern Basin and Range: Davis, Calif., Geothermal Resources Council, Special Report No. 13, p. 345-361.

Wannamaker, P.E., 2000, Comment on "The petrologic case for a dry lower crust" by Bruce W.D. Yardley, and John W. Valley: Journal of Geophysical Research, v. 105, no. B3, p. 60576064.

Wannamaker, P.E., Hohmann, G.W. and Ward, S.H., 1984, Magnetotelluric responses of threedimensional bodies in layered Earths: Geophysics, v. 49, no. 9, p. 1517-1533. 


\section{Appendix -- Magnetotelluric Data Plots}

For each station, nine separate plots are given in the Appendix:

1. Apparent Resistivity for the maximum TE (x symbol) and minimum TM (o symbol) modes with free rotation.

2. Impedance Phase for the maximum TE ( $\mathrm{x}$ symbol) and minimum TM (o symbol) rotation.

3. Rotation Angle for the impedance tensor.

4. Impedance Skew for the impedance tensor.

5. Multiple E-Predicted Coherency (E MULT Coh.) for the maximum (Ex-HxHy) (x symbol) and minimum (Ey-HxHy) (o symbol) modes of the electric field.

6. Impedance Polar Plots.

7. Tipper Magnitude of the vertical magnetic field.

8. Tipper Strike of the vertical magnetic field.

9. Multiple Coherency for Hz-Hx (x symbol) and Hz-Hy (o symbol). 


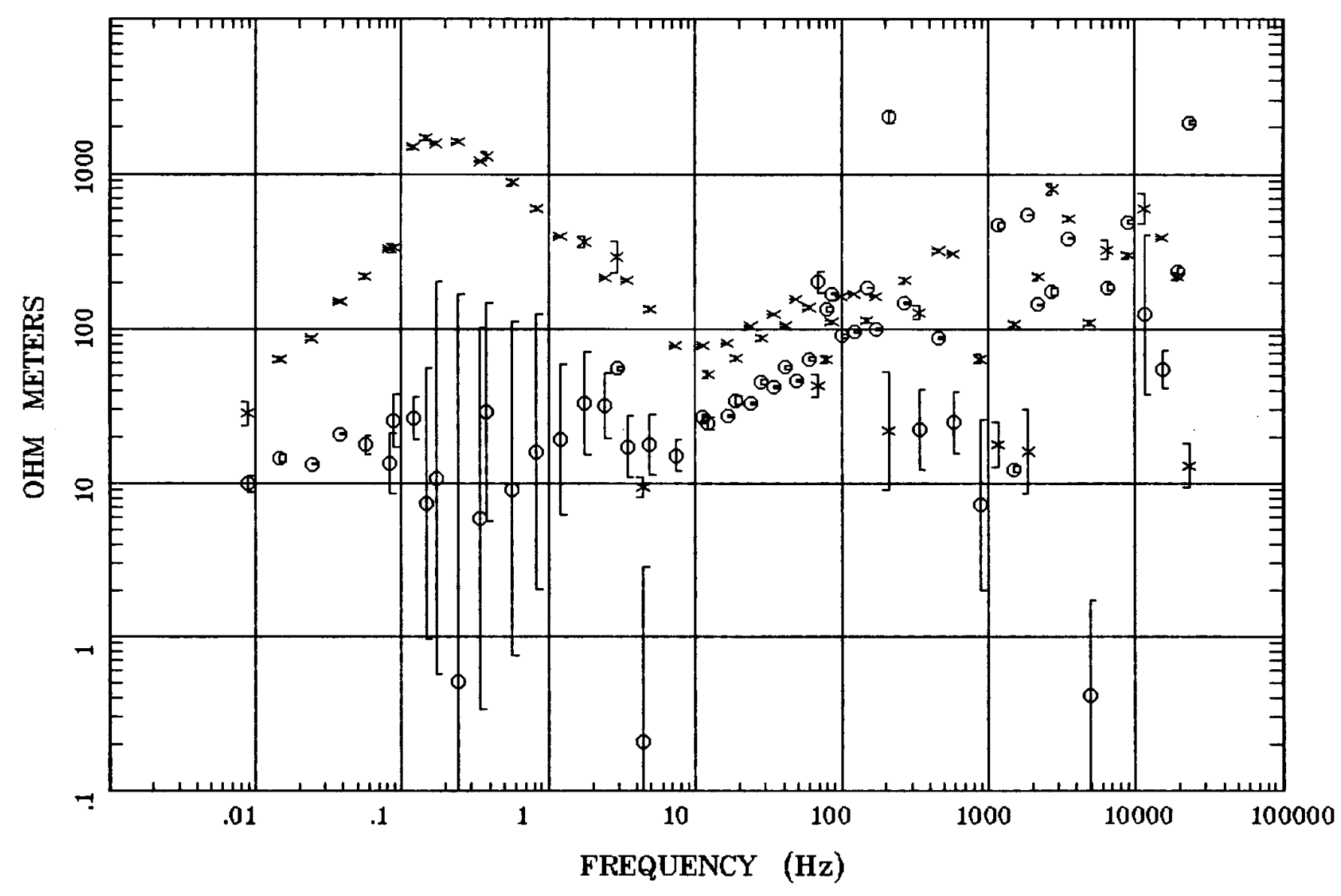

Client:

Remote: none

Acquired: $11: 1$ oct 08, 2001 Survey Co:USGS
Rotation:

Filename: ab2.avg

Channels: Ch1 Ch2 Ch3 Ch4 Ch5 Ch3 Ch4

Plotted: 16:59 Nov 16, 2001

< EMI - ElectroMagnetic Instruments > 
Hawthorne, Nevada STATION 2

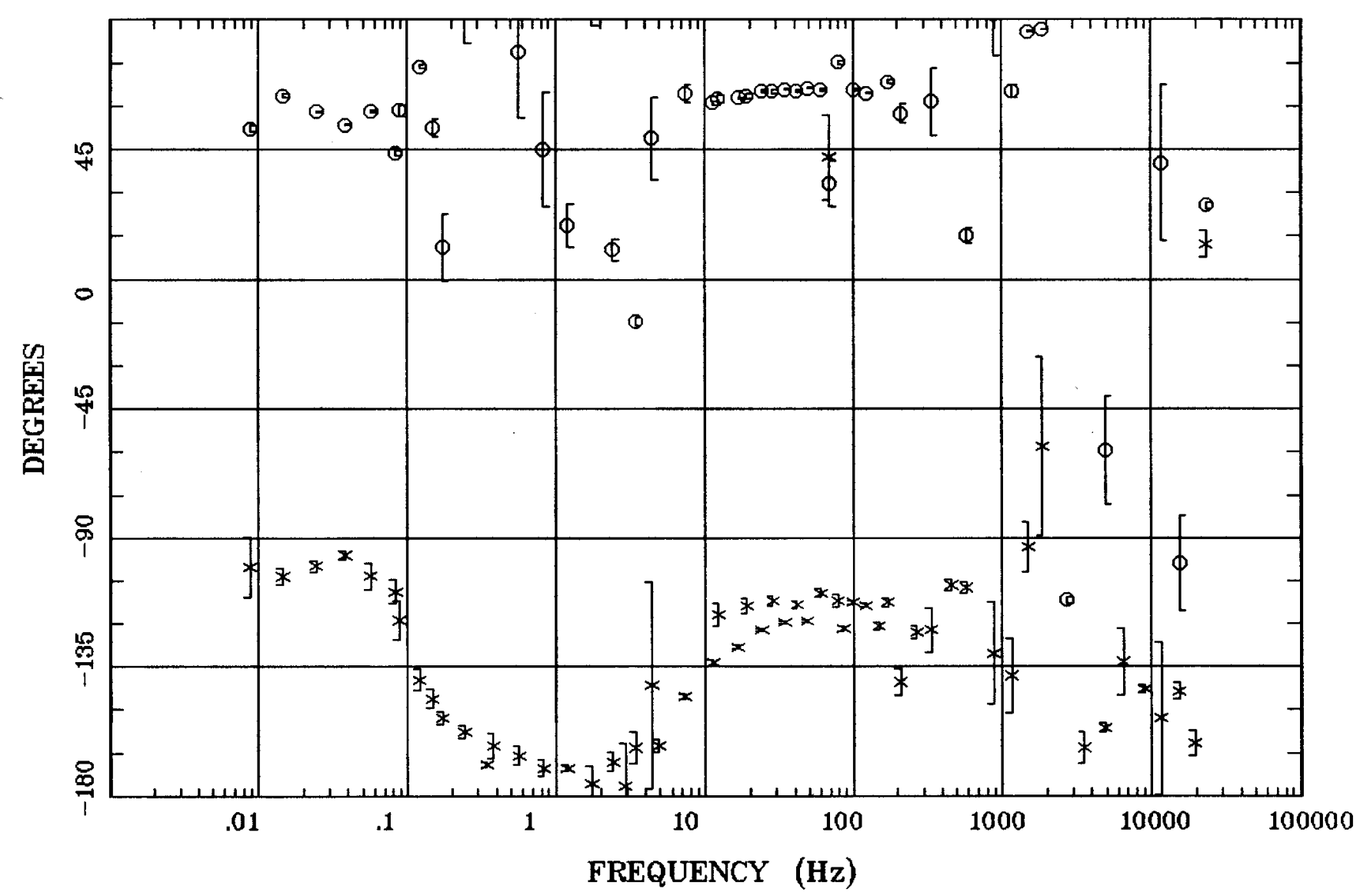

Client:

Remote: none

Acquired: 11:1 oct 08, 2001

Survey Co:USGS
Rotation:

Filename: ab2.avg

Channels: Ch1 Ch2 Ch3 Ch4 Ch5 Ch3 Ch4

Plotted: $16: 59$ Nov 16, 2001

< EMI - ElectroMagnetic Instruments > 


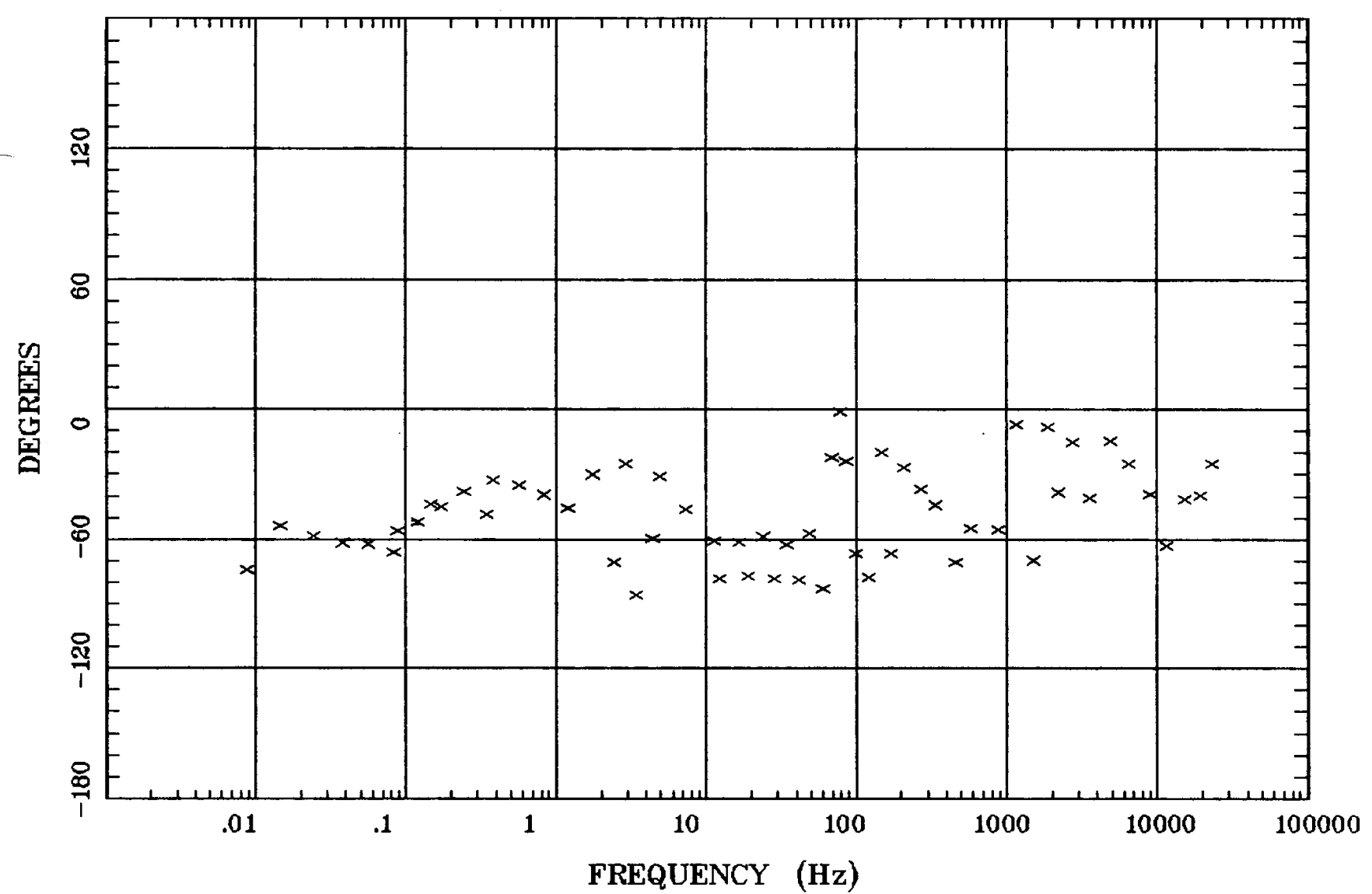

Client:

Remote: none

Acquired: 11:1 oct 08,2001

Survey Co:USGS
Rotation:

Filename: ab2.avg

Channels: Ch1 Ch2 Ch3 Ch4 Ch5 Ch3 Ch4

Plotted: 16:59 Nov 16, 2001

< EMI - ElectroMagnetic Instruments > 


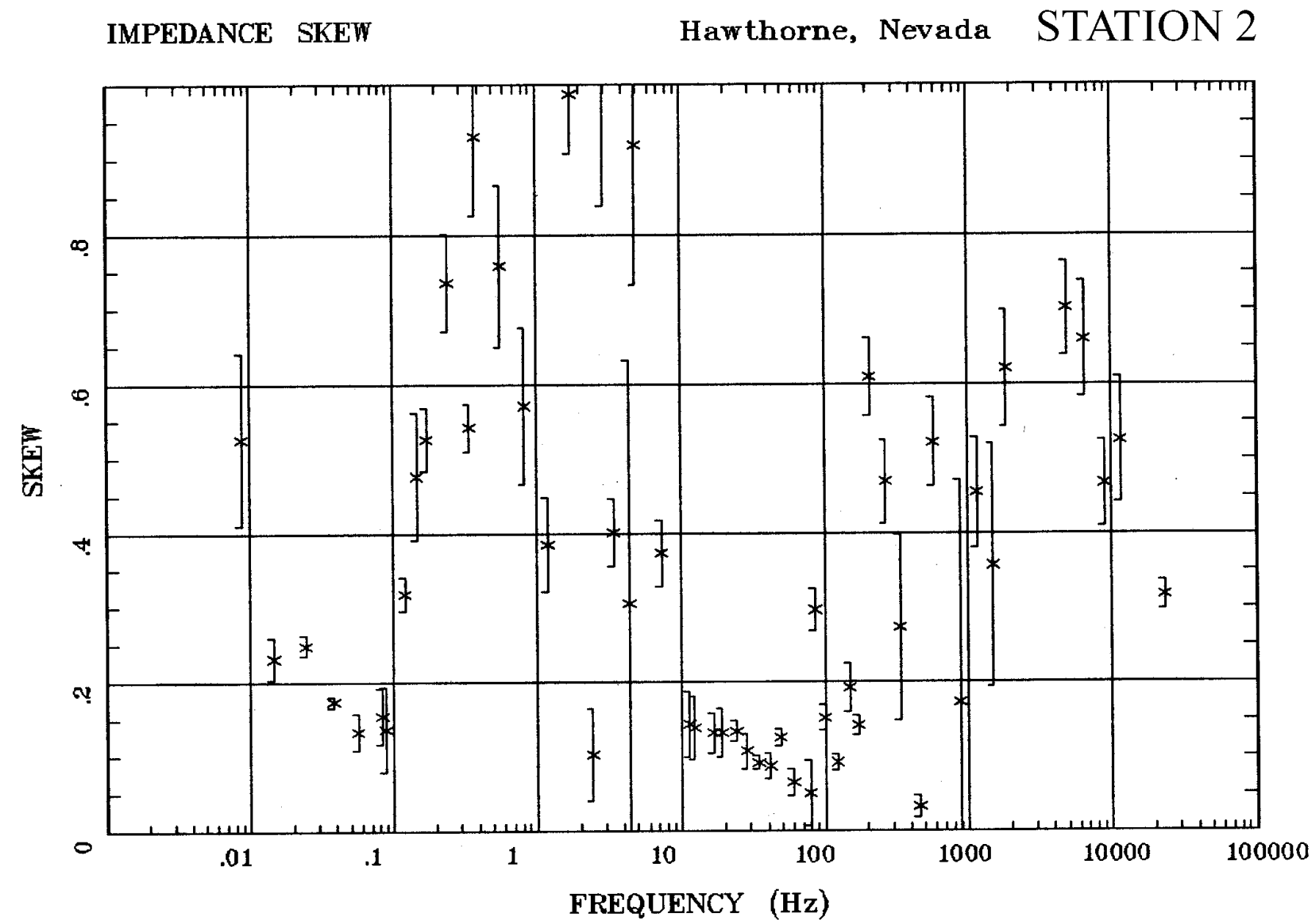

Client:

Remote: none

Acquired: 11:1 Oct 08, 2001

Survey Co:USGS

Rotation:

Filename: ab2.avg

Channels: Ch1 Ch2 Ch3 Ch4 Ch5 Ch3 Ch4

Plotted: $\quad 16: 59$ Nov 16, 2001

< EMI - ElectroMagnetic Instruments > 


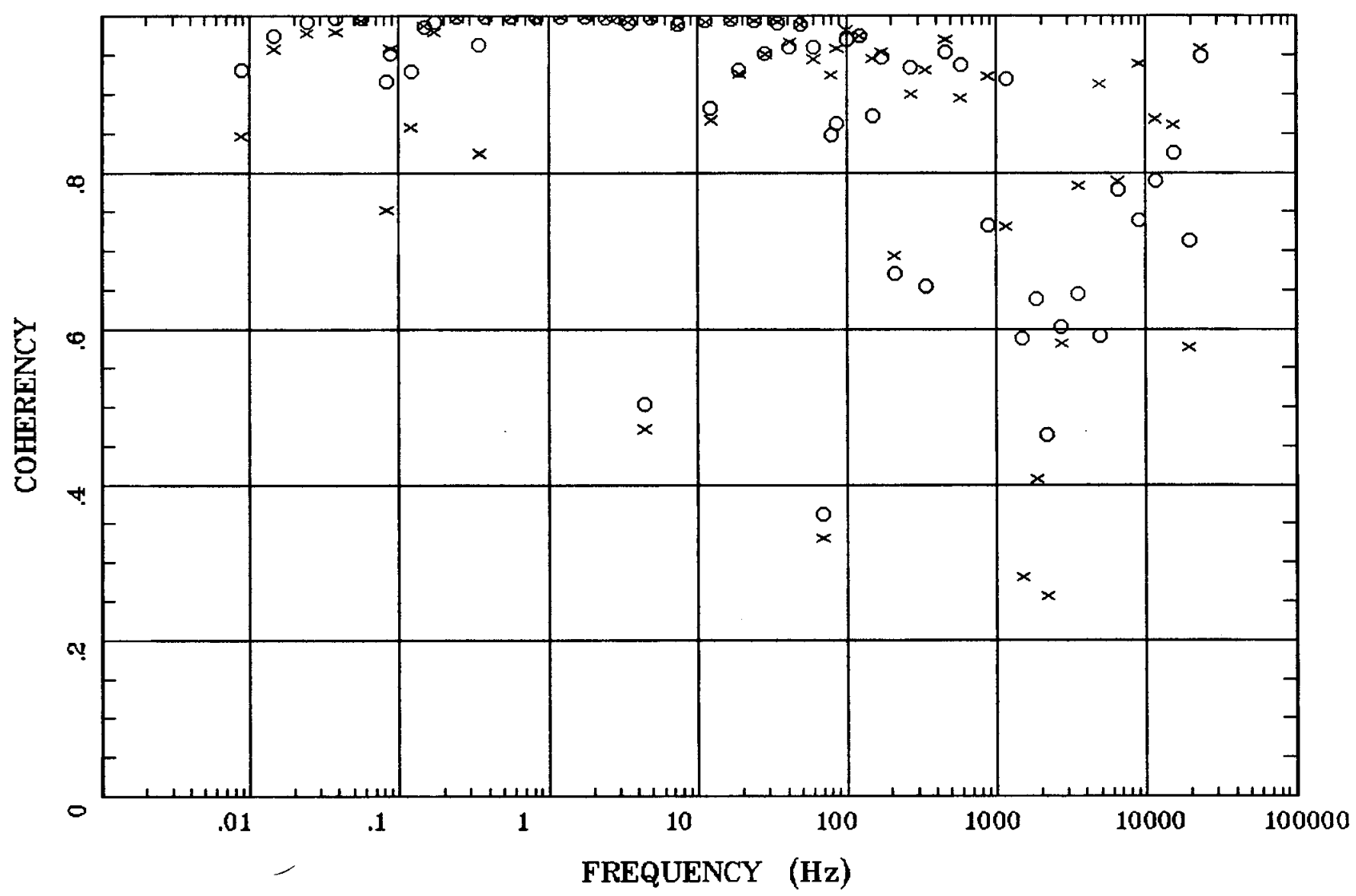

Client:

Remote: none

Acquired: 11:1 Oct 08, 2001

Survey Co:USGS
Rotation:

Filename: ab2.avg

Channels: Ch1 Ch2 Ch3 Ch4 Ch5 Ch3 Ch4

Plotted: 16:59 Nov 16, 2001

< EMI - ElectroMagnetic Instruments > 
Haw thorne, Nevada STATION 2

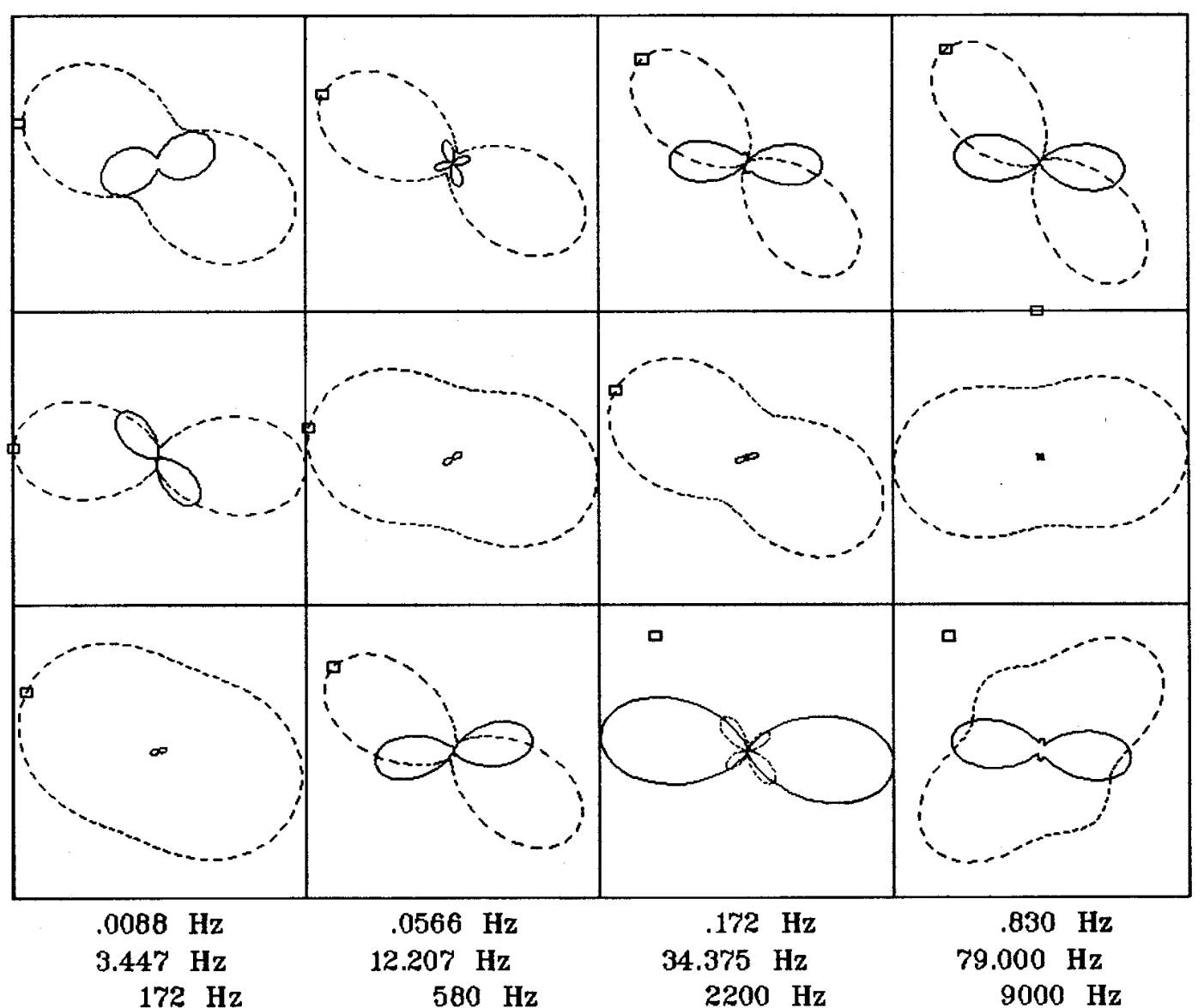

Client:

Remote: none

Acquired: 11:1 Oct 08, 2001

Survey Co:UsGS
Rotation:

Filename: ab2.avg

Channels: Ch1 Ch2 Ch3 Ch4 Ch5 Ch3 Ch4 Plotted: 17:00 Nov 16, 2001

< EMI - ElectroMagnetic Instruments > 
TIPPER MAGNITUDE

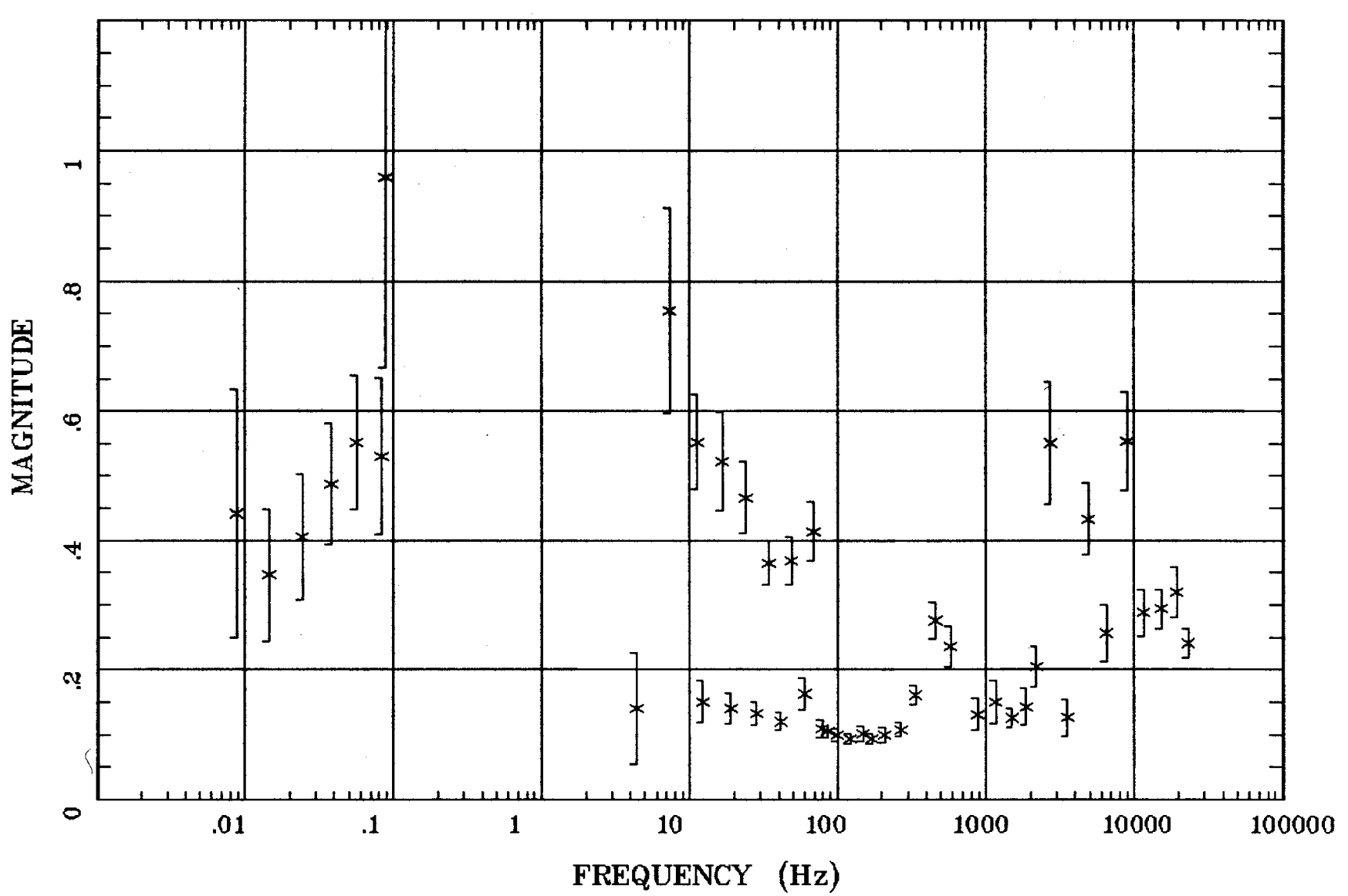

Rotation:

Filename: ab2.avg

Channels: Ch1 Ch2 Ch3 Ch4 Ch5 Ch3 Ch4

Plotted: 17:00 Nov 16, 2001

< EMI - ElectroMagnetic Instruments > 


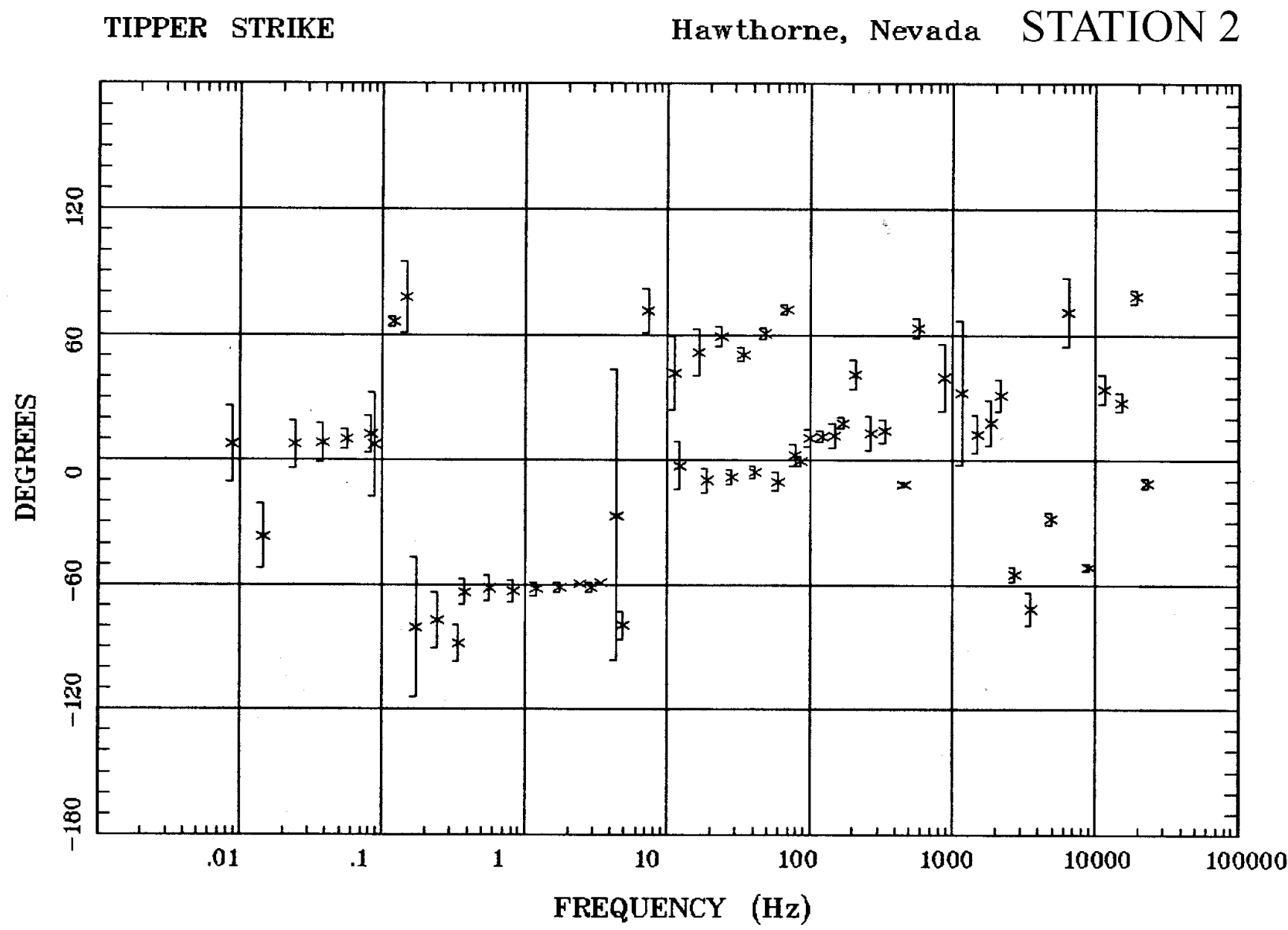

Client:

Remote: none

Acquired: 11:1 0ct 08, 2001 Survey Co:USGS
Rotation:

Filename: ab2.avg

Channels: Ch1 Ch2 Ch3 Ch4 Ch5 Ch3 Ch4

Plotted: 17:00 Nov 16, 2001

< EMI - ElectroMagnetic Instruments > 
HzHx.x Coh HzHy.o

Hawthorne, Nevada STATION 2

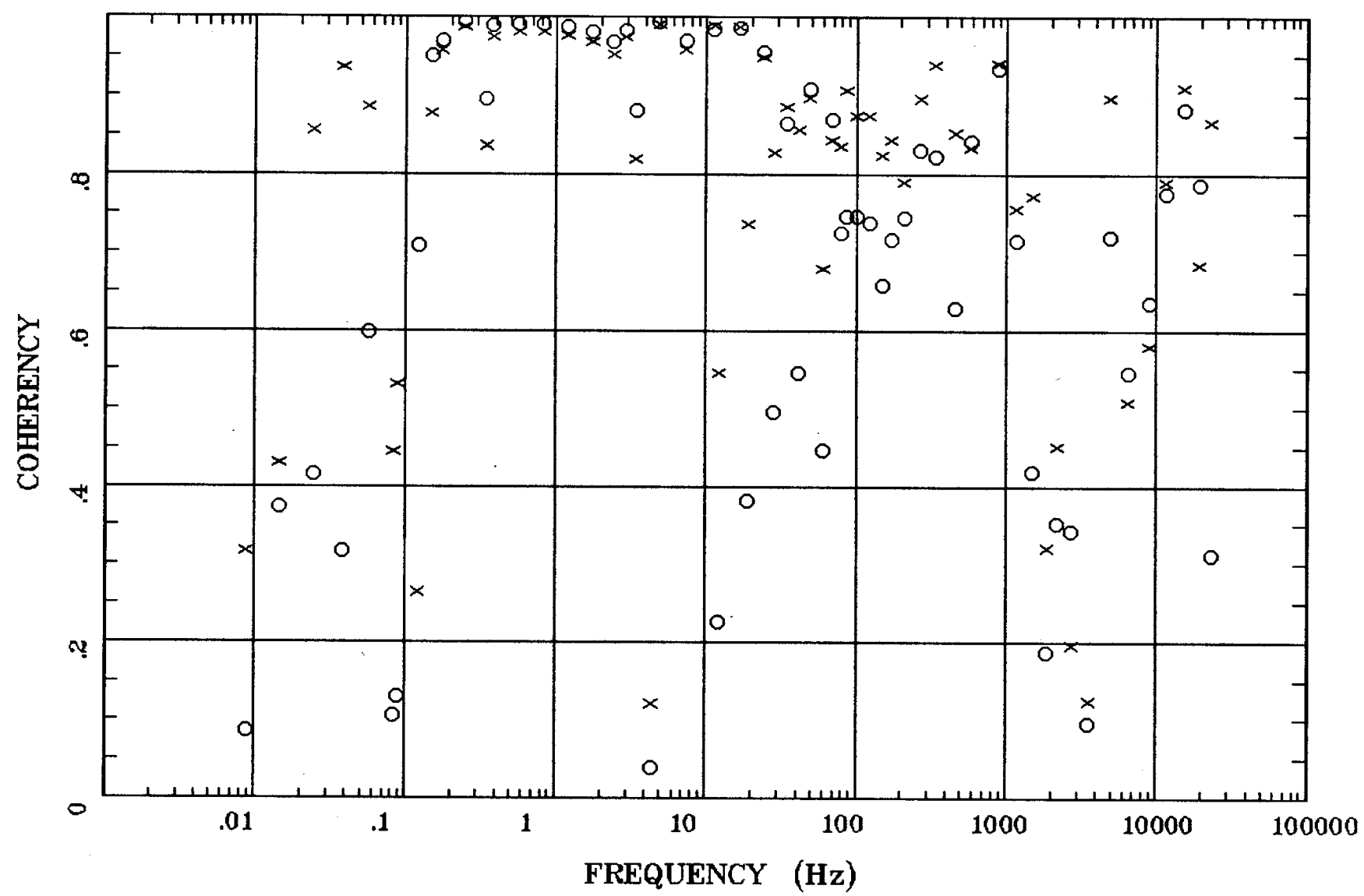

Client:

Remote: none

Acquired: 11:1 Oct 08, 2001

Survey Ca:USGS

Rotation:

Filename: ab2.avg

Channels: Ch1 Ch2 Ch3 Ch4 Ch5 Ch3 Ch4

Plotted: $\quad$ 17:00 Nov 16, 2001

< EMI - ElectroMagnetic Instruments > 


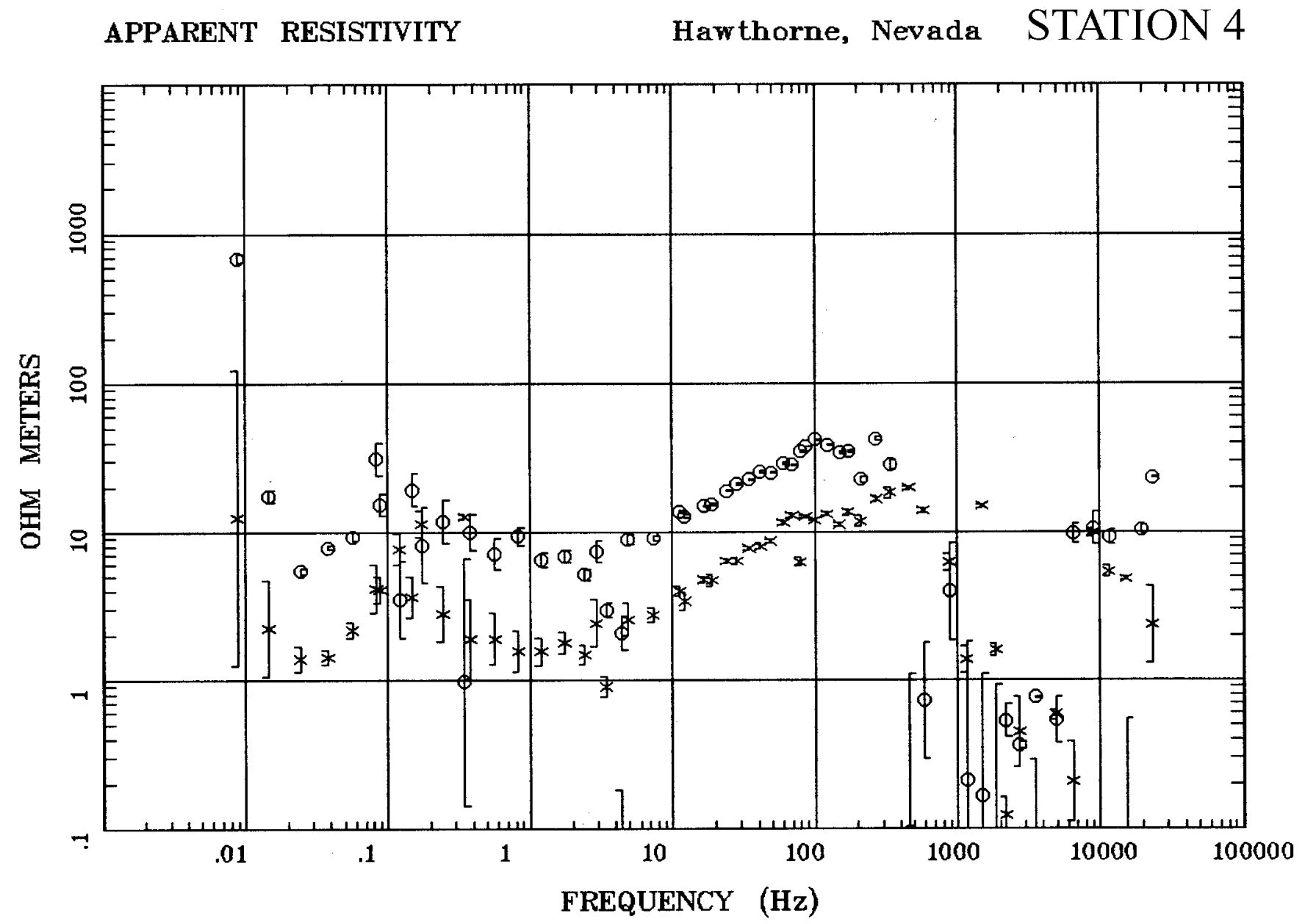

Client:

Remote: none

Acquired: 12:2 oct 07, 2001 Survey Co:USGS
Rotation:

Filename: ab4.avg

Channels: Ch1 Ch2 Ch3 Ch4 Ch5 Ch3 Ch4

Plotted: 14:08 Nov 16, 2001

< EMI - ElectroMagnetic Instruments > 
IMPEDANCE PHASE

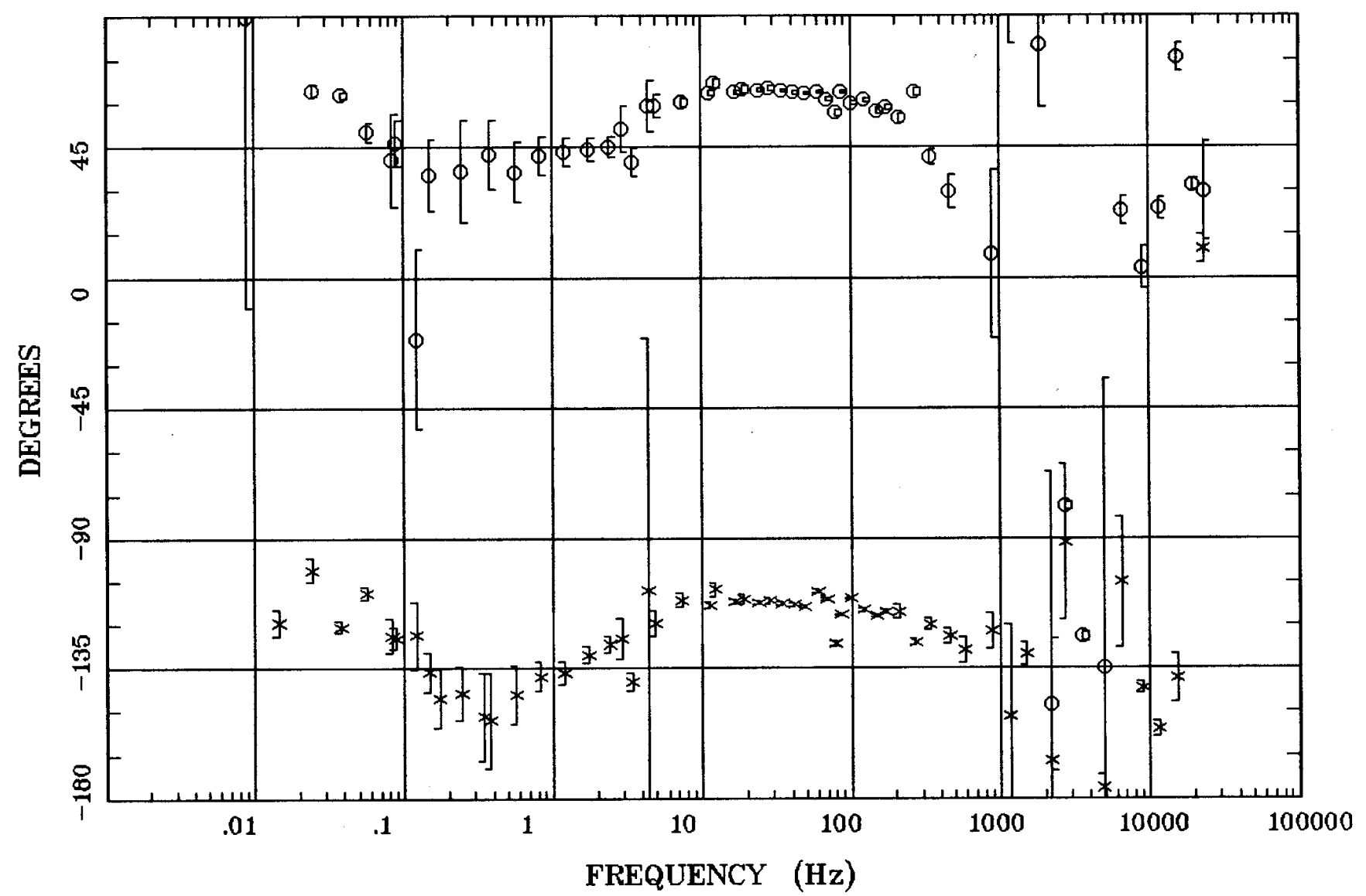

Rotation:

Filename: ab4.avg

Channels: Ch1 Ch2 Ch3 Ch4 Ch5 Ch3 Ch4

Plotted: 14:08 Nov 16, 2001

< EMI - ElectroMagnetic Instruments >
Remote: none

Acquired: 12:2 oct 07, 2001

Survey Co:USGS
Haw thorne, Nevada STATION 4 


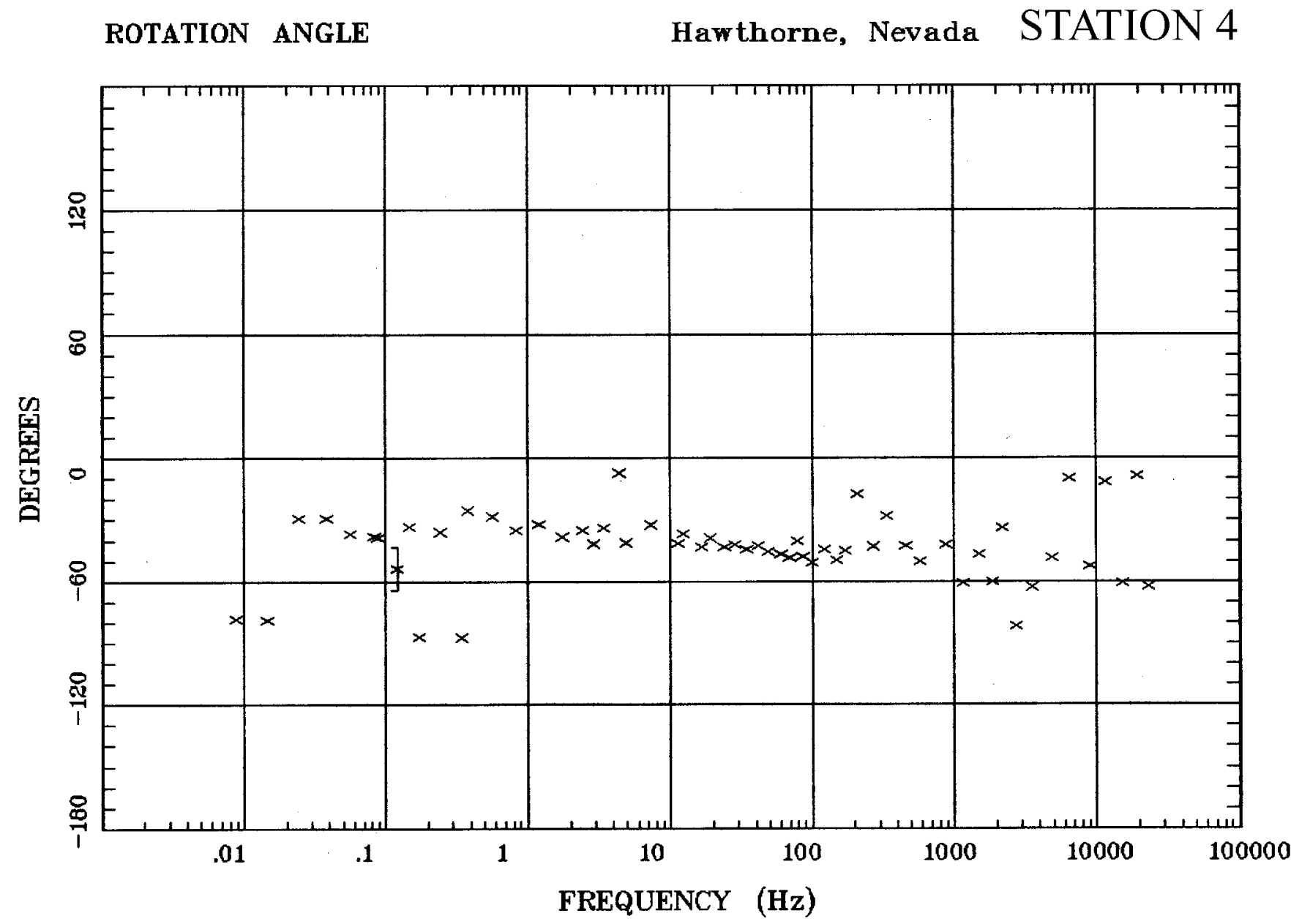

Client:

Remote: none

Filename: ab4.avg

Acquired: 12:2 Oct 07, 2001

Survey Co:USGS

Channels: Ch1 Ch2 Ch3 Ch4 Ch5 Ch3 Ch4

Plotted: 14:08 Nov 16, 2001

< EMI - ElectroMagnetic Instruments > 


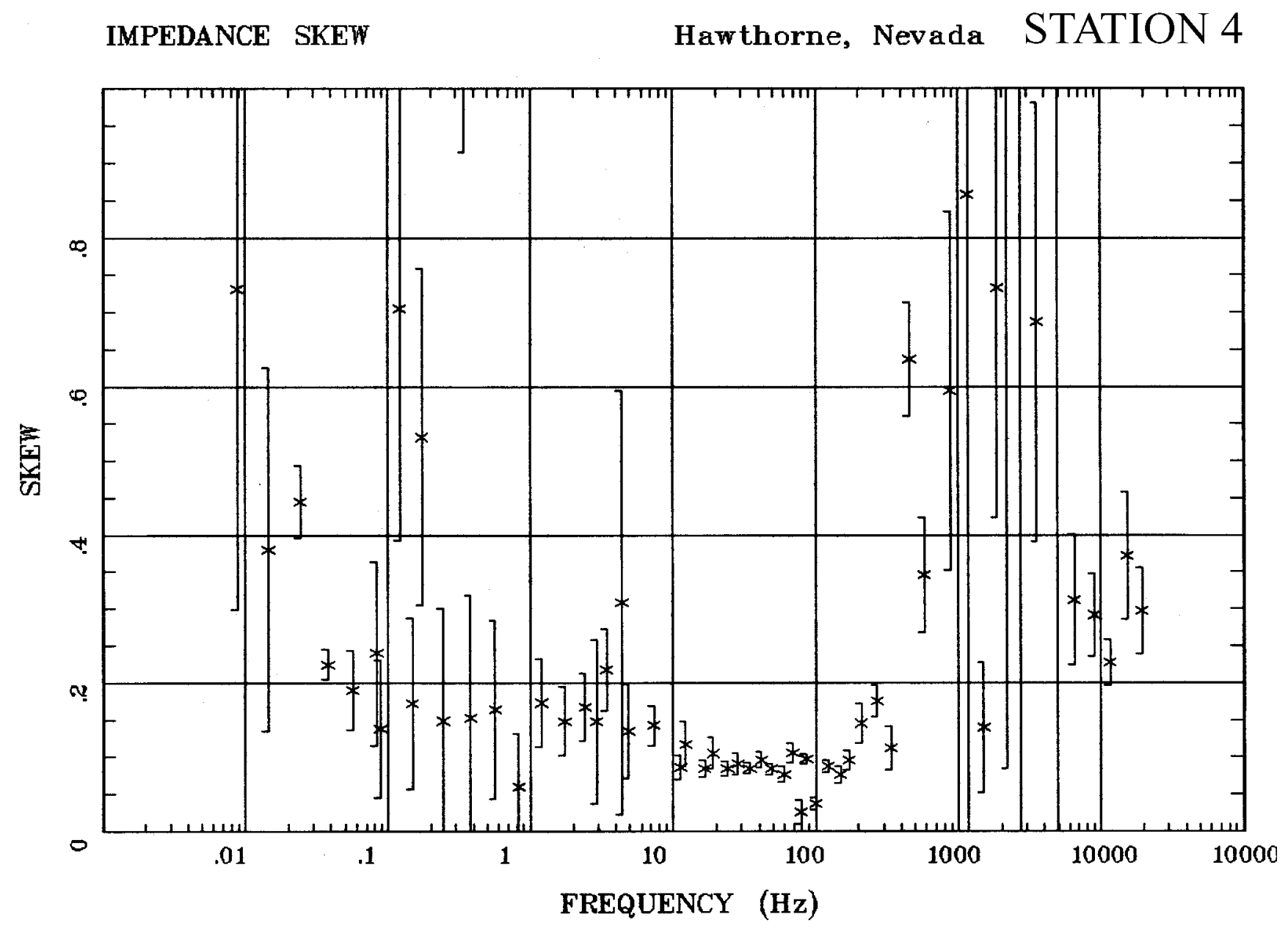

Client:

Remote: none

Acquired: 12:2 oct 07, 2001 Survey Co:USGS
Rotation:

Filename: ab4.avg

Channels: Ch1 Ch2 Ch3 Ch4 Ch5 Ch3 Ch4

Plotted: 14:08 Nov 16, 2001

< EMI - ElectroMagnetic Instruments > 


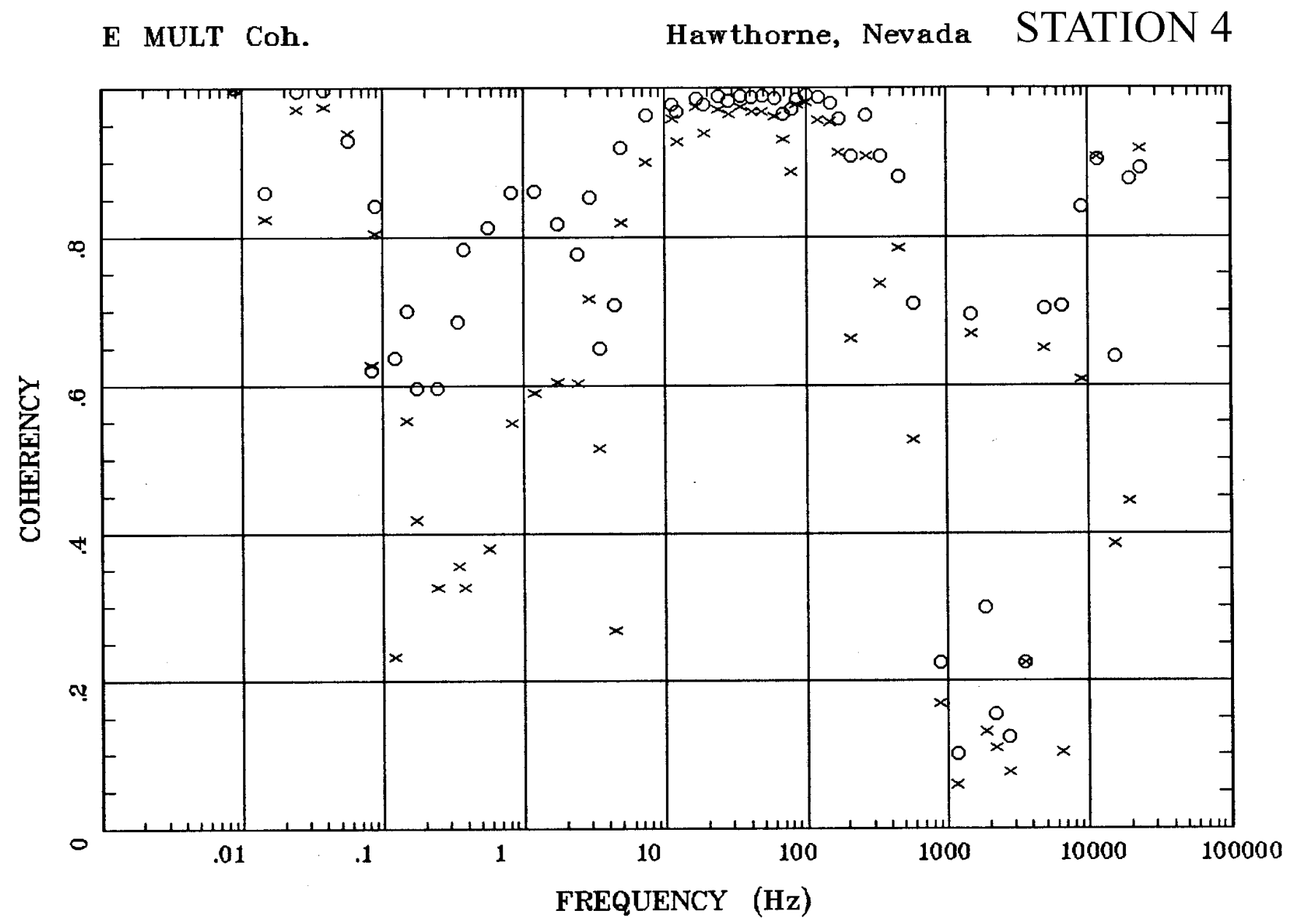

Client:

Remote: none

Acquired: $12: 2$ oct 07,2001 Survey Co:USGS
Rotation:

Filename: ab4.avg

Channels: Ch1 Ch2 Ch3 Ch4 Ch5 Ch3 Ch4

Plotted: 14:08 Nov 16, 2001

< EMI - ElectroMagnetic Instruments > 


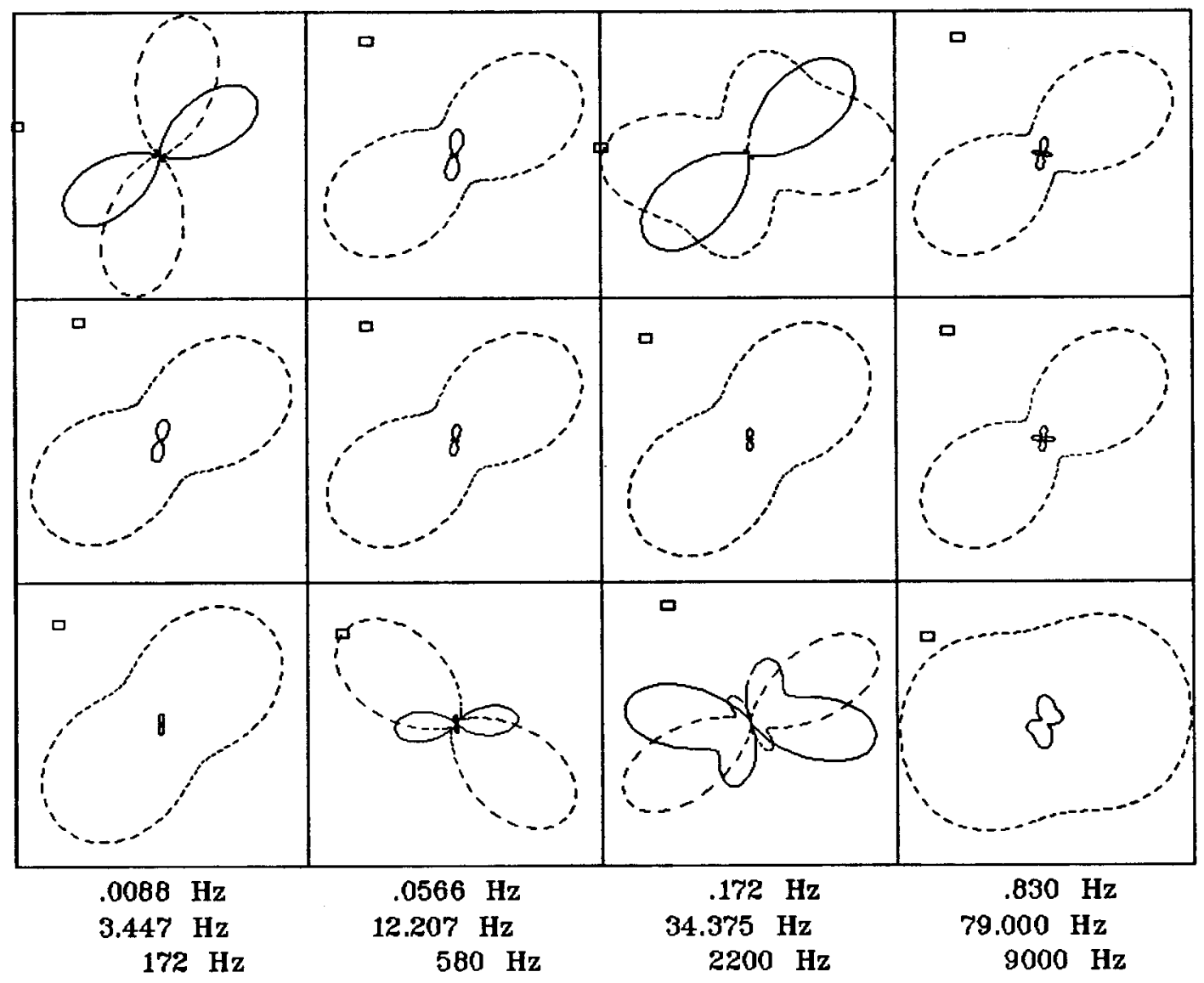

Client:

Remote: none

Acquired: 12:2 oct 07,2001 Survey Co:USGS
Rotation:

Filename: ab4.avg

Channels: Ch1 Ch2 Ch3 Ch4 Ch5 Ch3 Ch4

Plotted: 14:08 Nov 16, 2001

< EMI - ElectroMagnetic Instruments > 


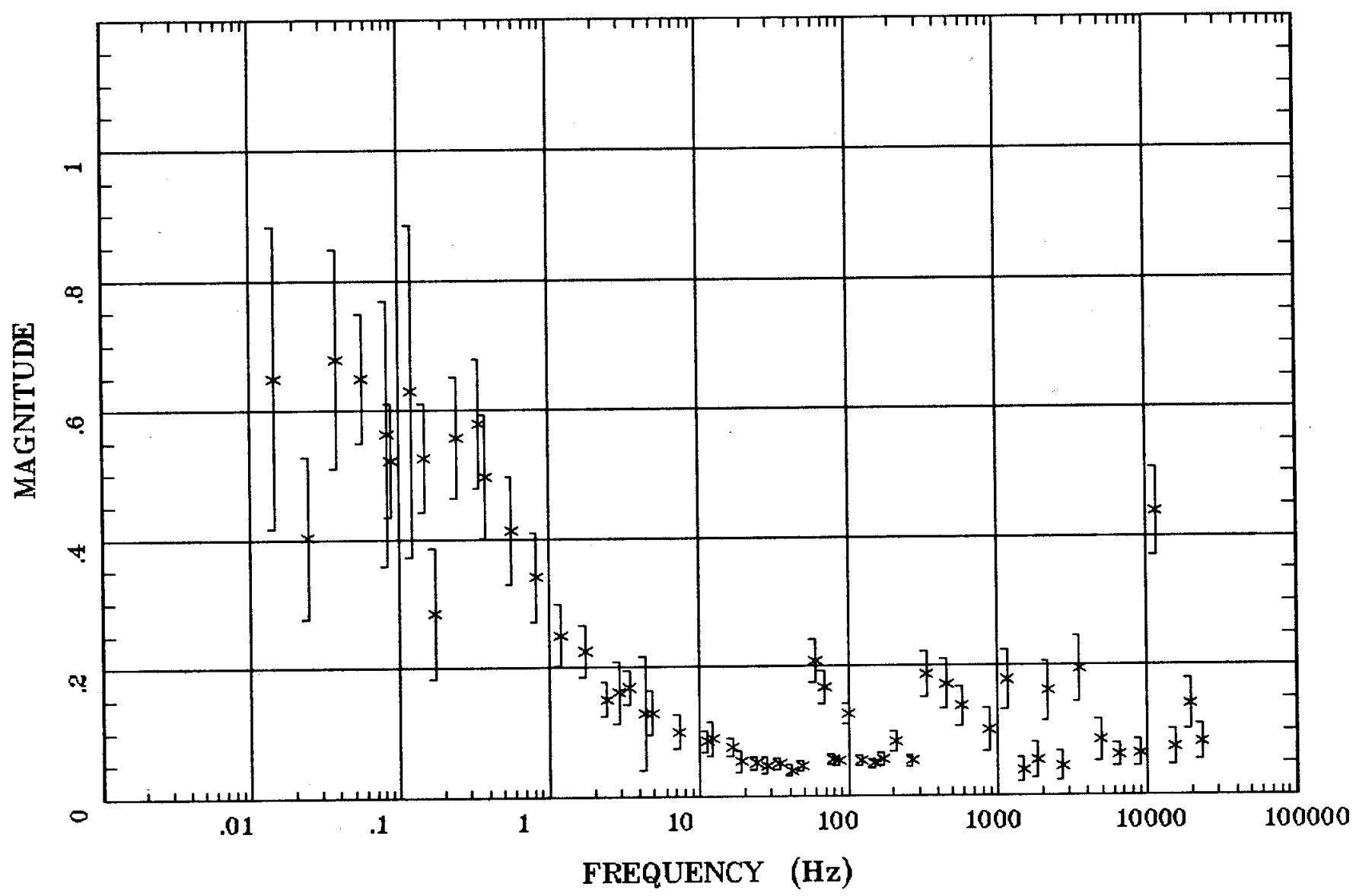

Client:

Remote: none

Acquired: 12:2 oct 07, 2001

Survey Co:USGS

\section{Rotation:}

Filename: ab4.avg

Channels: Ch1 Ch2 Ch3 Ch4 Ch5 Ch3 Ch4 Plotted: 14:08 Nov 16, 2001

< EMI - ElectroMagnetic Instruments > 
TIPPER STRIKE

Hawthorne, Nevada STATION 4

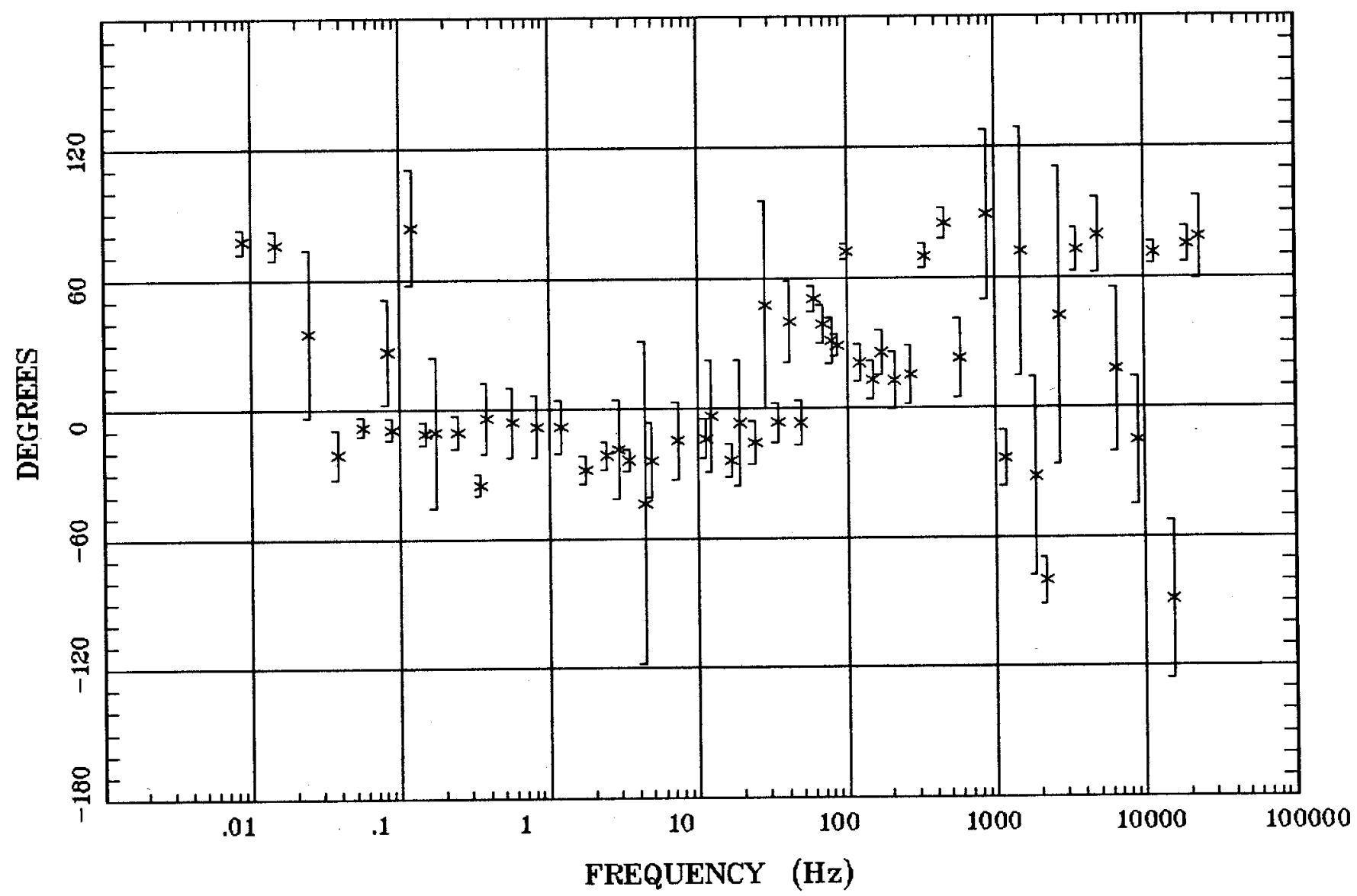

Client:

Remote: none

Acquired: 12:2 oct 07,2001

Survey Co:USGS
Rotation:

Filename: ab4.avg

Channels: Ch1 Ch2 Ch3 Ch4 Ch5 Ch3 Ch4

Platted: 14:08 Nov 16, 2001

< EMI - ElectroMagnetic Instruments > 


\section{HzHx.x Coh HzHy.o}

Hawthorne, Nevada STATION 4

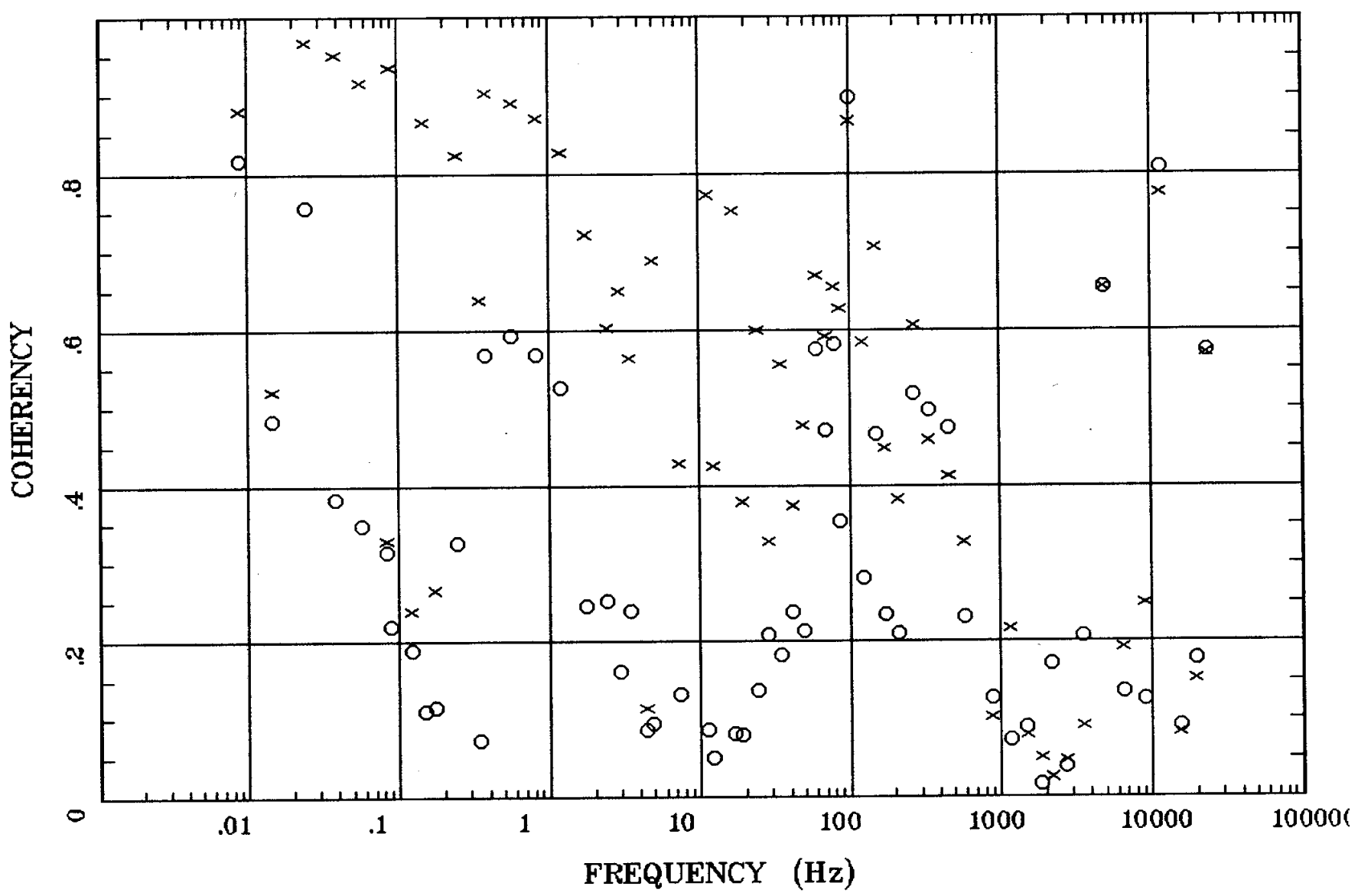

Client:

Remote: none

Acquired: 12:2 oct 07, 2001

Survey Co:USGS
Rotation:

Filename: ab4.avg

Channels: Ch1 Ch2 Ch3 Ch4 Ch5 Ch3 Ch4 Plotted: 14:08 Nov 16, 2001

< EMI - ElectroMagnetic Instruments > 


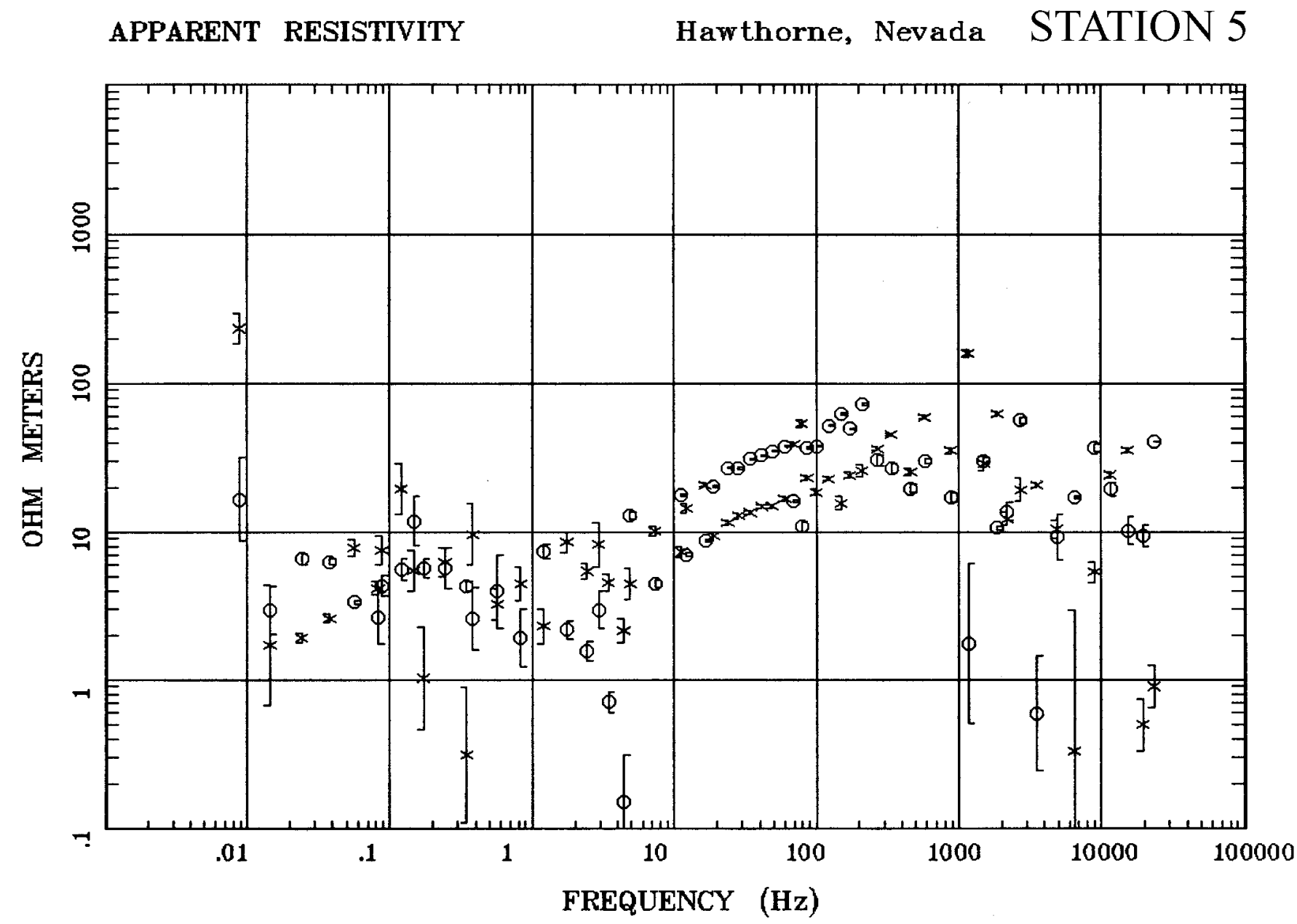

Client:

Remote: none

Acquired: 14:1 Oct 07, 2001

Survey Co:USGS
Rotation:

Filename: ab5.avg

Channels: Ch1 Ch2 Ch3 Ch4 Ch5 Ch3 Ch4

Plotted: 14:11 Nov 16, 2001

< EMI - ElectroMagnetic Instruments > 
Haw thorne, Nevada STATION 5

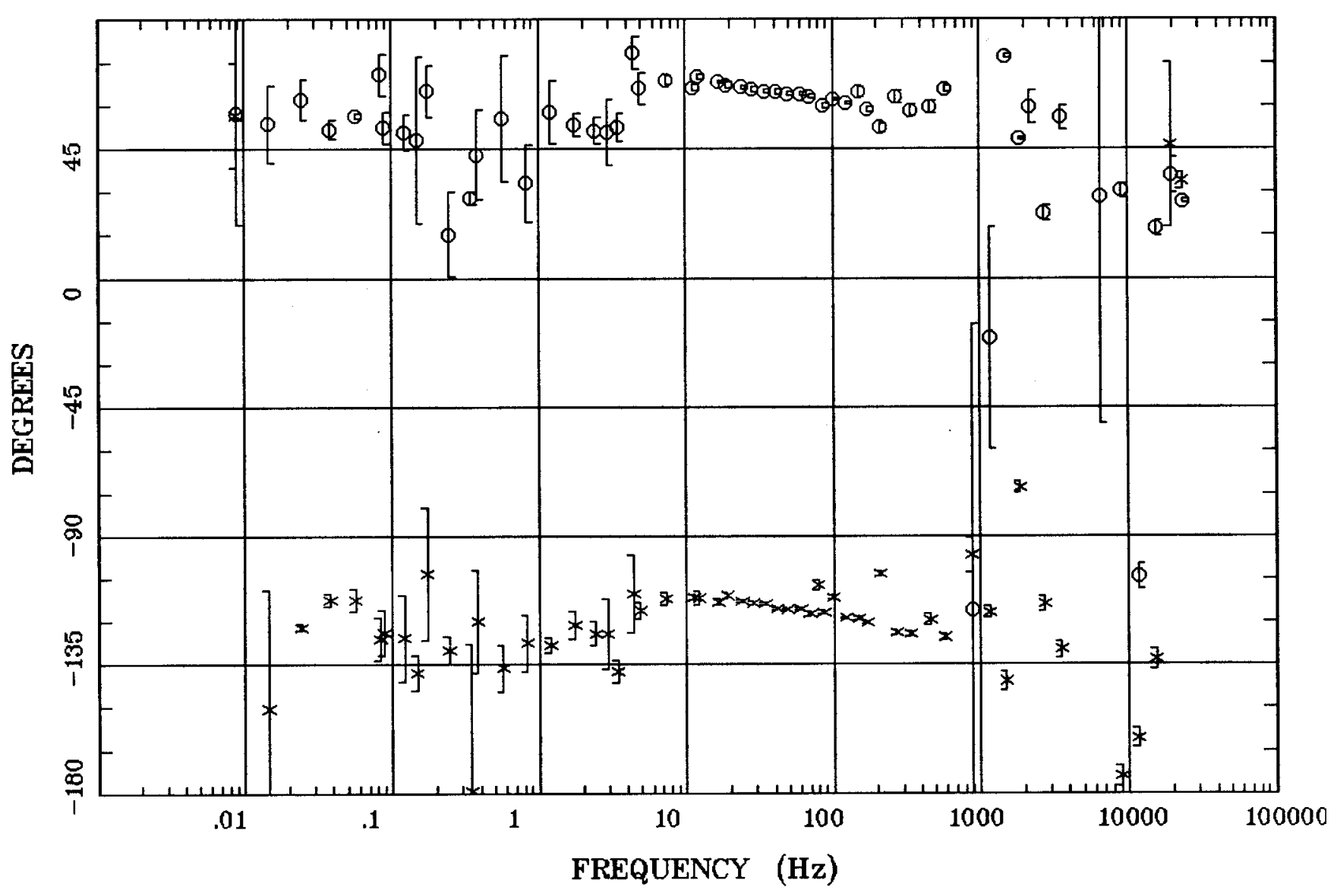

Client:

Rotation:

Remote: none

Acquired: 14:1 oct 07, 2001

Survey Co:USGS

Filename: ab5.avg

Channels: Ch1 Ch2 Ch3 Ch4 Ch5 Ch3 Ch4

Plotted: 14:11 Nor 16, 2001

< EMI - ElectroMagnetic Instruments > 


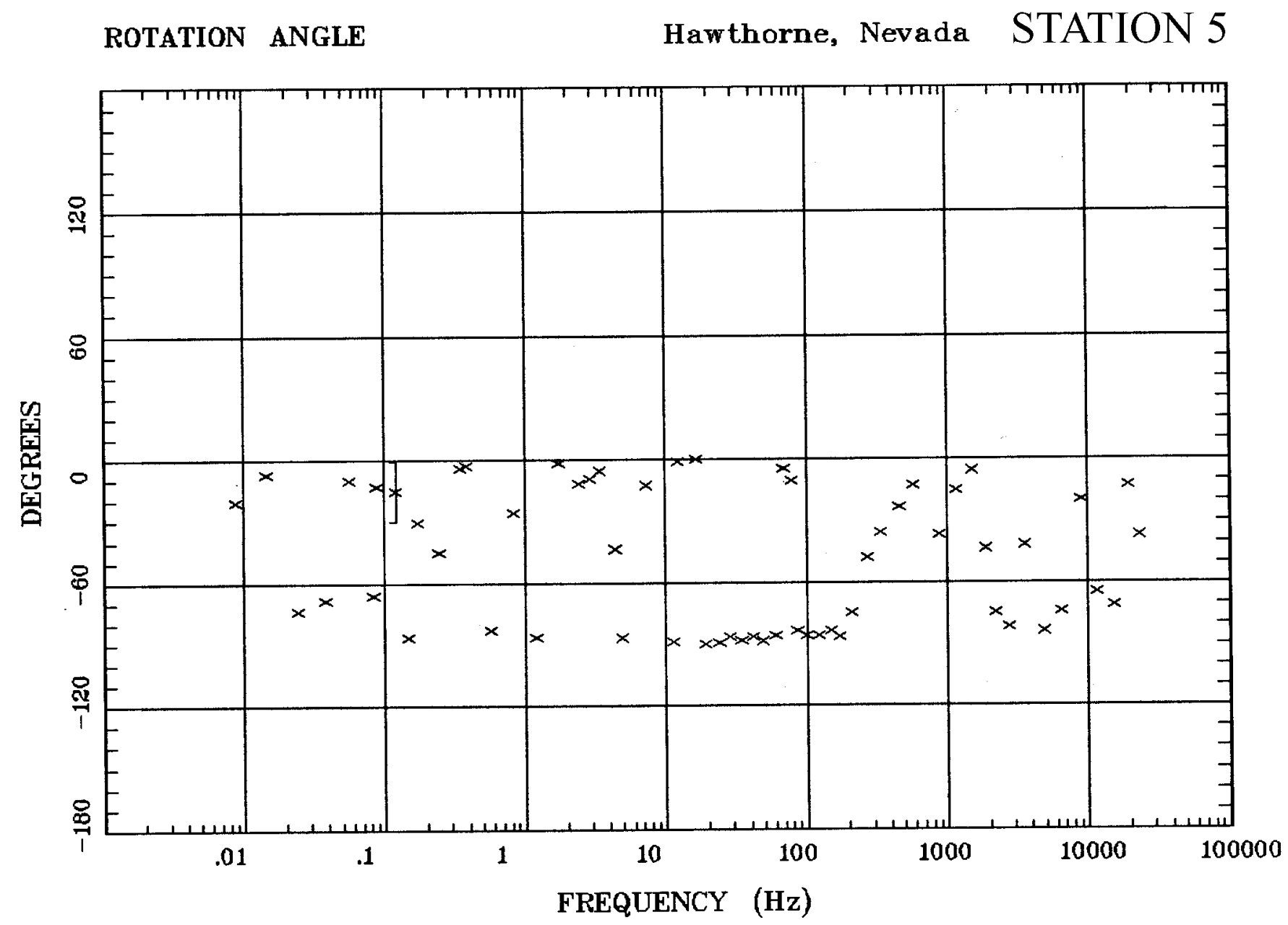

Client:

Remote: none

Acquired: 14:1 Oct 07, 2001

Survey Co:USGS

\section{Rotation:}

Filename: ab5.evg

Channels: Ch1 Ch2 Ch3 Ch4 Ch5 Ch3 Ch4

Plotted: 14:11 Nop 16, 2001

< EMI - ElectroMagnetic Instruments > 


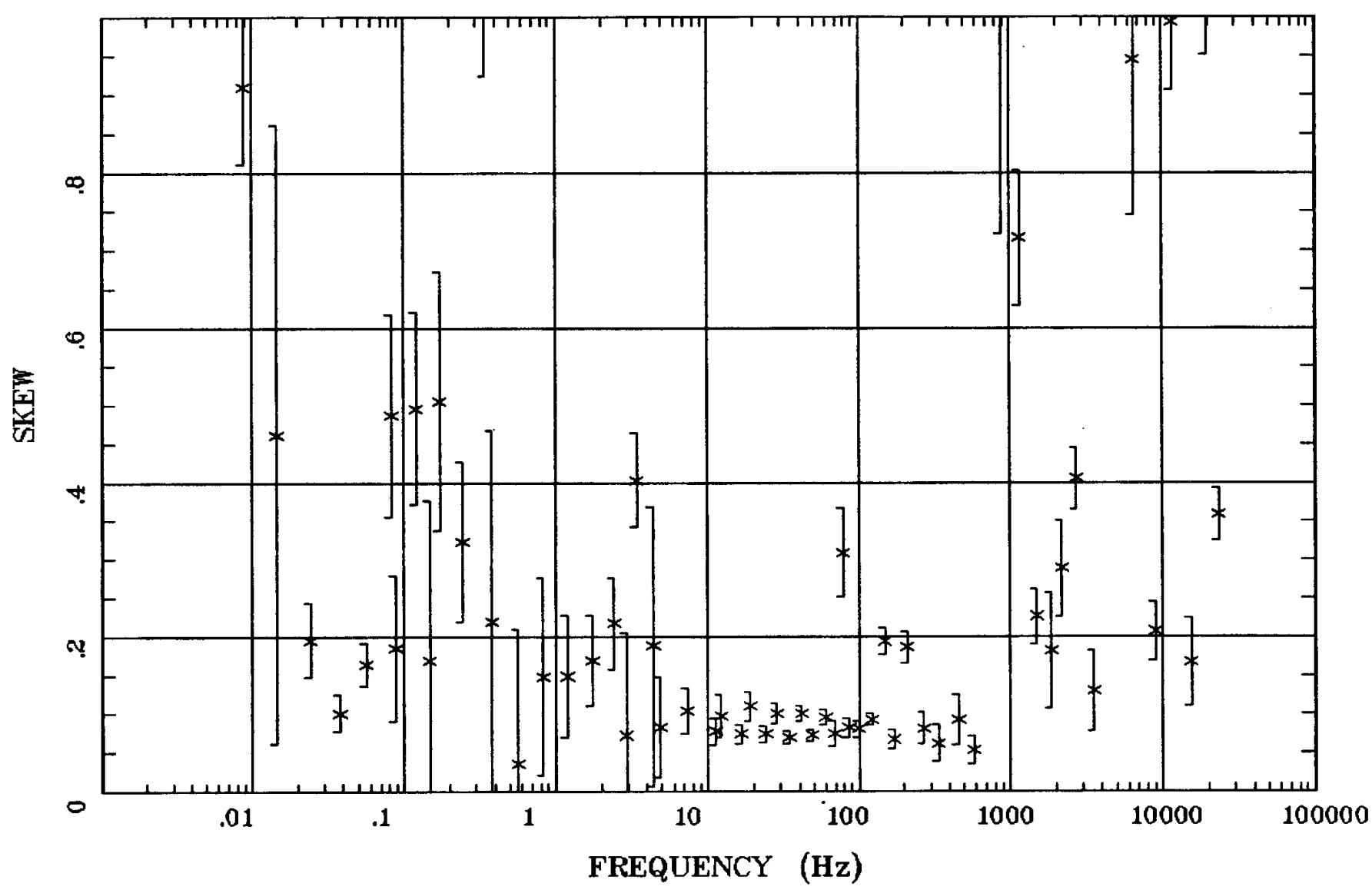

Client:

Remote: none

Acquired: 14:1 Oct 07, 2001 Survey Co:USGS
Rotation:

Filename: ab5.avg

Channels: Ch1 Ch2 Ch3 Ch4 Ch5 Ch3 Ch4

Plotted: 14:11 Nov 16, 2001

< EMI - ElectroMagnetic Instruments > 
E MULT Coh.

Hawthorne, Nevada STATION 5

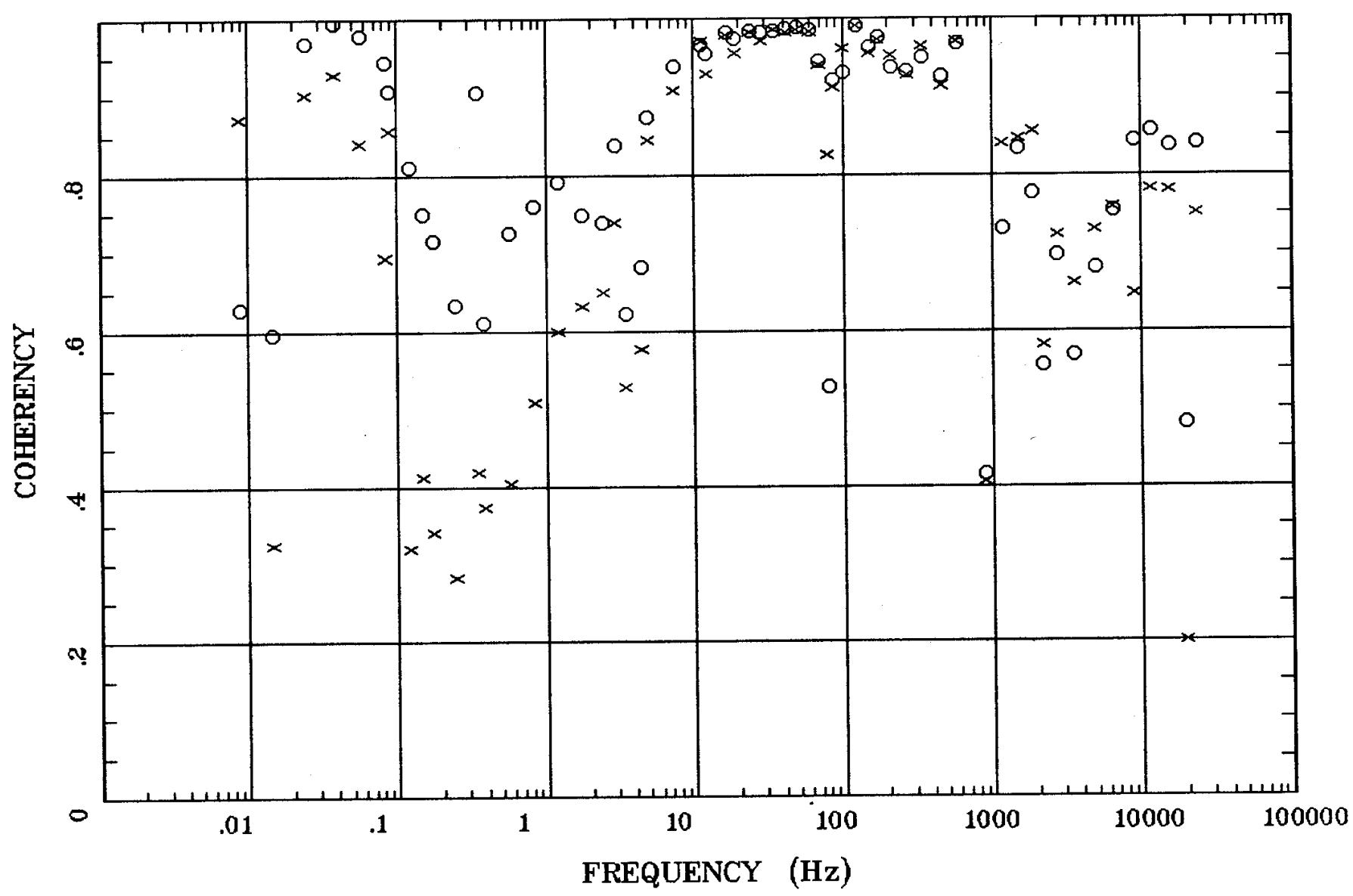

Client:

Remote: none

Acquired: 14:1 oct 07, 2001

Survey Co:USGS
Rotation:

Filename: ab5.avg

Channels: Ch1 Ch2 Ch3 Ch4 Ch5 Ch3 Ch4

Plotted: 14:11 Nov 16, 2001

< EMI - ElectroMagnetic Instruments > 


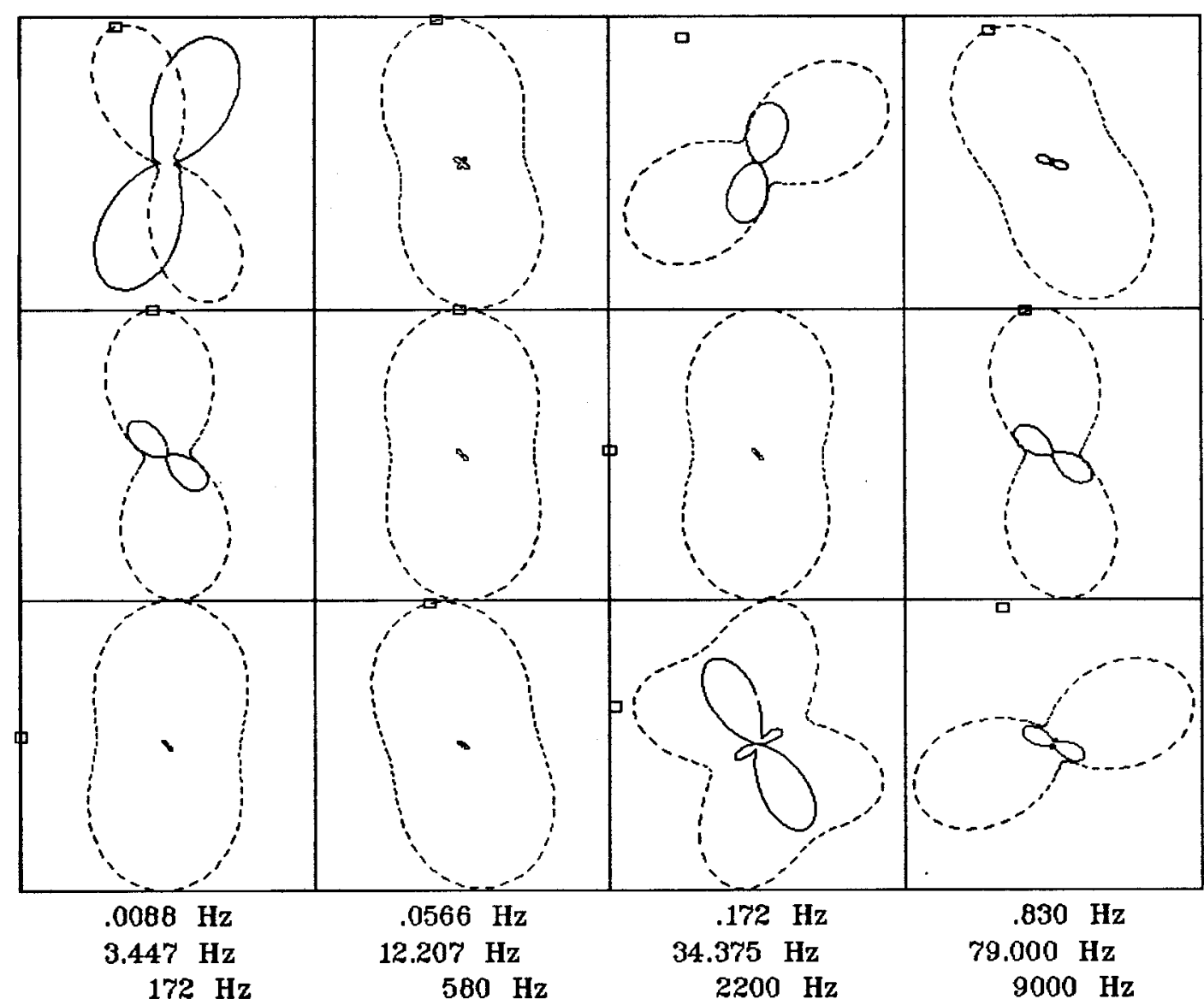

Client:

Rotation

Remote: none

Filename: ab5.avg

Channels: Ch1 Ch2 Ch3 Ch4 Ch5 Ch3 Ch4

Acquired: 14:1 oct 07, 2001

Plotted: 14:11 Nov 16, 2001

Survey Co:USGS

< EMI - ElectroMagnetic Instruments 


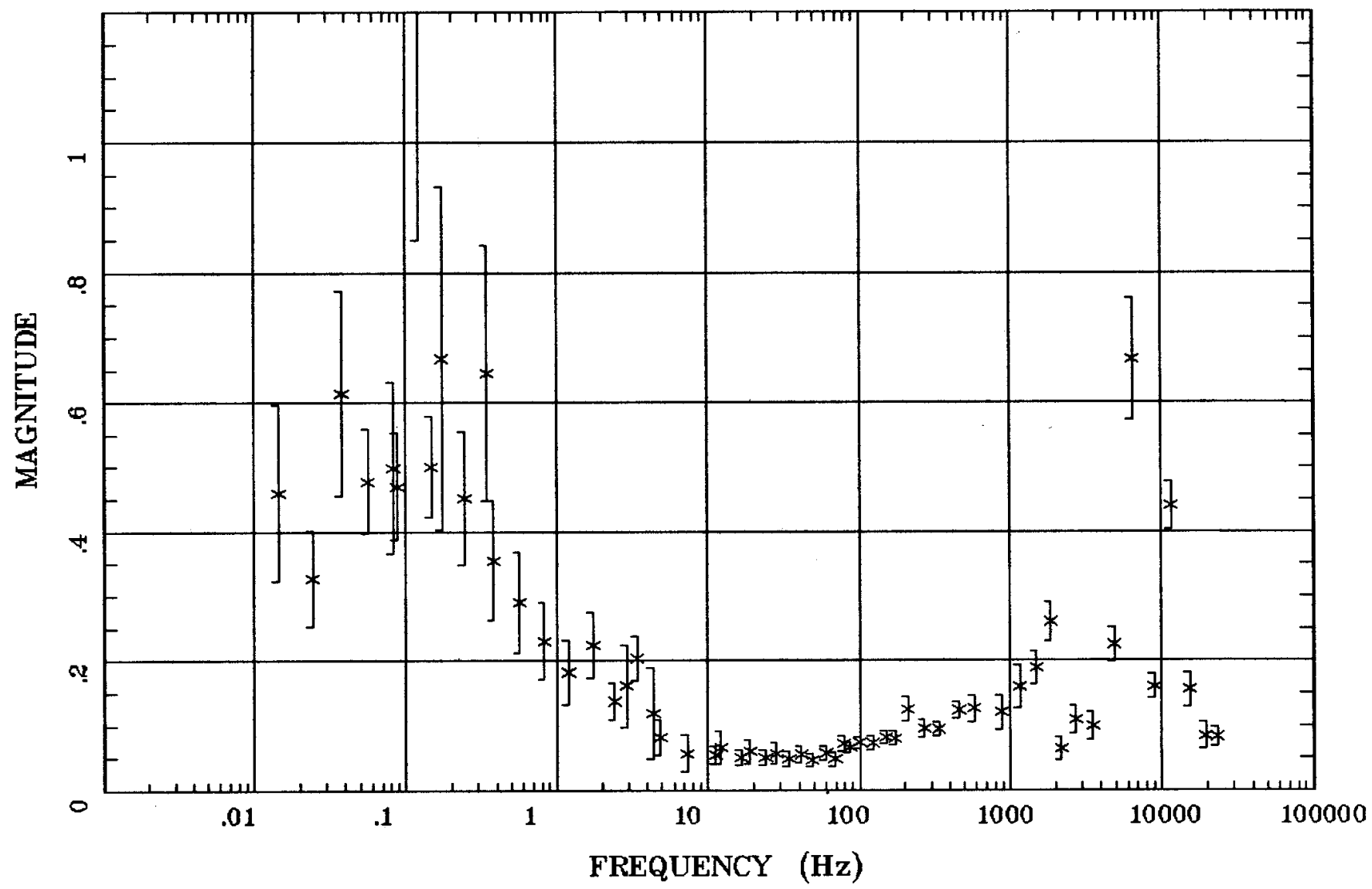

Client:

Remote: none

Acquired: 14:1 Oct 07, 2001 Survey Co:USGS
Rotation:

Filename: ab5.avg

Channels: Ch1 Ch2 Ch3 Ch4 Ch5 Ch3 Ch4

Plotted: 14:11 Nov 16, 2001

< EMI - ElectroMagnetic Instruments > 


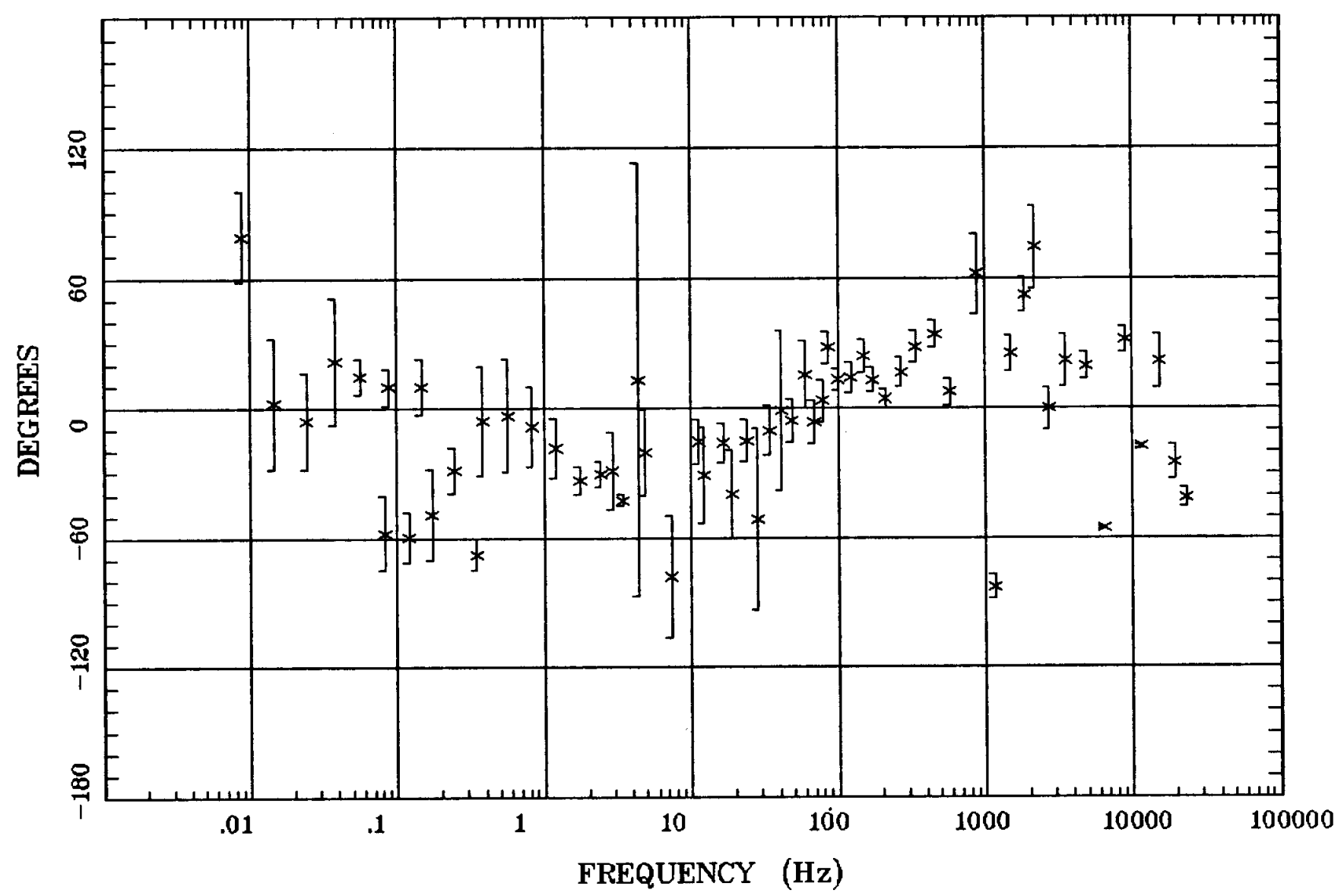

Client:

Remote: none

Acquired: 14:1 oct 07,2001

Survey Co:USGS
Rotation

Filename: ab5.avg

Channels: Ch1 Ch2 Ch3 Ch4 Ch5 Ch3 Ch4

Plotted: 14:11 Nov 16, 2001

< EMI - ElectroMagnetic Instruments > 
HzHx.x Coh HzHy.o

Hawthorne, Nevada STATION 5

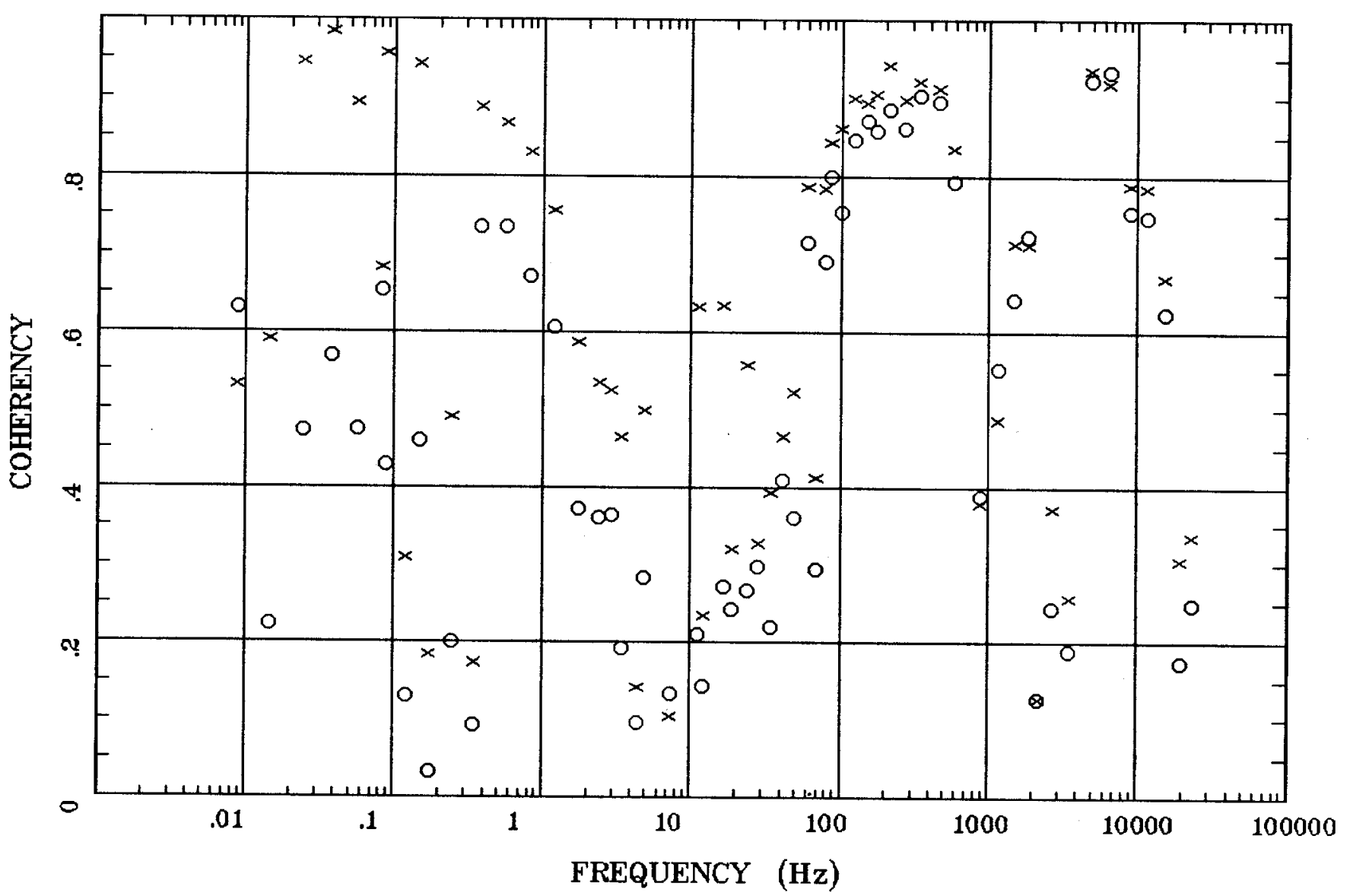

Client:

Remote: none

Acquired: 14:1 Oct 07, 2001

Survey Co:USGS
Rotation:

Filename: ab5.avg

Channels: Ch1 Ch2 Ch3 Ch4 Ch5 Ch3 Ch4

Plotted: 14:11 Nov 16, 2001

< EMI - ElectroMagnetic Instruments > 


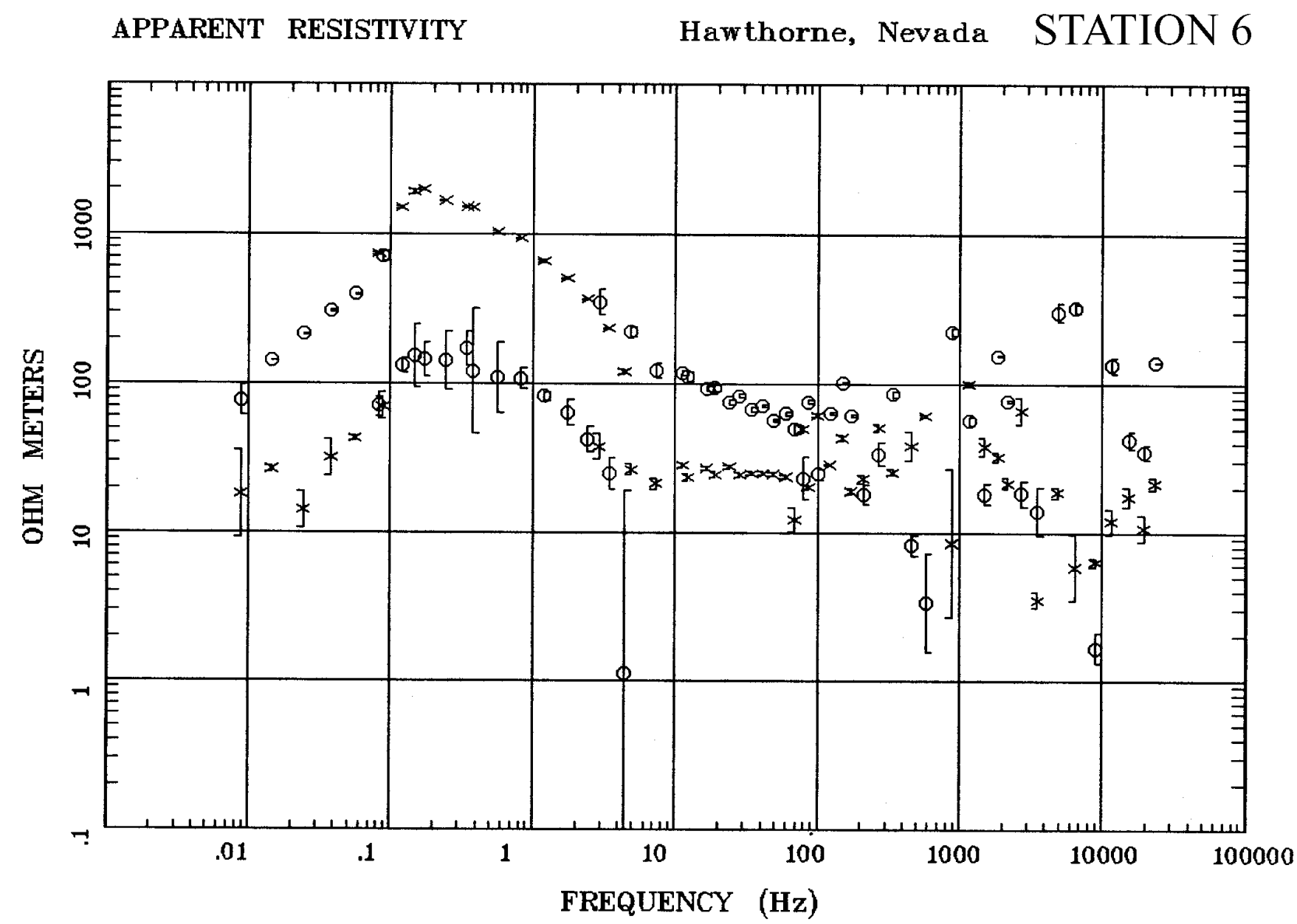

Client:

Remote: none

Acquired: 09:4 oct 09, 2001 Survey Co:USGS
Rotation:

Filename: ab6.avg

Channels: Ch1 Ch2 Ch3 Ch4 Ch5 Ch3 Ch4

Plotted: 14:13 Nov 16, 2001

< EMI - ElectroMagnetic Instruments > 


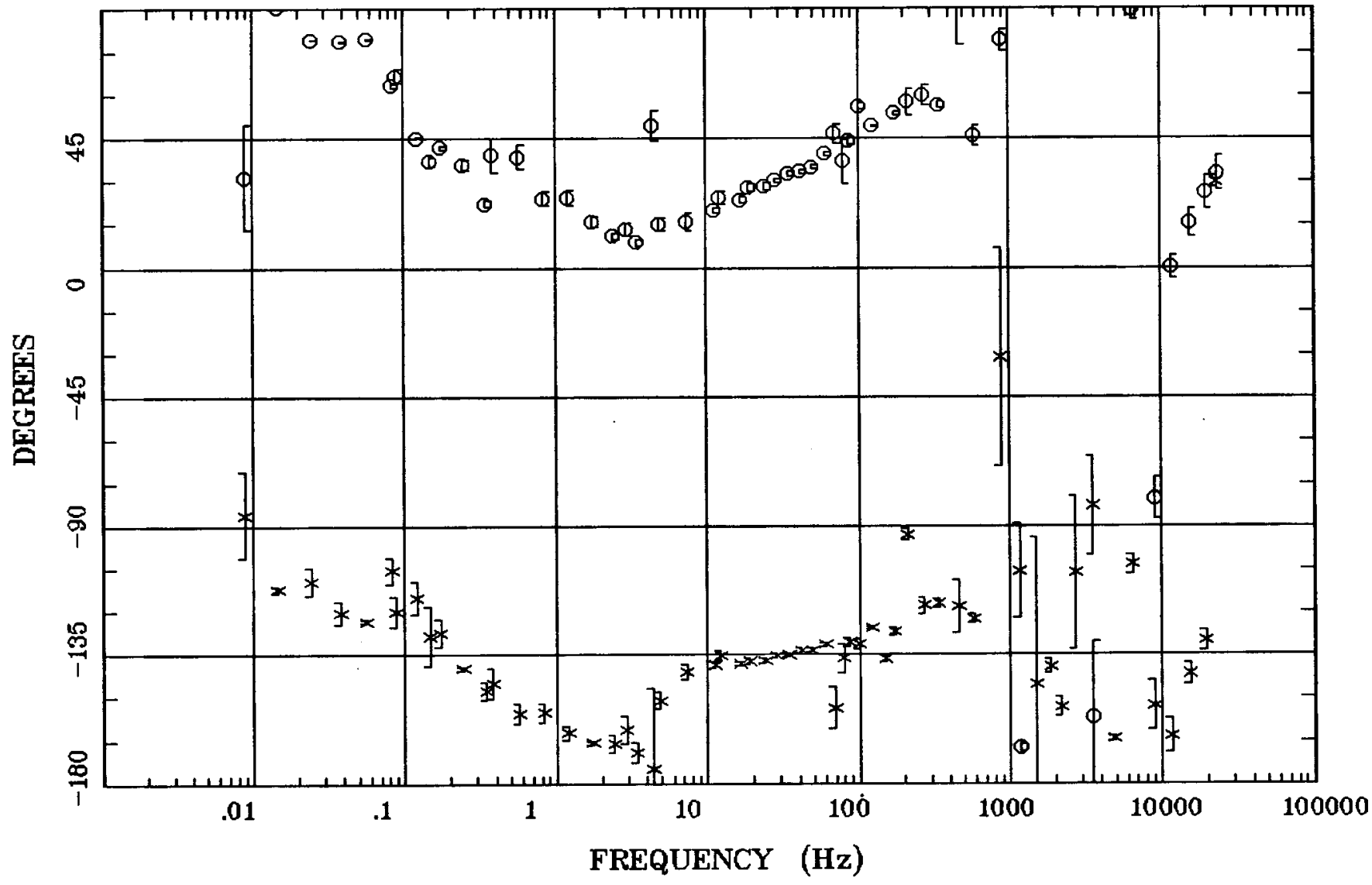

Client:

Remote: none

Acquired: 09:4 oct 09,2001

Survey Co:USGS
Rotation:

Filename: ab6.avg

Channels: Ch1 Ch2 Ch3 Ch4 Ch5 Ch3 Ch4

Plotted: 14:13 Nov 16, 2001

< EMI - ElectroMagnetic Instruments > 


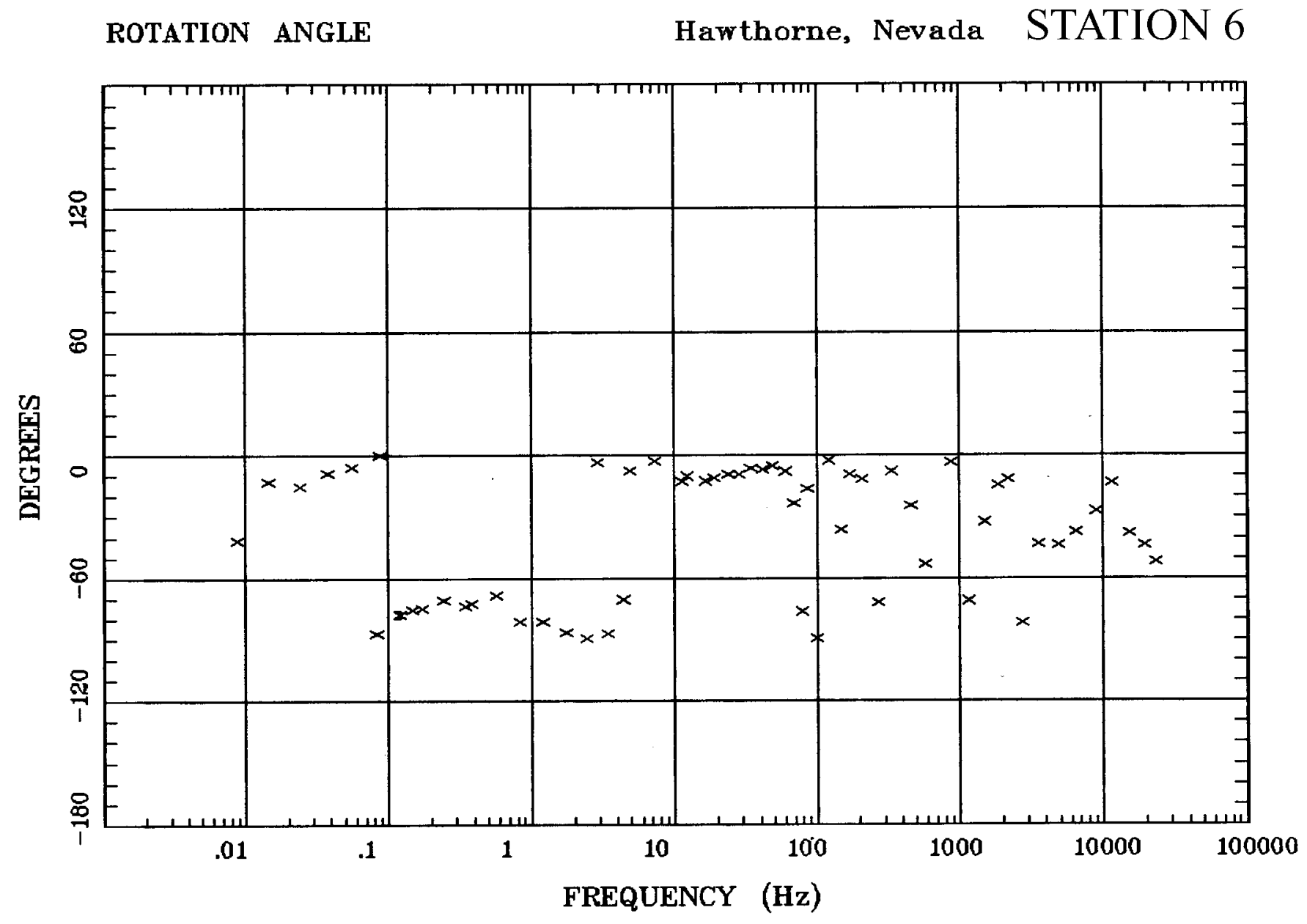

Client:

Remote: none

Acquired: 09:4 oct 09, 2001

Survey Co:USGS
Rotation:

Filename: ab6.avg

Channels: Ch1 Ch2 Ch3 Ch4 Ch5 Ch3 Ch4 Plotted: 14:13 Nov 16, 2001

< EMI - ElectroMagnetic Instruments > 


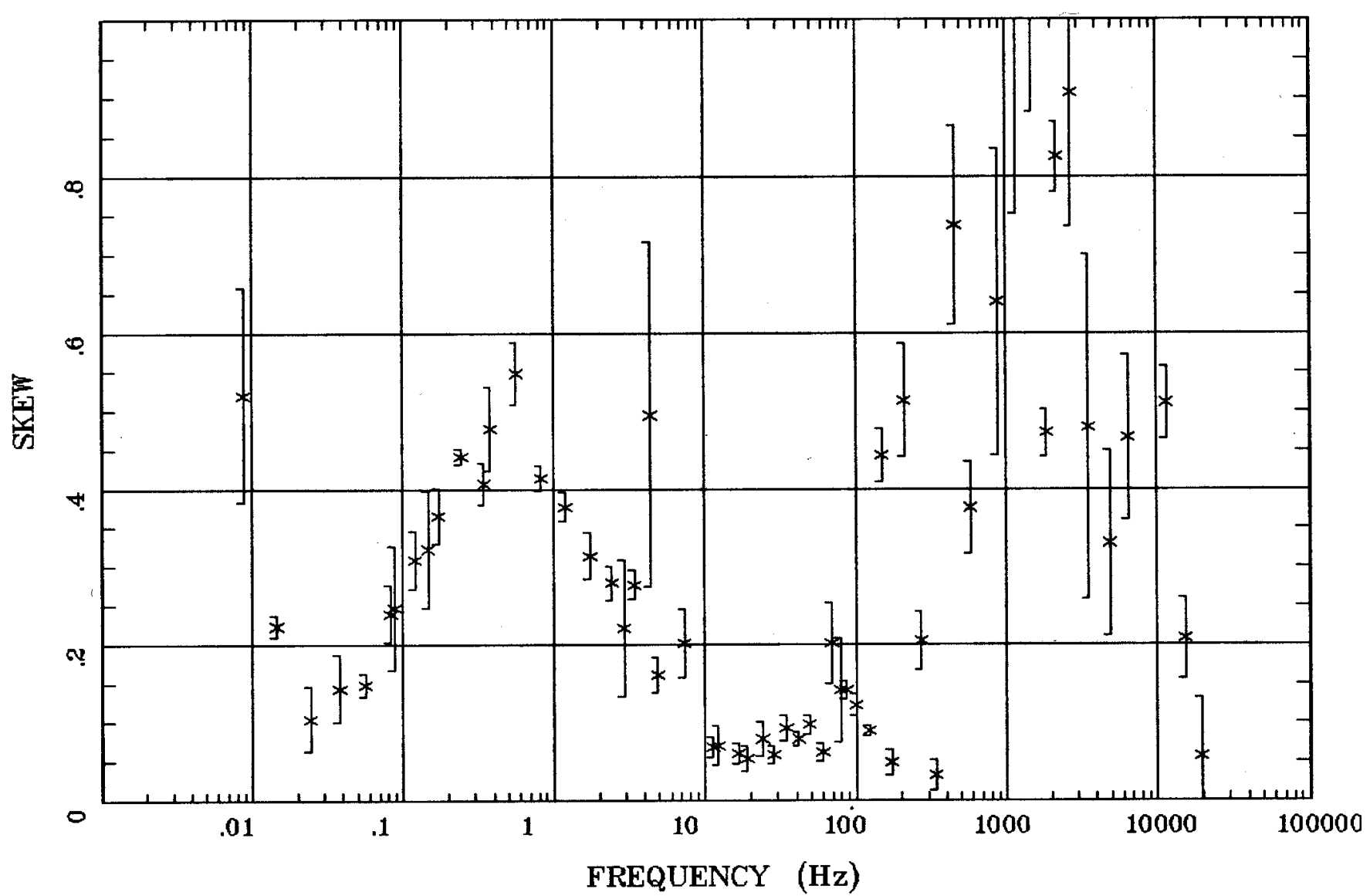

Client:

Remote: none

Acquired: 09:4 oct 09, 2001

Survey Co:USGS
Rotation:

Filename: ab6.avg

Channels: Ch1 Ch2 Ch3 Ch4 Ch5 Ch3 Ch4

Plotted: $14: 13$ Nov 16, 2001

< EMI - ElectroMagnetic Instruments > 


\section{E MULT Coh.}

Hawthorne, Nevada STATION 6

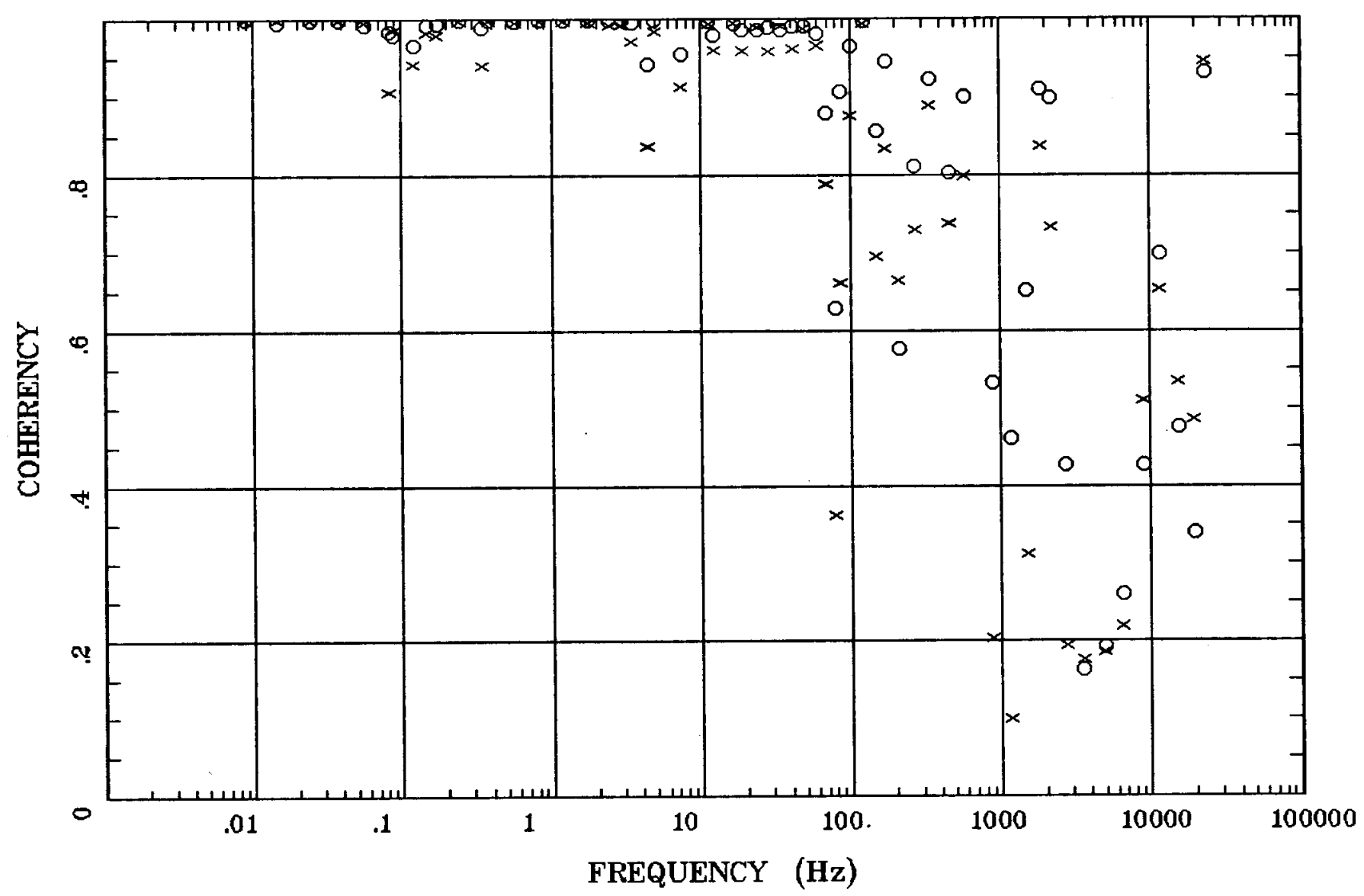

Client:

Remote: none

Acquired: 09:4 oct 09, 2001

Survey Co:USGS
Rotation:

Filename: ab6.avg

Channels: Ch1 Ch2 Ch3 Ch4 Ch5 Ch3 Ch4

Plotted: 14:13 Nov 16, 2001

< EMI - ElectroMagnetic Instruments > 


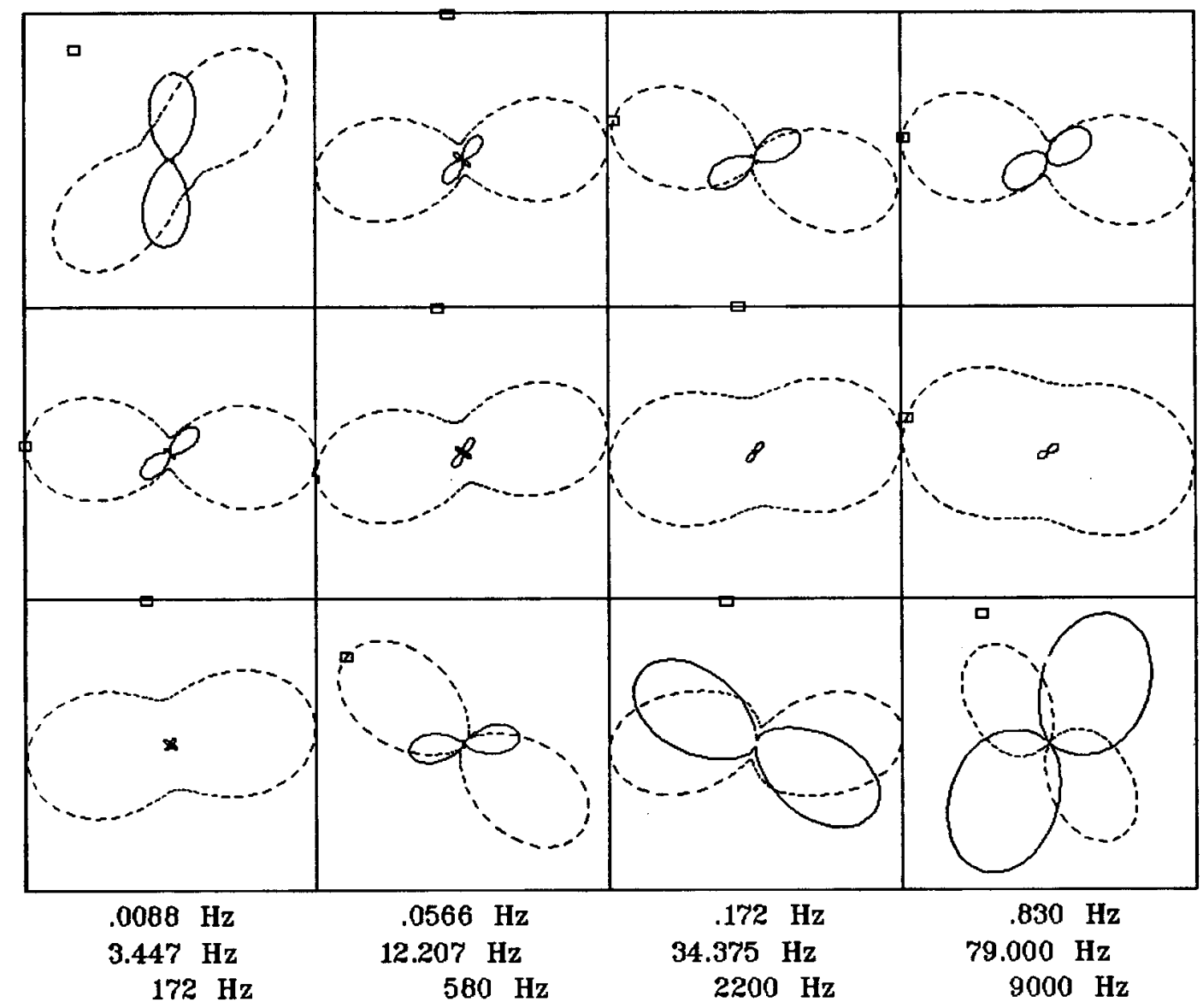

Client:

Remote: none

Acquired: 09:4 oct 09, 2001

Survey Co:USGS

Rotation:

Filename: ab6.avg

Channels: Ch1 Ch2 Ch3 Ch4 Ch5 Ch3 Ch4

Plotted: 14:13 Nov 16, 2001

< EMI - ElectroMagnetic Instruments > 


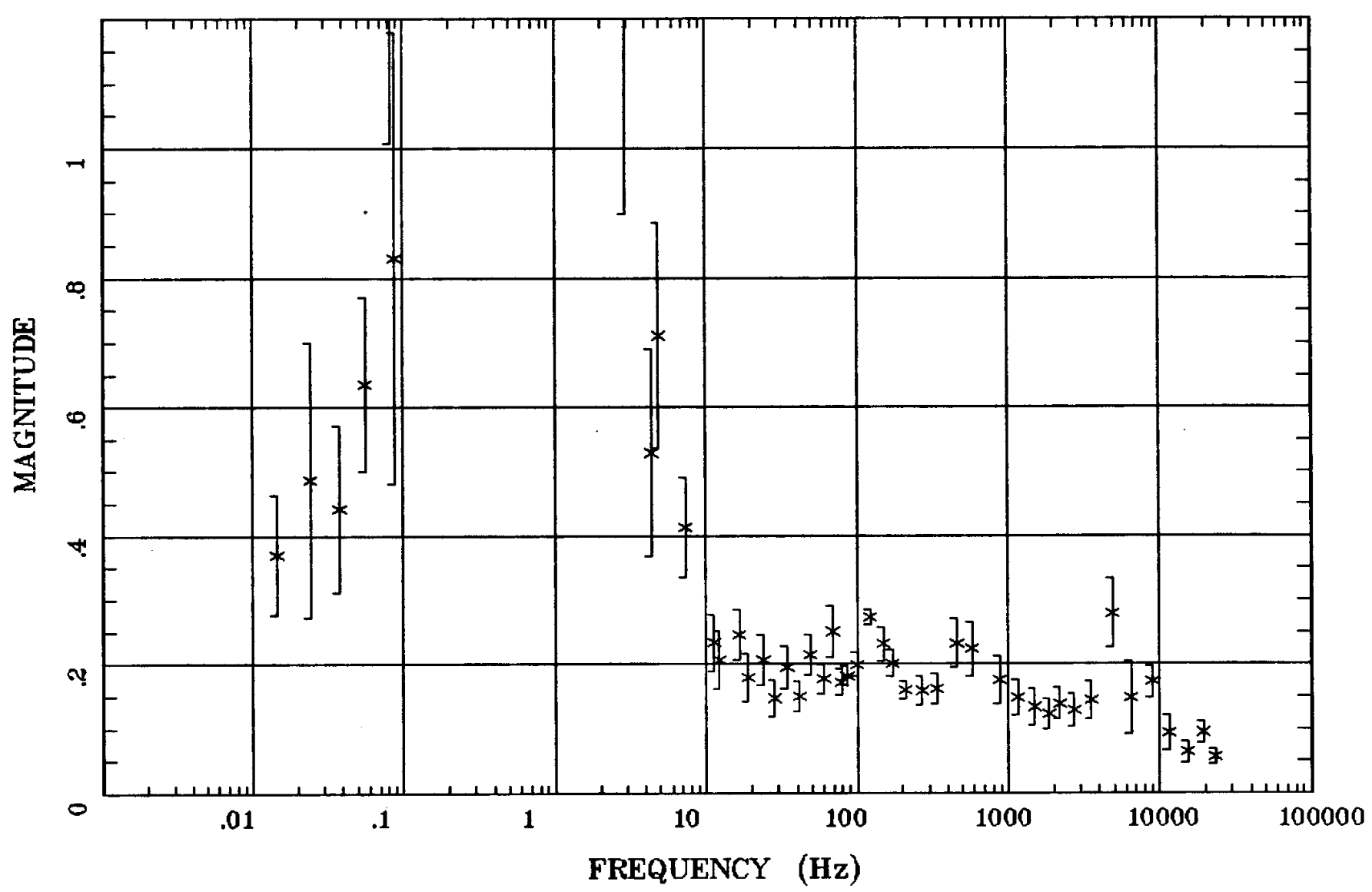

Client:

Remote: none

Acquired: 09:4 Oct 09, 2001 Survey Co:USGS
Rotation:

Filename: ab6.avg

Channels: Ch1 Ch2 Ch3 Ch4 Ch5 Ch3 Ch4

Plotted: 14:13 Nov 16, 2001

< EMI - ElectroMagnetic Instruments > 
TIPPER STRIKE

Hawthorne, Nevada STATION 6

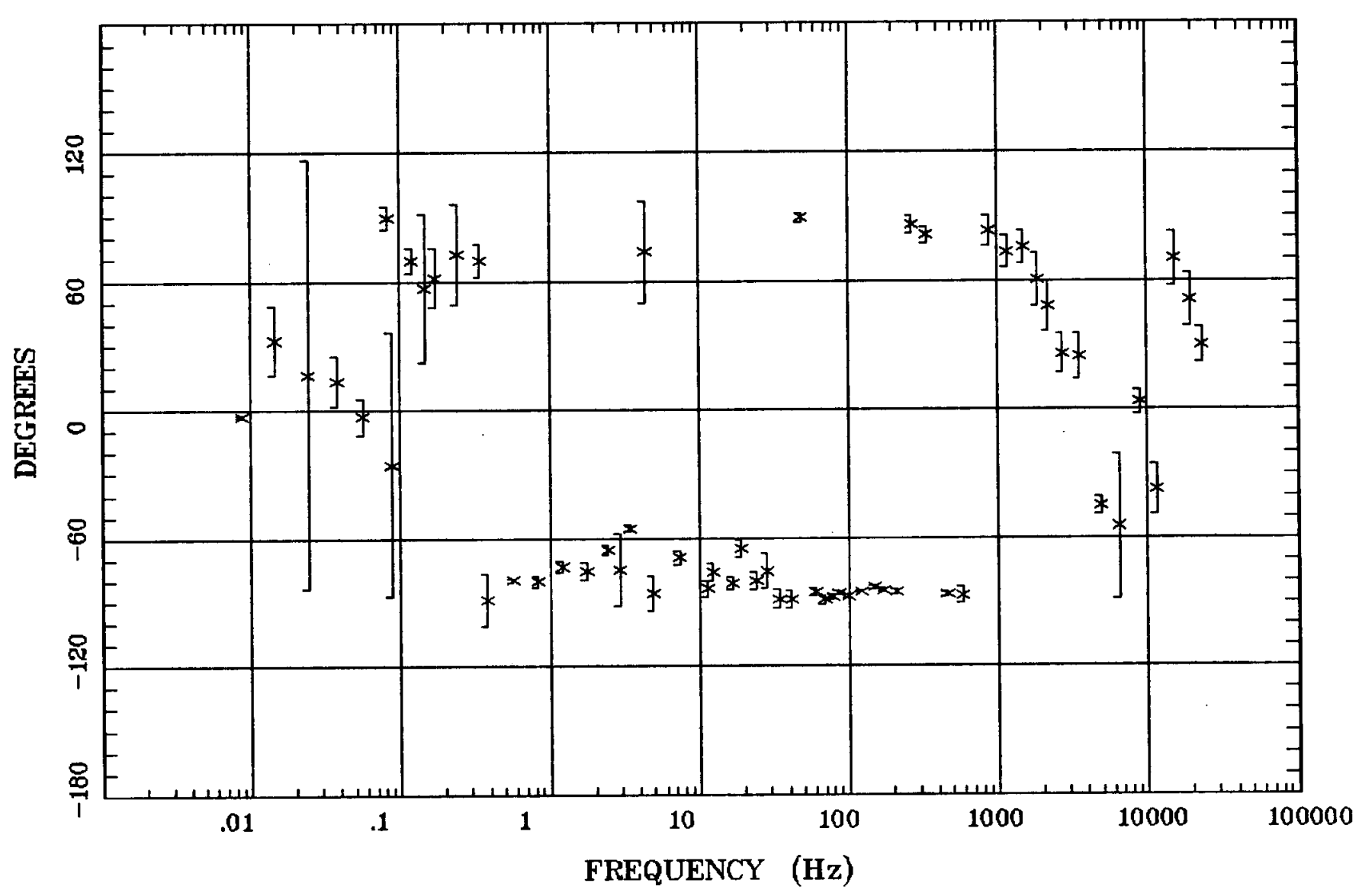

Client:

Remote: none

Acquired: 09:4 oct 09, 2001 Survey Co:USGS
Rotation:

Filename: ab6.avg

Channels: Ch1 Ch2 Ch3 Ch4 Ch5 Ch3 Ch4

Plotted: 14:13 Nov 16, 2001

< EMI - ElectroMagnetic Instruments > 
HzHx.x Coh HzHy.o

Hawthorne, Nevada STATION 6

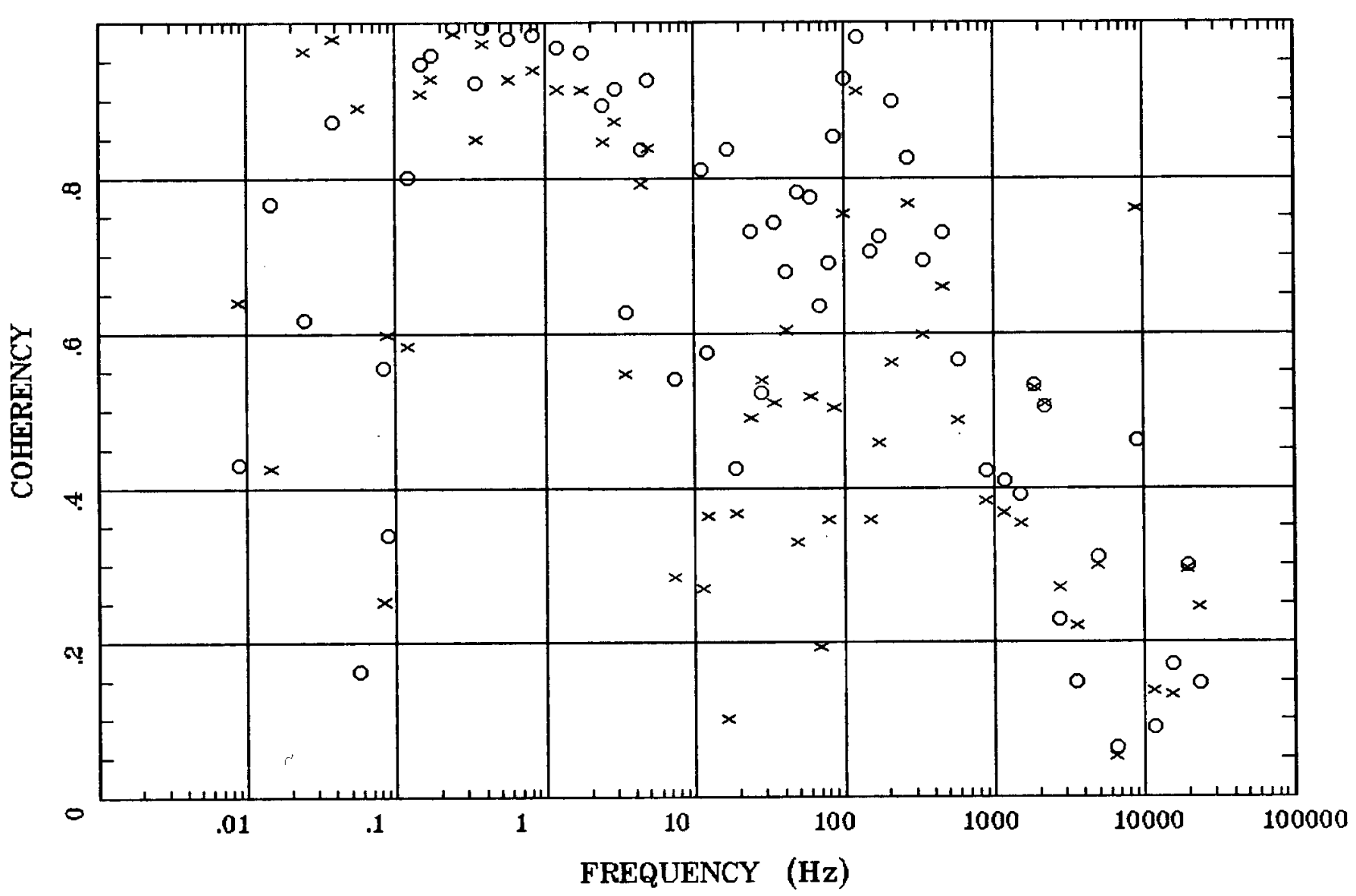

Client:

Remote: none

Acquired: 09:4 Oct 09,2001

Survey Co:USGS

Rotation:

Filename: ab6.avg

Channels: Ch1 Ch2 Ch3 Ch4 Ch5 Ch3 Ch4

Platted: 14:13 Nov 16, 2001

< EMI - ElectroMagnetic Instruments > 


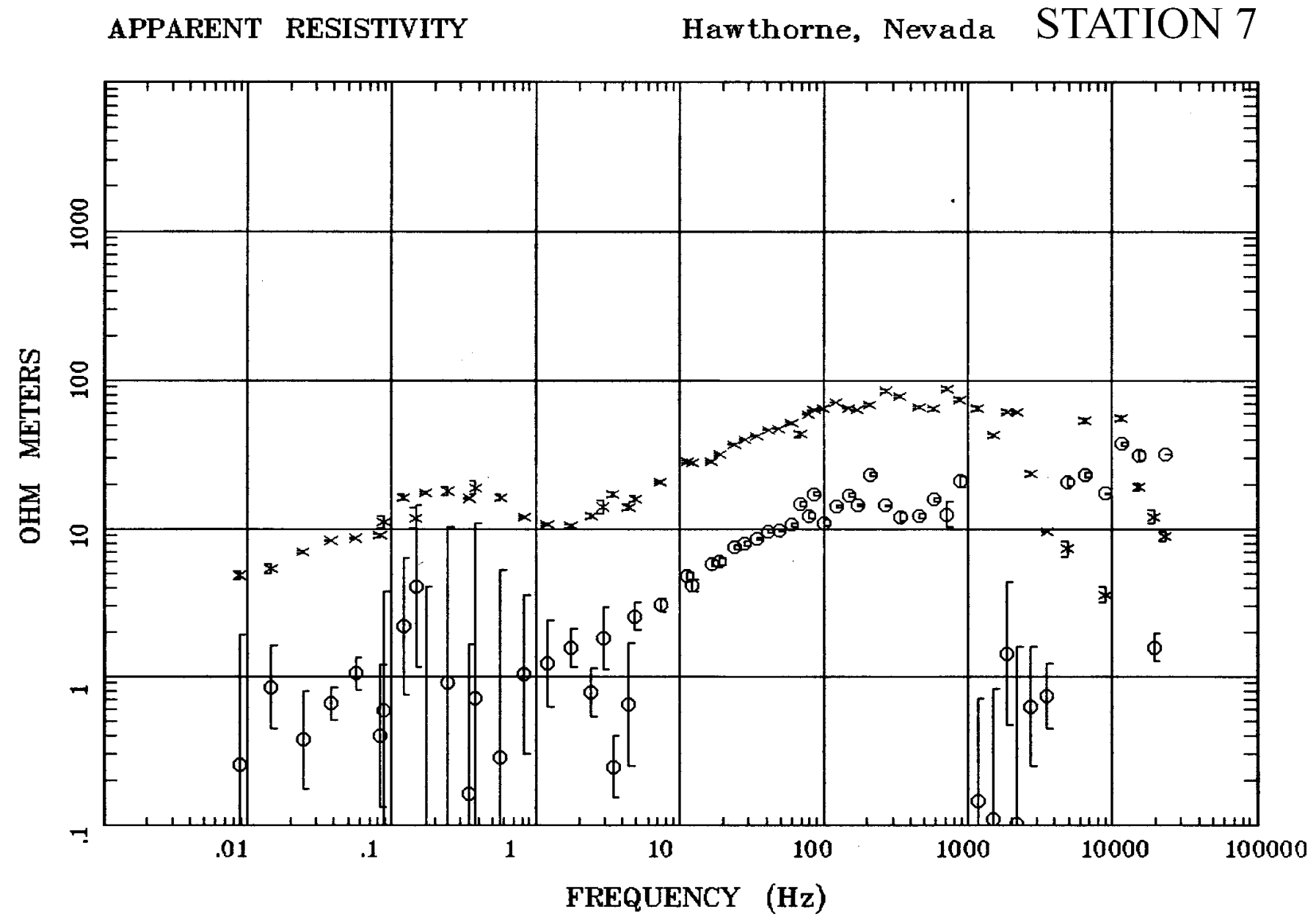

Client:

Remote: none

Acquired: 13:2 oct 09, 2001 Survey Co:USGS
Rotation:

Filename: ab7.avg

Channels: Ch1 Ch2 Ch3 Ch4 Ch5 Ch3 Ch4

Plotted: 14:14 Nov 16, 2001

< EMI - ElectroMagnetic Instruments > 


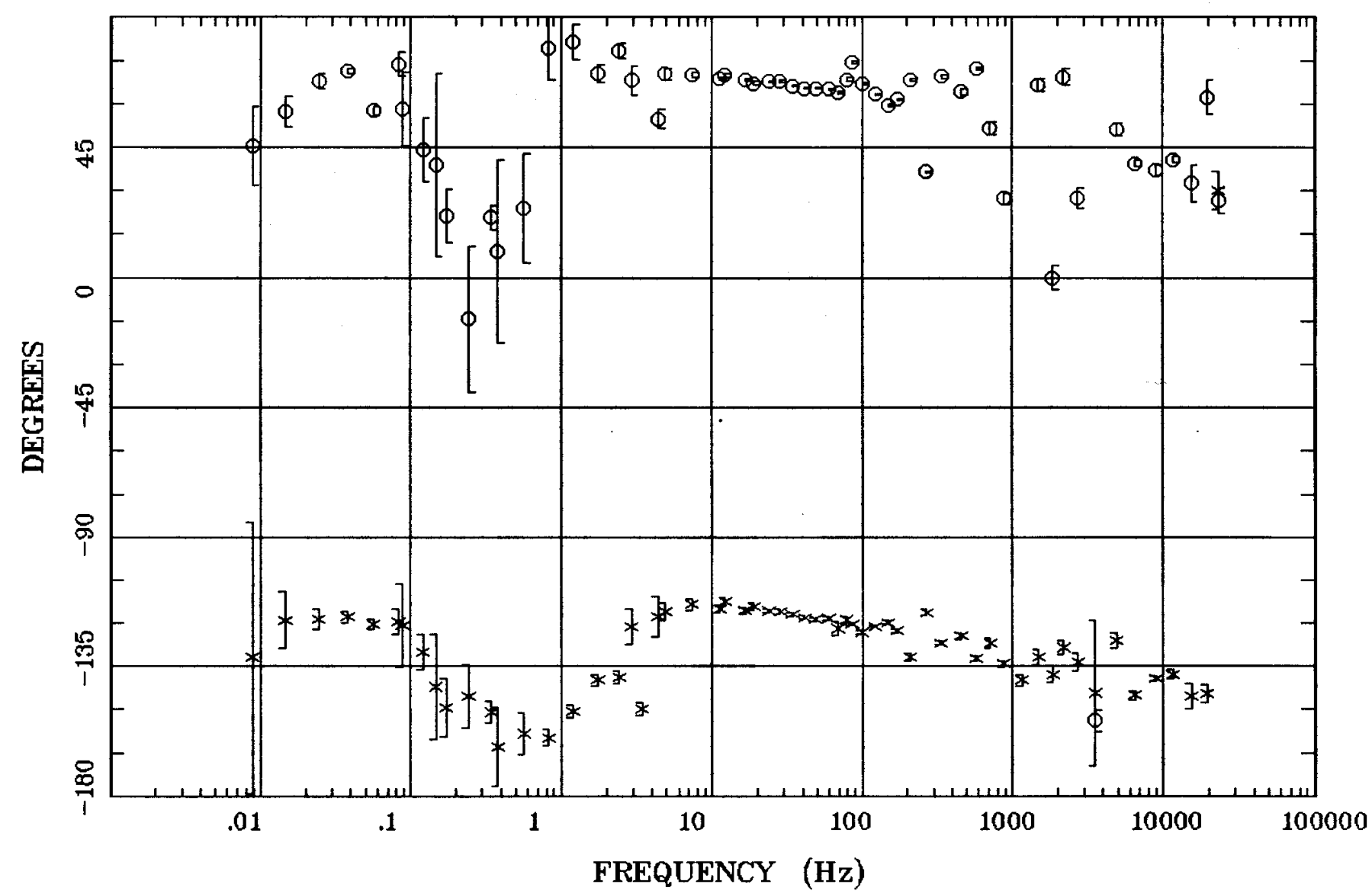

Client:

Remote: none

Acquired: 13:2 Oct 09, 2001

Survey Co:USGS
Rotation:

Filename: ab7.avg

Channels: Ch1 Ch2 Ch3 Ch4 Ch5 Ch3 Ch4

Plotted: 14:14 Nov 16, 2001

< EMI - ElectroMagnetic Instruments > 


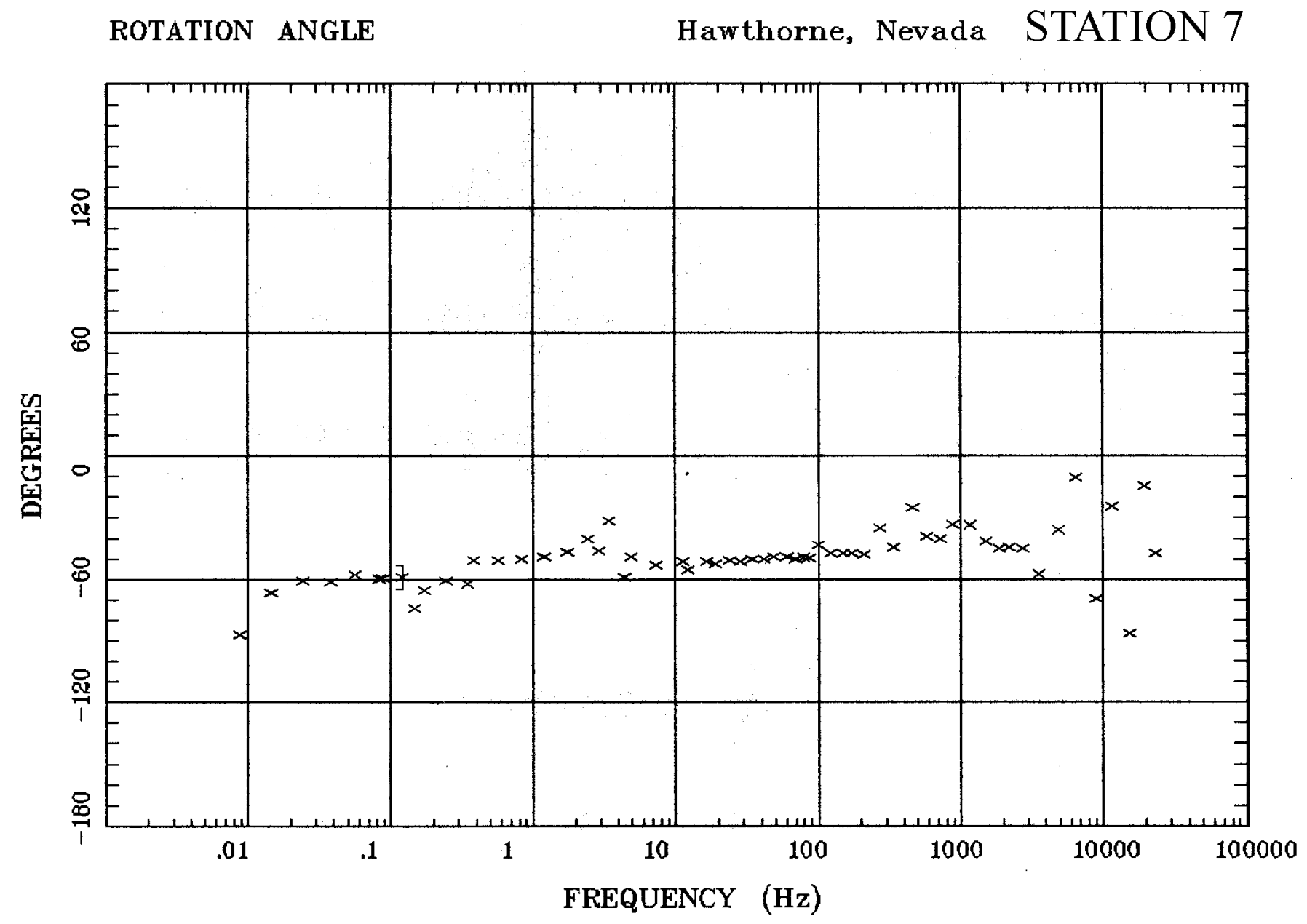

Client:

Remote: none

Acquired: 13:2 oct 09, 2001 Survey Co:USGS
Rotation:

Filename: ab7.avg

Channels: Ch1 Ch2 Ch3 Ch4 Ch5 Ch3 Ch4

Plotted: 14:14 Nov 16, 2001

< EMI - ElectroMagnetic Instruments > 


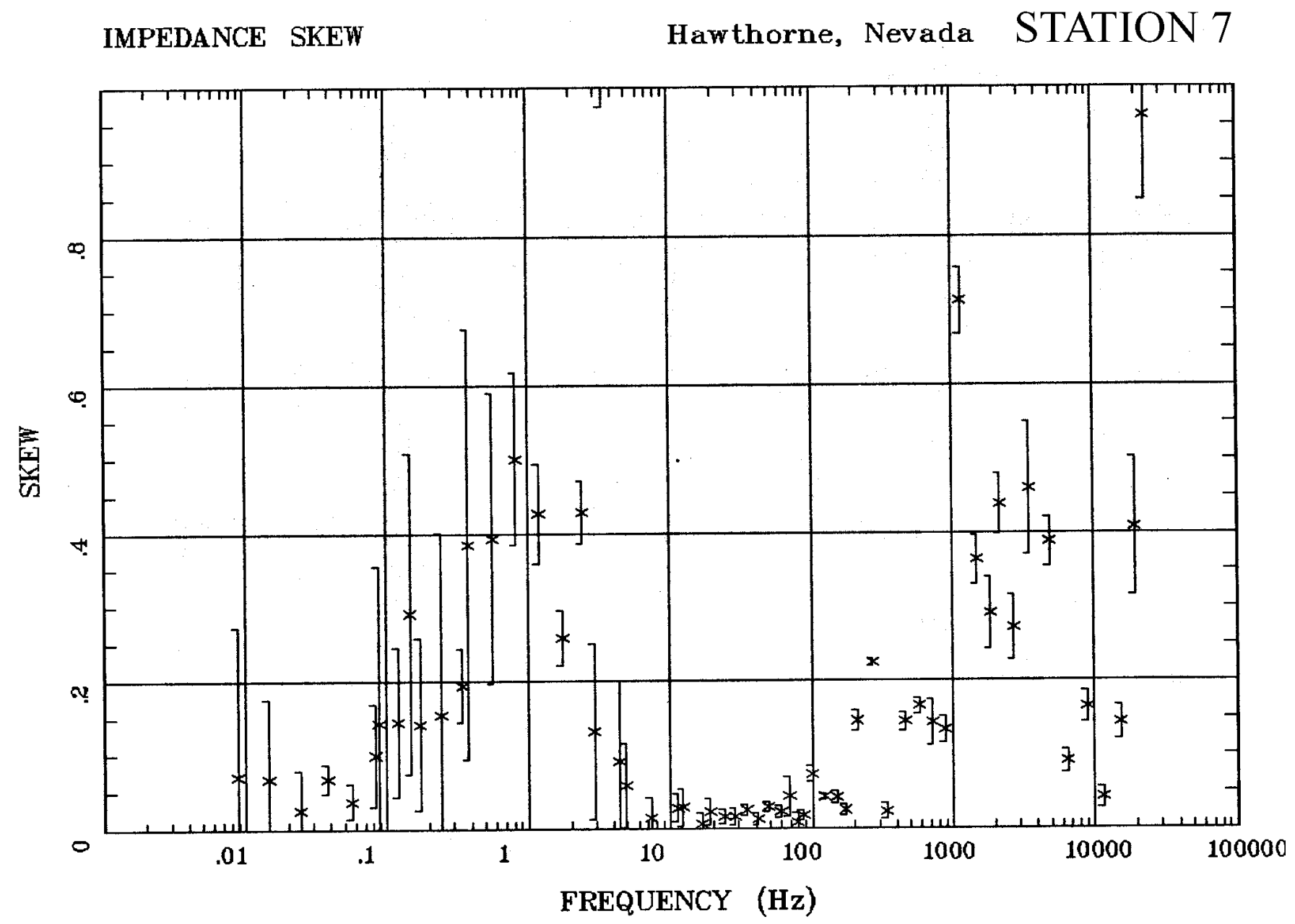

Client:

Remote: none

Acquired: 13:2 oct 09, 2001

Survey Co:USGS

Rotation:

Filename: ab7.avg

Channels: Ch1 Ch2 Ch3 Ch4 Ch5 Ch3 Ch4

Plotted: 14:14 Nov 16, 2001

< EMI - ElectroMagnetic Instruments > 


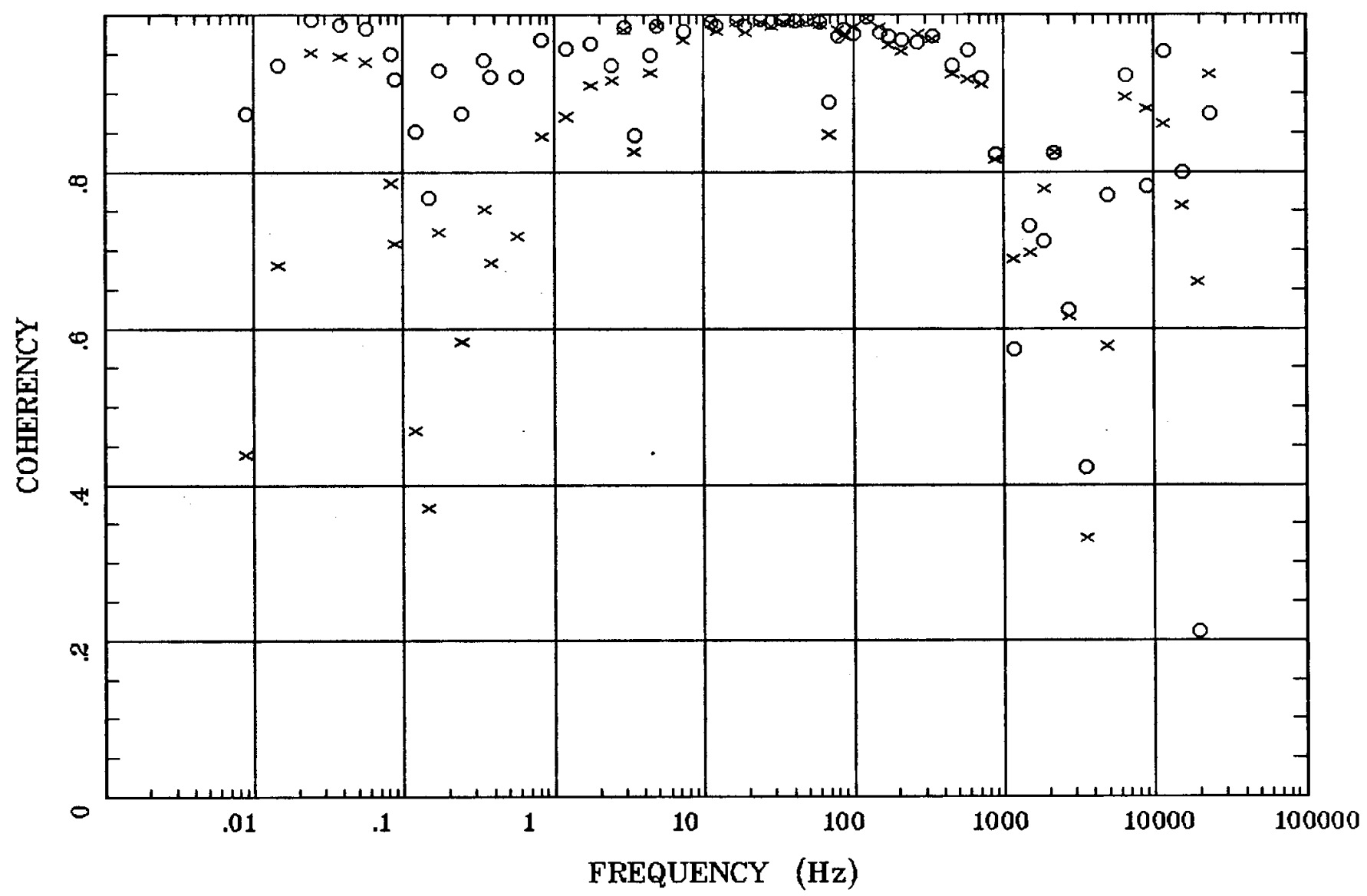

Client:

Remote: none

Acquired: 13:2 oct 09, 2001

Survey Co:USGS

Rotation:

Filename: ab7.avg

Channels: Ch1 Ch2 Ch3 Ch4 Ch5 Ch3 Ch4

Plotted: 14:14 Nov 16, 2001

< EMI - ElectroMagnetic Instruments > 
Haw thorne, Nevada STATION 7

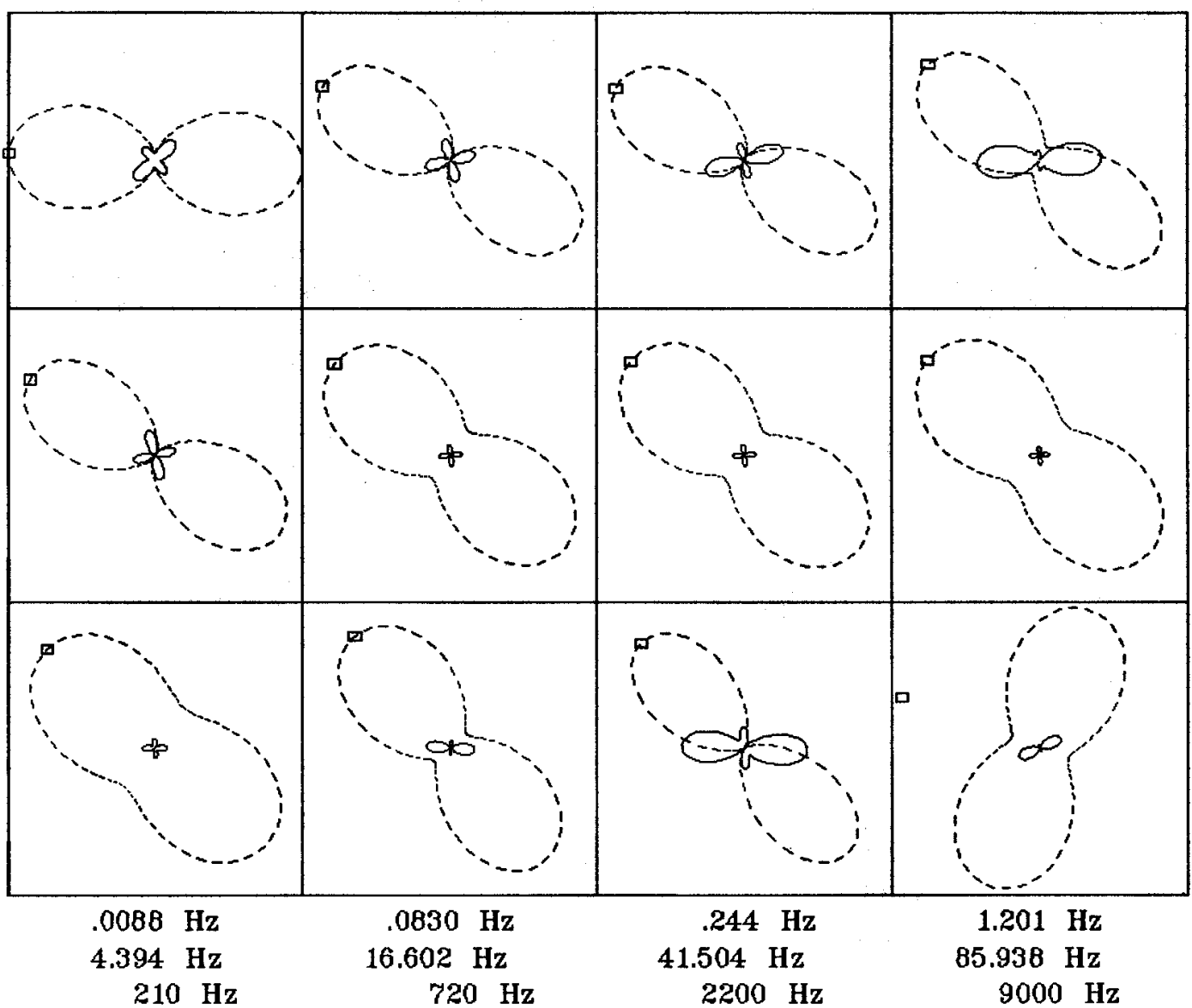

Client:

Rotation

Remote: none

Filename: $a b 7 . a v g$

Channels: Ch1 Ch2 Ch3 Ch4 Ch5 Ch3 Ch4

Acquired: 13:2 oct 09, 2001

Survey Ca:USGS

Plotted: 14:14 Nov 16, 2001

< EMI - ElectroMagnetic Instruments 
TIPPER MAGNITUDE

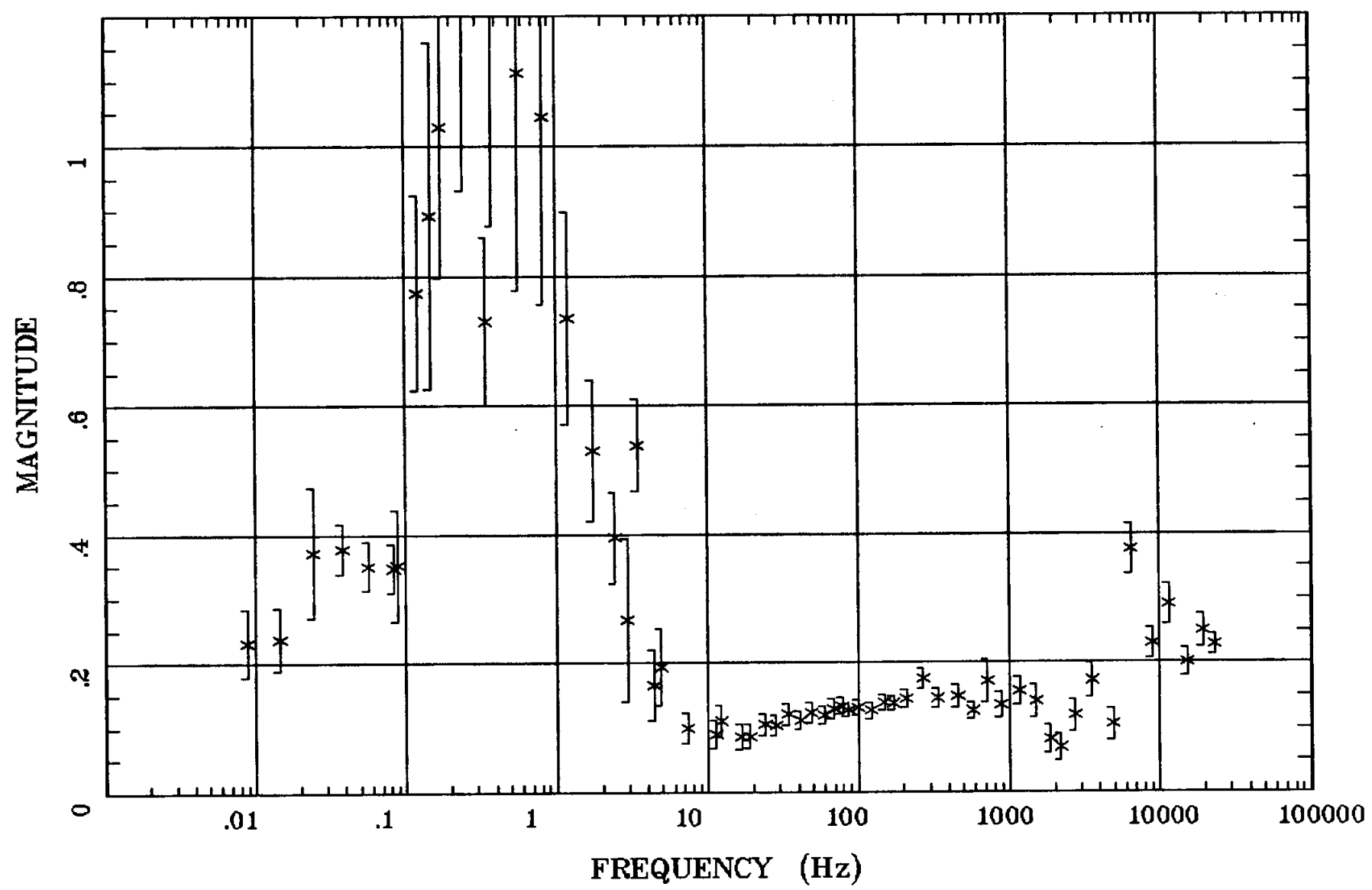

Client:

Remote: none

Acquired: 13:2 oct 09,2001

Survey Co:USGS
Haw thorne, Nevada

Filename: ab7.avg

Channels: Ch1 Ch2 Ch3 Ch4 Ch5 Ch3 Ch4

Plotted: 14:14 Nov 16, 2001

< EMI - ElectroMagnetic Instruments > 


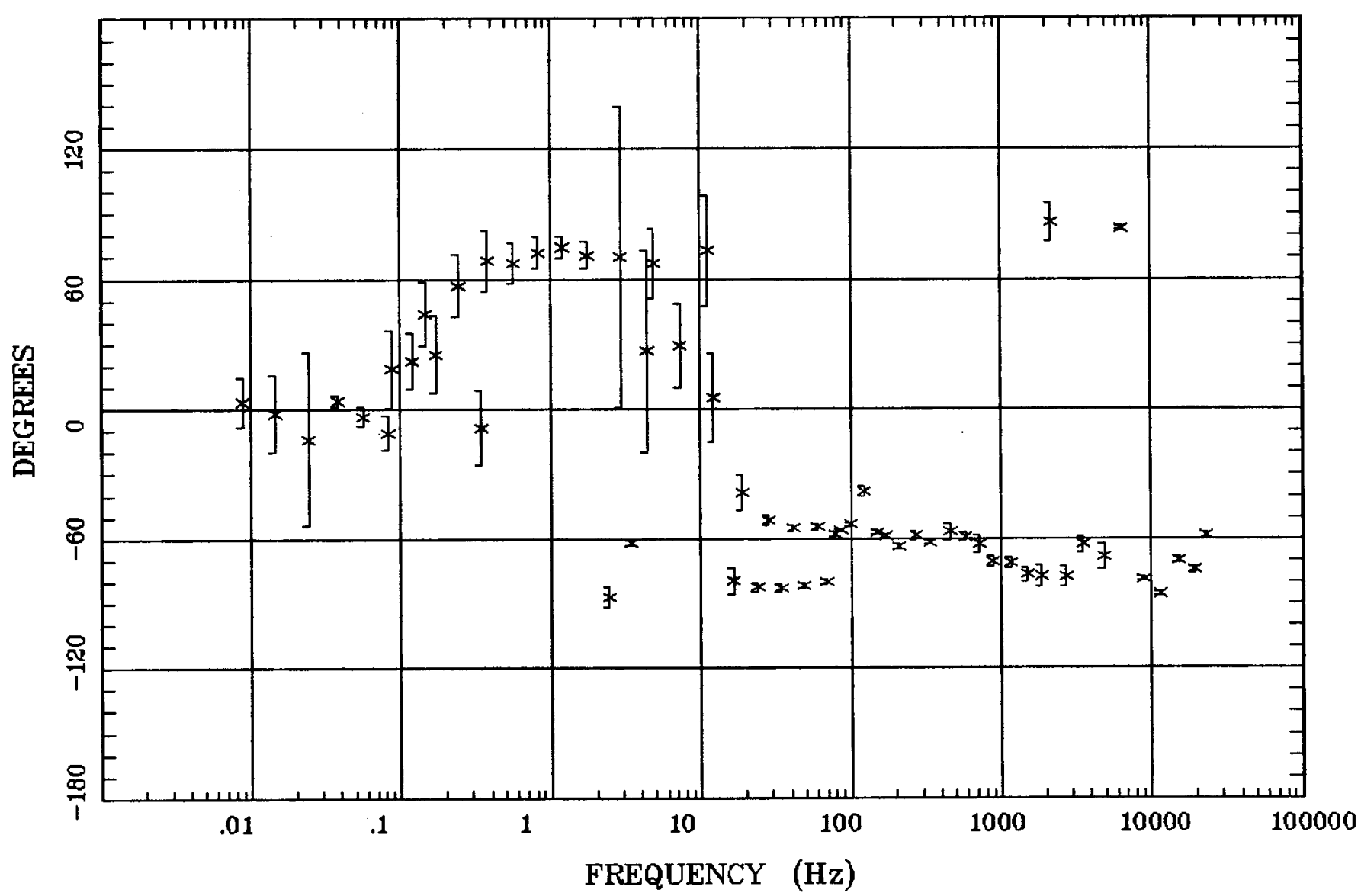

Client:

Remote: none

Acquired: 13:2 Oct 09,2001

Survey Ca:USGS
Rotation:

Filename: ab7.avg

Channels: Ch1 Ch2 Ch3 Ch4 Ch5 Ch3 Ch4

Plotted: 14:14 Nov 16, 2001

< EMI - ElectroMagnetic Instruments > 


\section{HzHx.x Coh HzHy.o}

Hawthorne, Nevada STATION 7

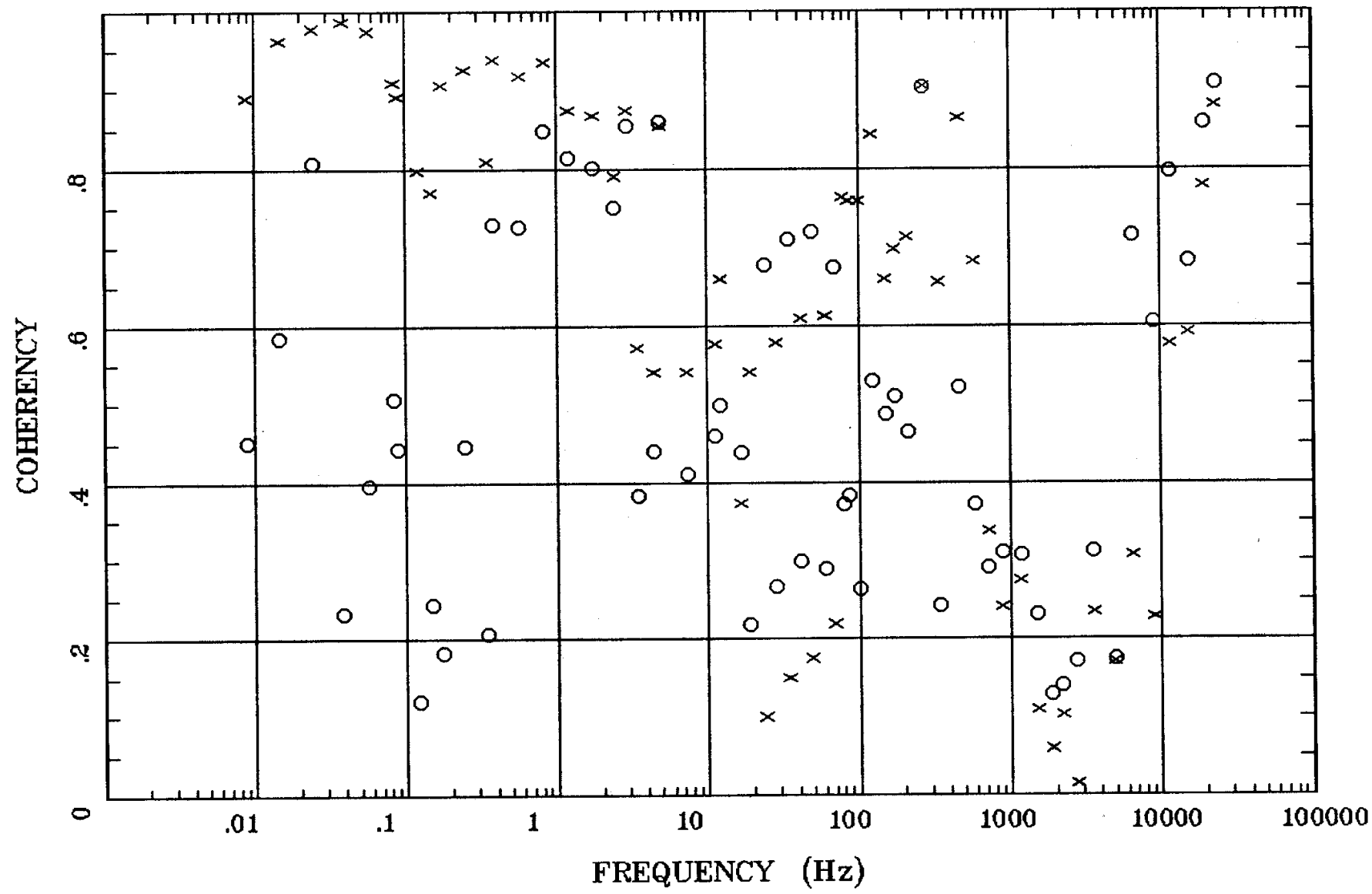

Client:

Remote: none

Acquired: 13:2 oct 09, 2001

Survey Co:USGS
Rotation:

Filename: ab7.avg

Channels: Ch1 Ch2 Ch3 Ch4 Ch5 Ch3 Ch4 Plotted: 14:14 Nov 16, 2001

< EMI - ElectroMagnetic Instruments > 


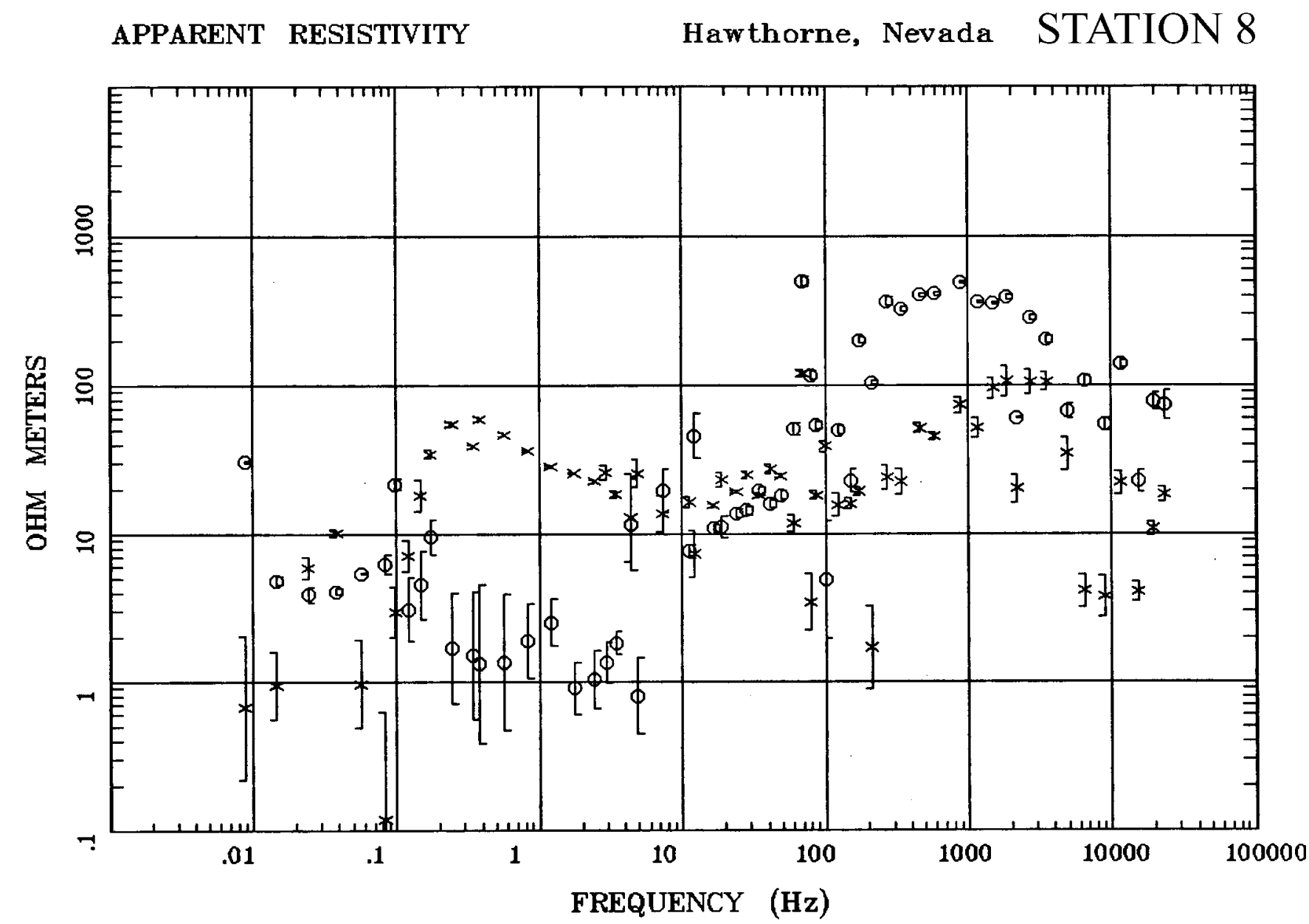

\section{Client:}

Remote: none

Acquired: 12:4 oct 10, 2001 Survey Co:USGS
Rotation:

Filename: ab8.avg

Channels: Ch1 Ch2 Ch3 Ch4 Ch5 Ch3 Ch4 Plotted: 14:15 Nov 16, 2001

< EMI - ElectroMagnetic Instruments > 
Hawthorne, Nevada STATION 8

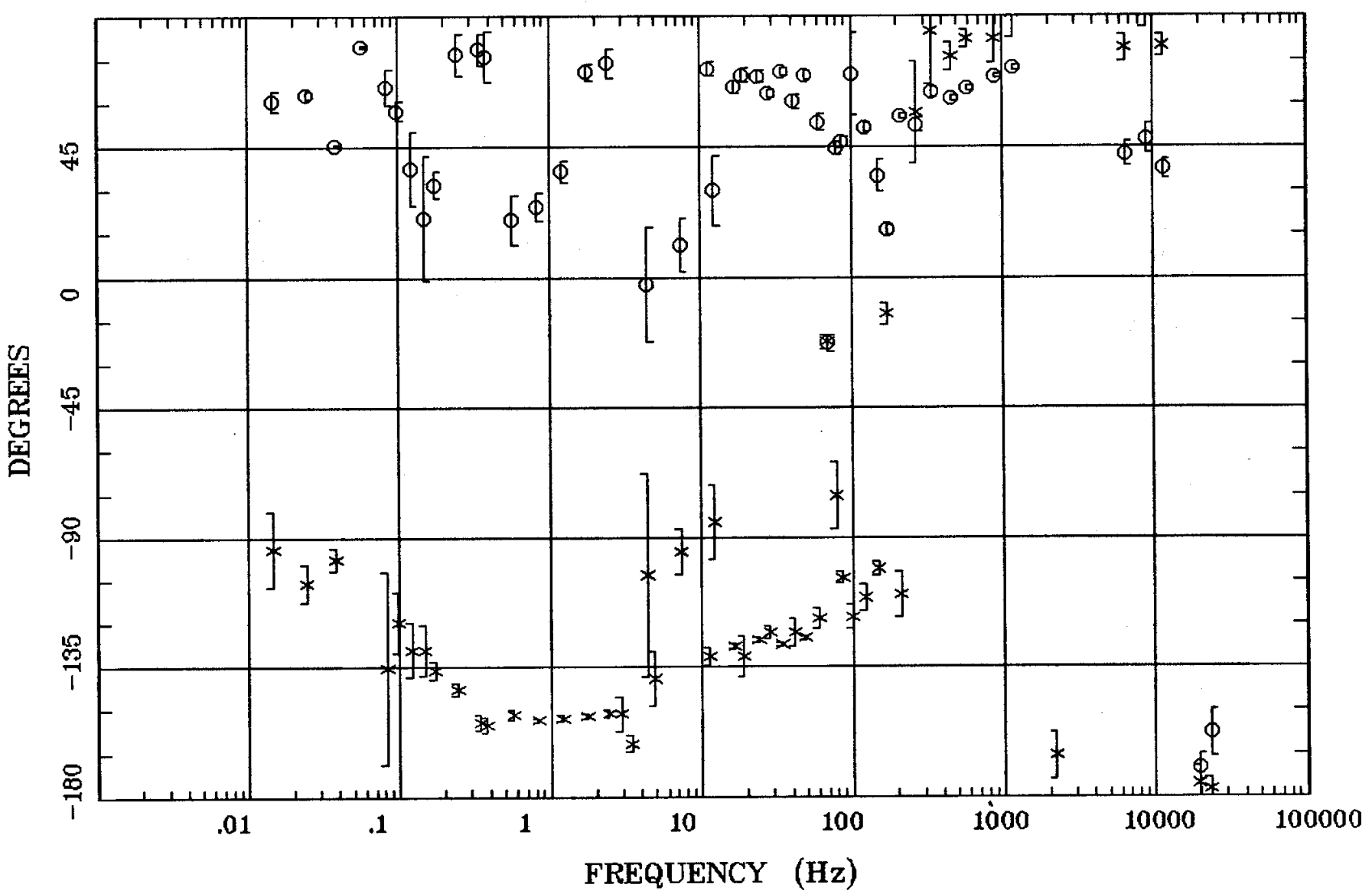

Client:

Remote: none

Acquired: 12:4 Oct 10, 2001 Survey Co:USGS
Rotation:

Filename: ab8.avg

Channels: Ch1 Ch2 Ch3 Ch4 Ch5 Ch3 Ch4 Plotted: 14:15 Nov 16, 2001

$<$ EMI - ElectroMagnetic Instruments 


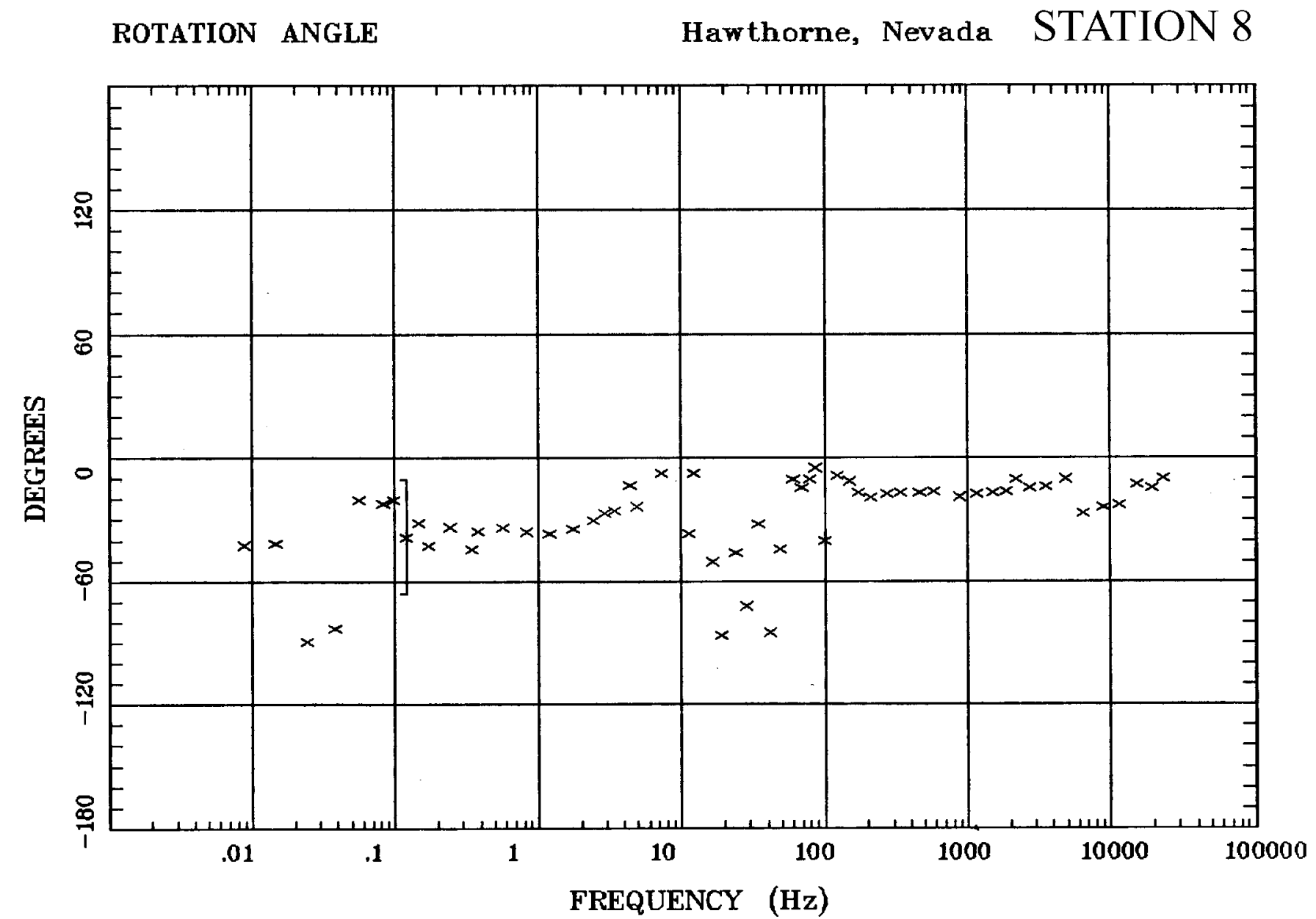

Client:

Remote: none

Acquired: 12:4 oct 10, 2001 Survey Co:USGS
Rotation:

Filename: ab8.avg

Channels: Ch1 Ch2 Ch3 Ch4 Ch5 Ch3 Ch4

Plotted: 14:15 Nov 16, 2001

< EMI - ElectroMagnetic Instruments 


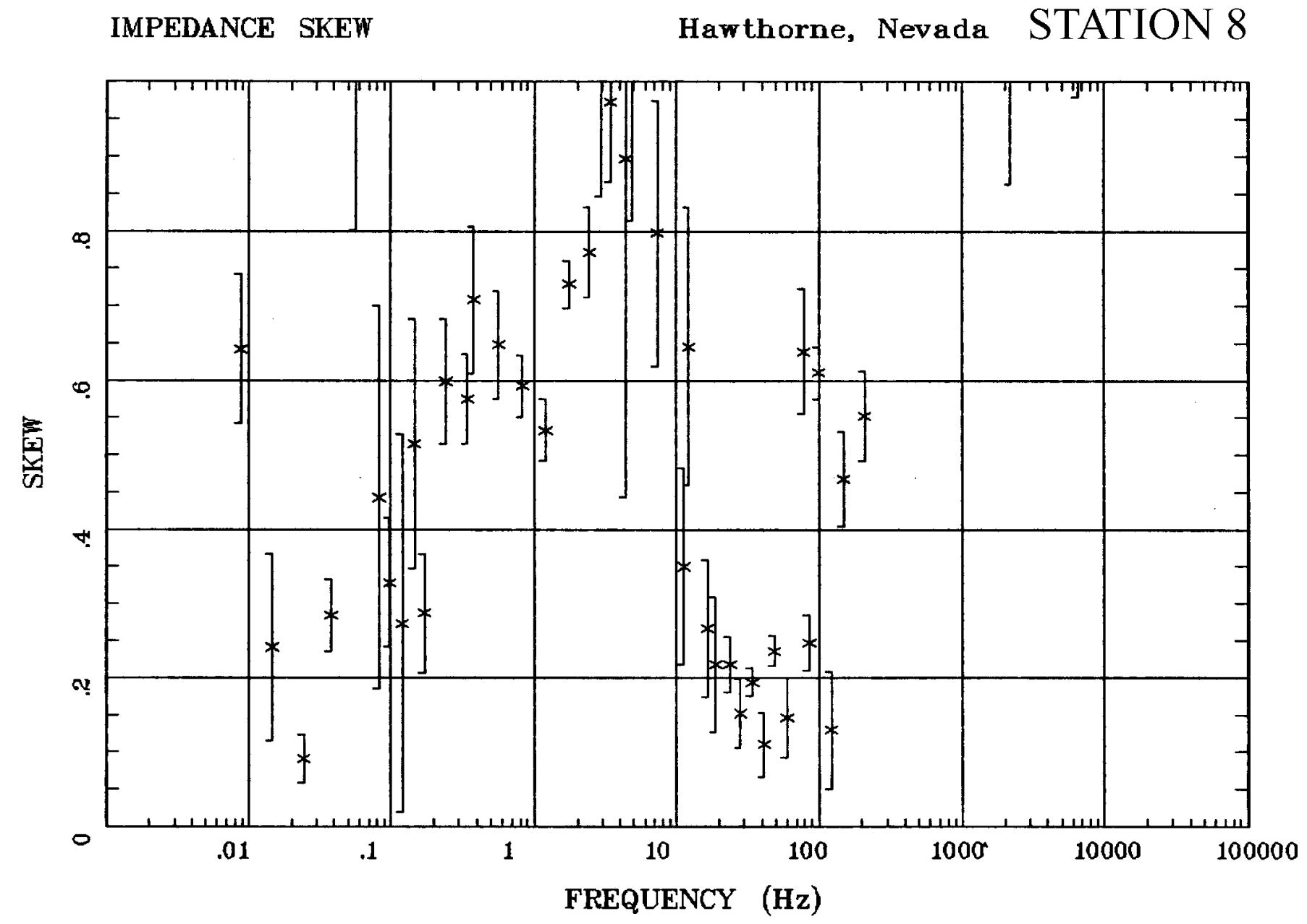

Client:

Remote: none

Acquired: 12:4 oct 10, 2001

Survey Co:USGS
Rotation:

Filename: ab8.avg

Channels: Ch1 Ch2 Ch3 Ch4 Ch5 Ch3 Ch4 Plotted: 14:15 Nov 16, 2001

< EMI - ElectroMagnetic Instruments > 
E MULT Coh.

Hawthorne, Nevada STATION 8

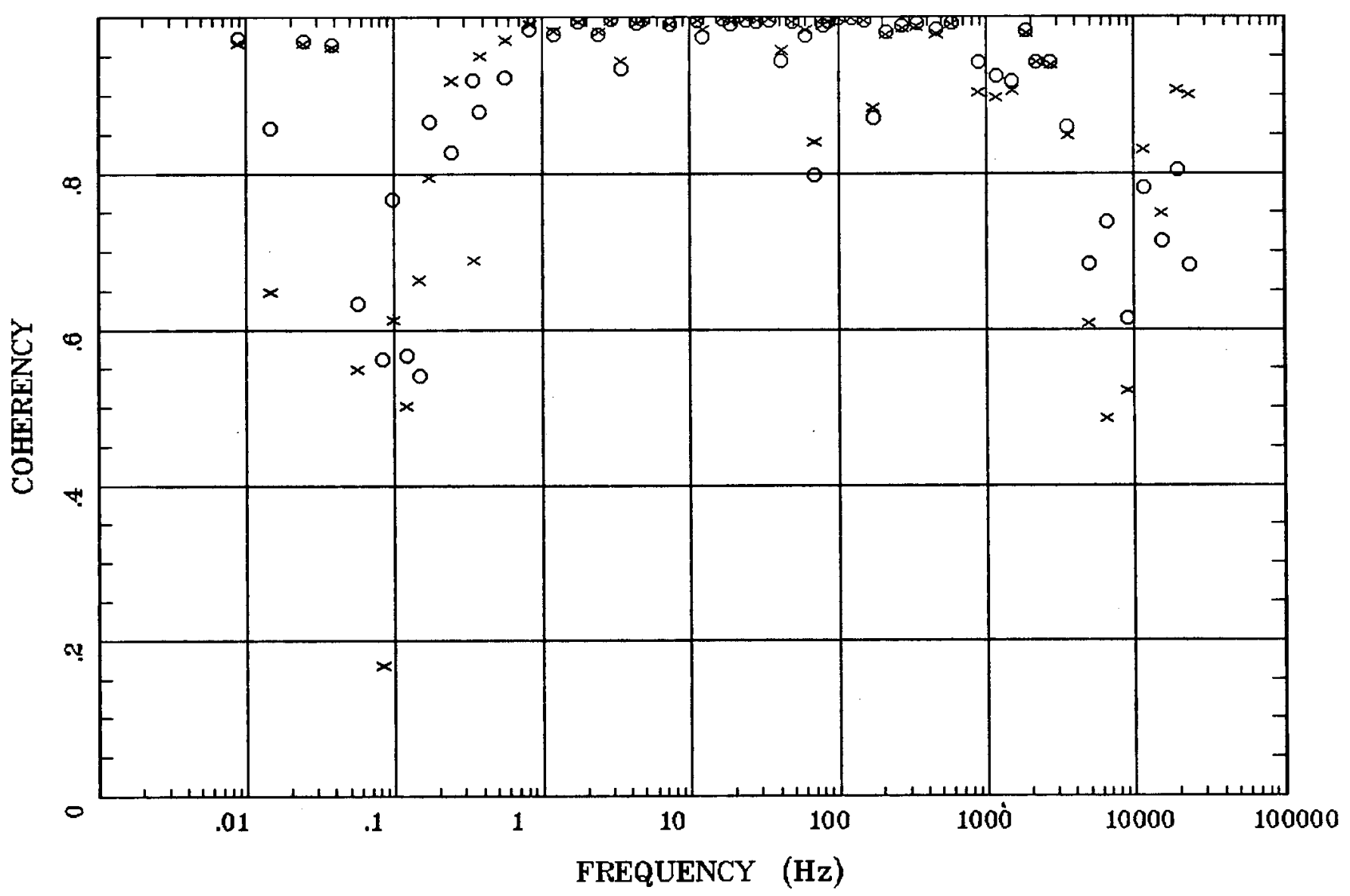

Client:

Remote: none

Acquired: 12:4 oct 10, 2001

Survey Co:USGS
Rotation:

Filename: ab8.avg

Channels: Ch1 Ch2 Ch3 Ch4 Ch5 Ch3 Ch4 Plotted: 14:15 Nov 16, 2001

< EMI - ElectroMagnetic Instruments > 


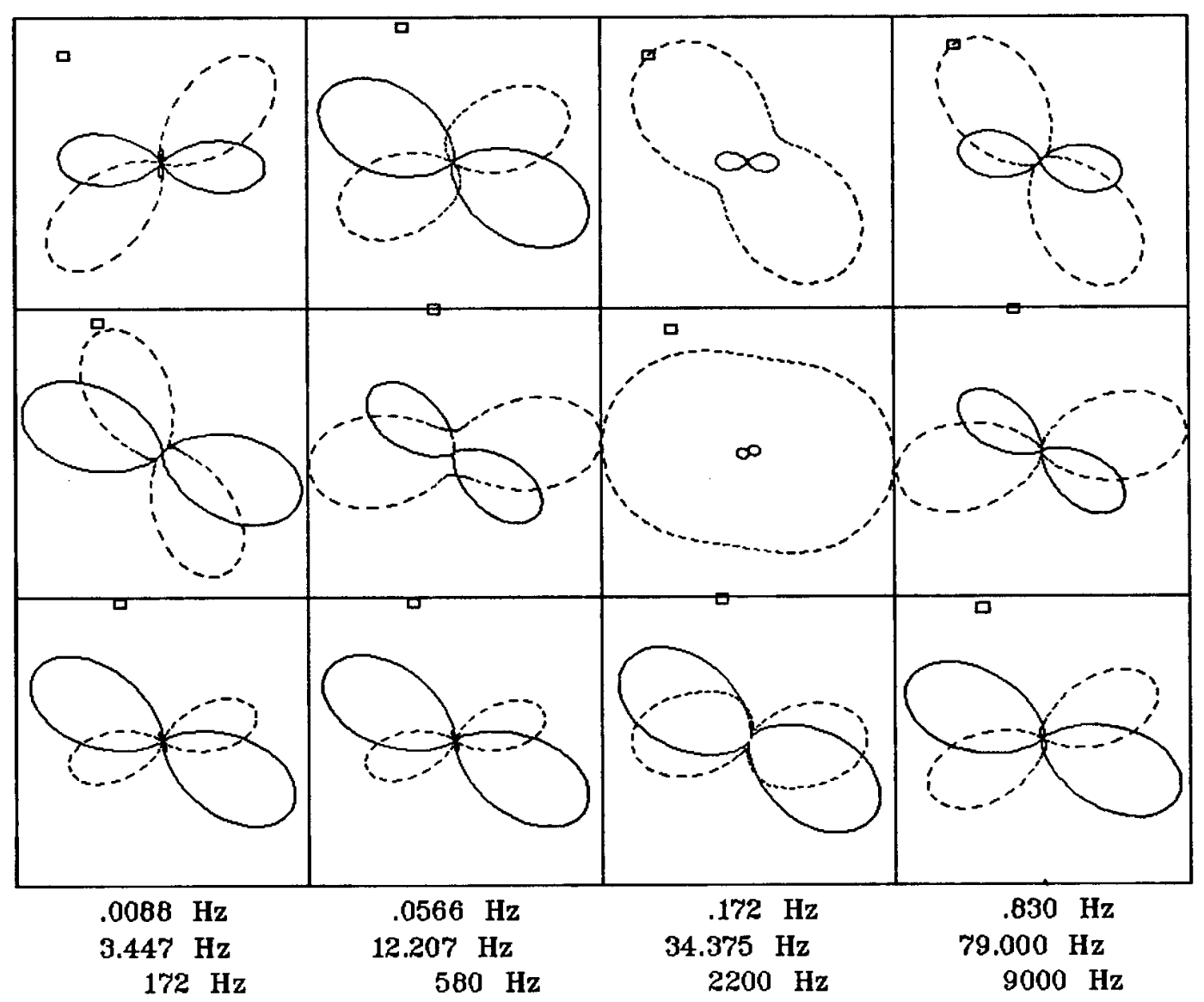

\section{Client:}

Rotation:

Remote: none

Acquired: 12:4 Oct 10, 2001

Filename: ab8.avg

Channels: Ch1 Ch2 Ch3 Ch4 Ch5 Ch3 Ch4

Plotted: 14:15 Nov 16, 2001

Survey Co:USGS

< EMI - ElectroMagnetic Instruments > 


\section{TIPPER MAGNITUDE}

Haw thorne, Nevada STATION 8

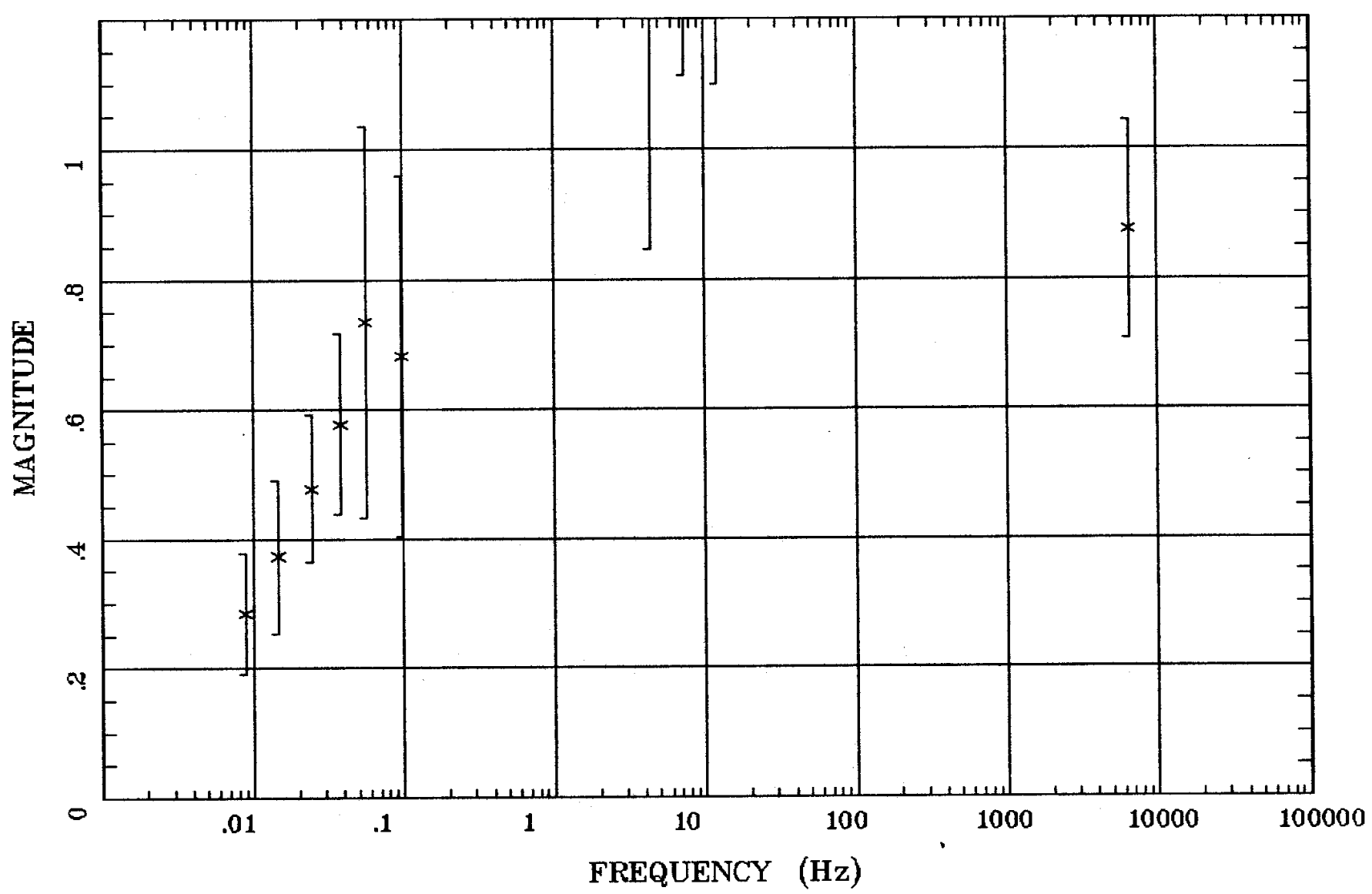

Client:

Remote: none

Acquired: 12:4 Oct 10, 2001

Survey Co:Usgs
Rotation:

Filename: ab8.avg

Channels: Ch1 Ch2 Ch3 Ch4 Ch5 Ch3 Ch4

Plotted: 14:15 Nov 16, 2001

$<$ EMI - ElectroMagnetic Instruments > 


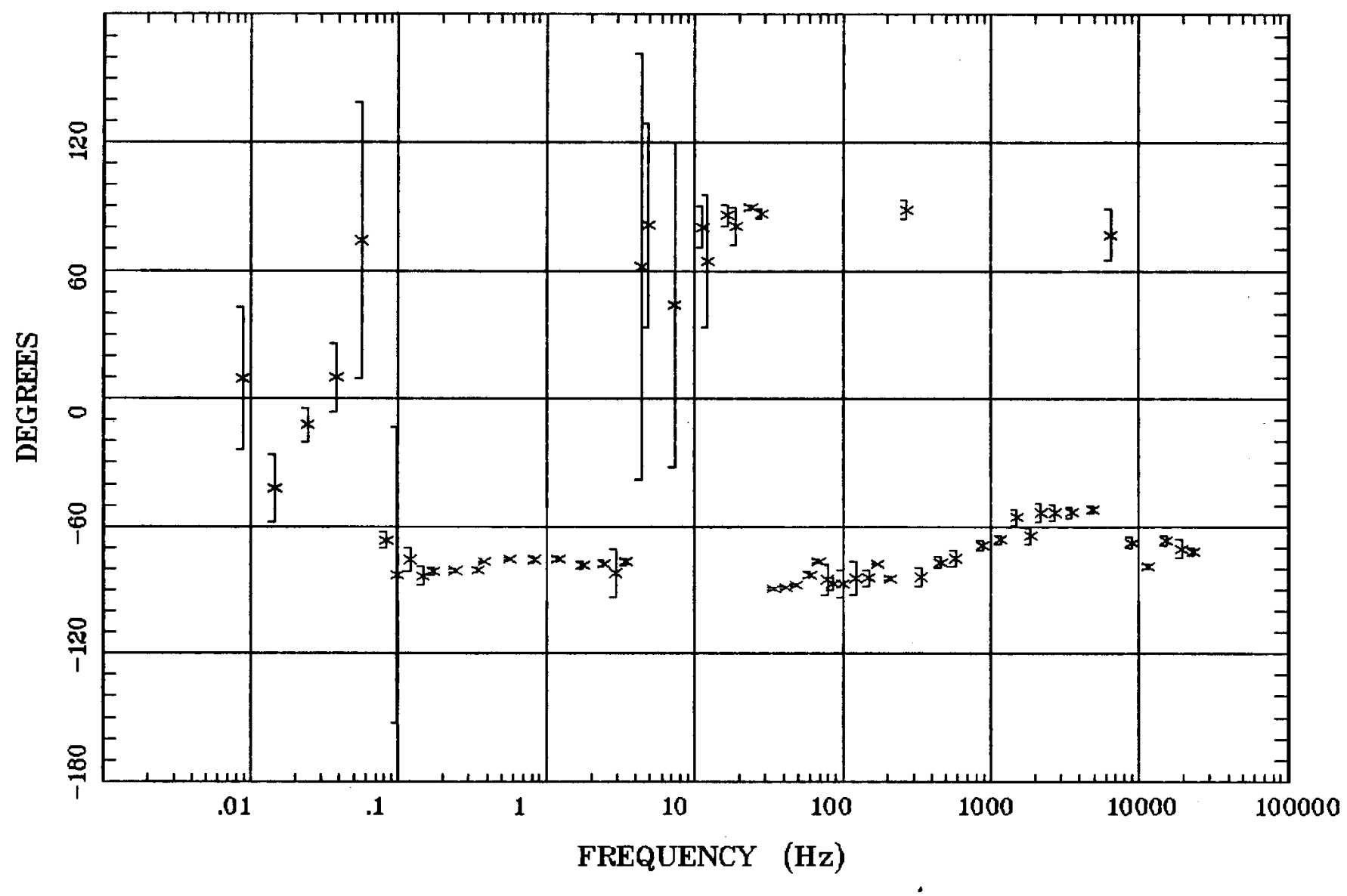

Client:

Remote: none

Acquired: 12:4 oct 10, 2001

Survey Co:USGS
Rotation:

Filename: ab8.avg

Channels: Ch1 Ch2 Ch3 Ch4 Ch5 Ch3 Ch4 Plotted: 14:15 Nov 16, 2001

< EMI - ElectroMagnetic Instruments > 
HzHx.x Coh HzHy.o

Hawthorne, Nevada STATION 8

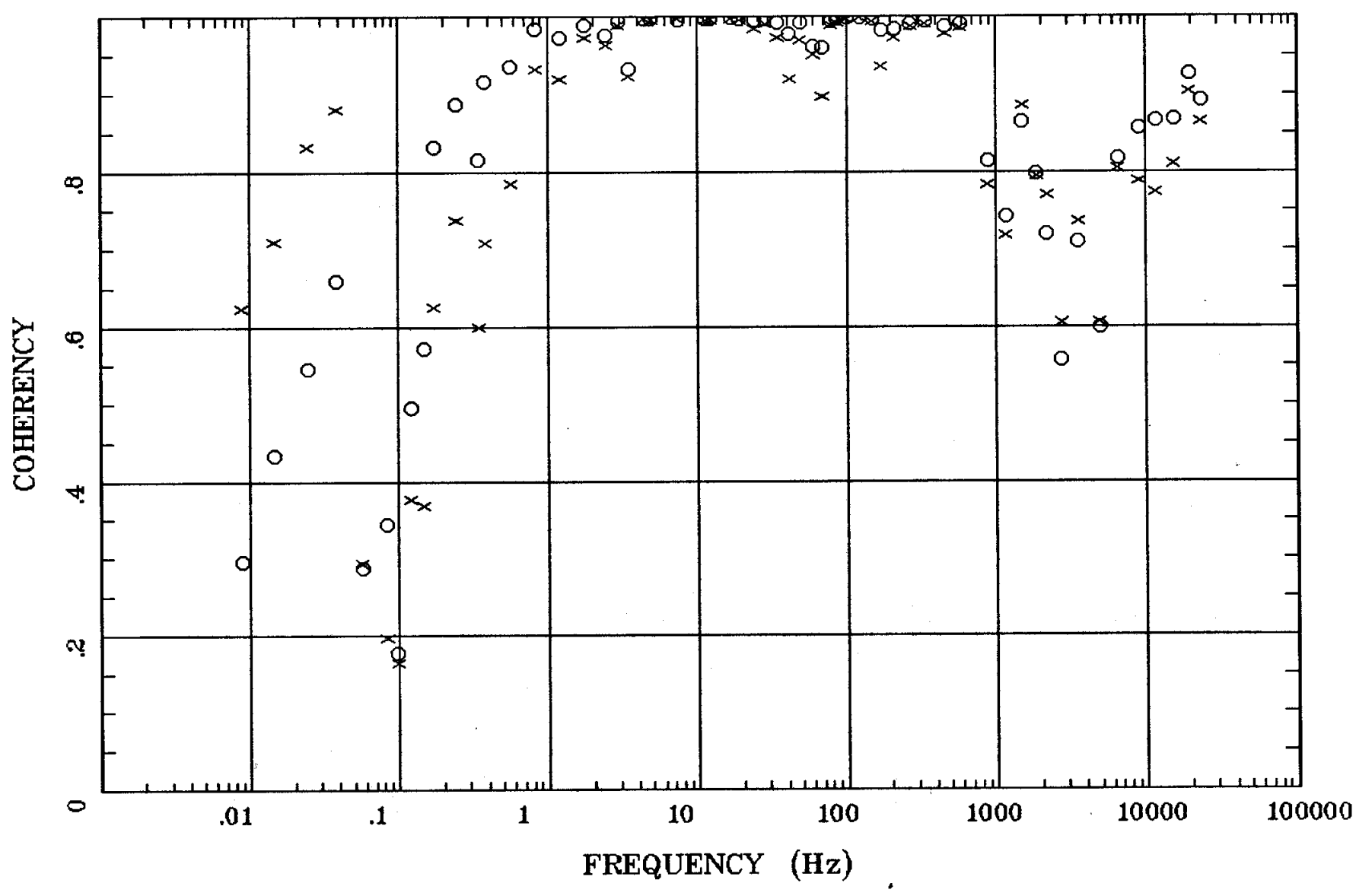

Client:

Remote: none

Acquired: $12: 4$ Oct 10, 2001

Survey Co:USGS
Rotation:

Filename: abB.avg

Channels: Ch1 Ch2 Ch3 Ch4 Ch5 Ch3 Ch4

Plotted: 14:15 Nov 16, 2001

< EMI - ElectroMagnetic Instruments > 


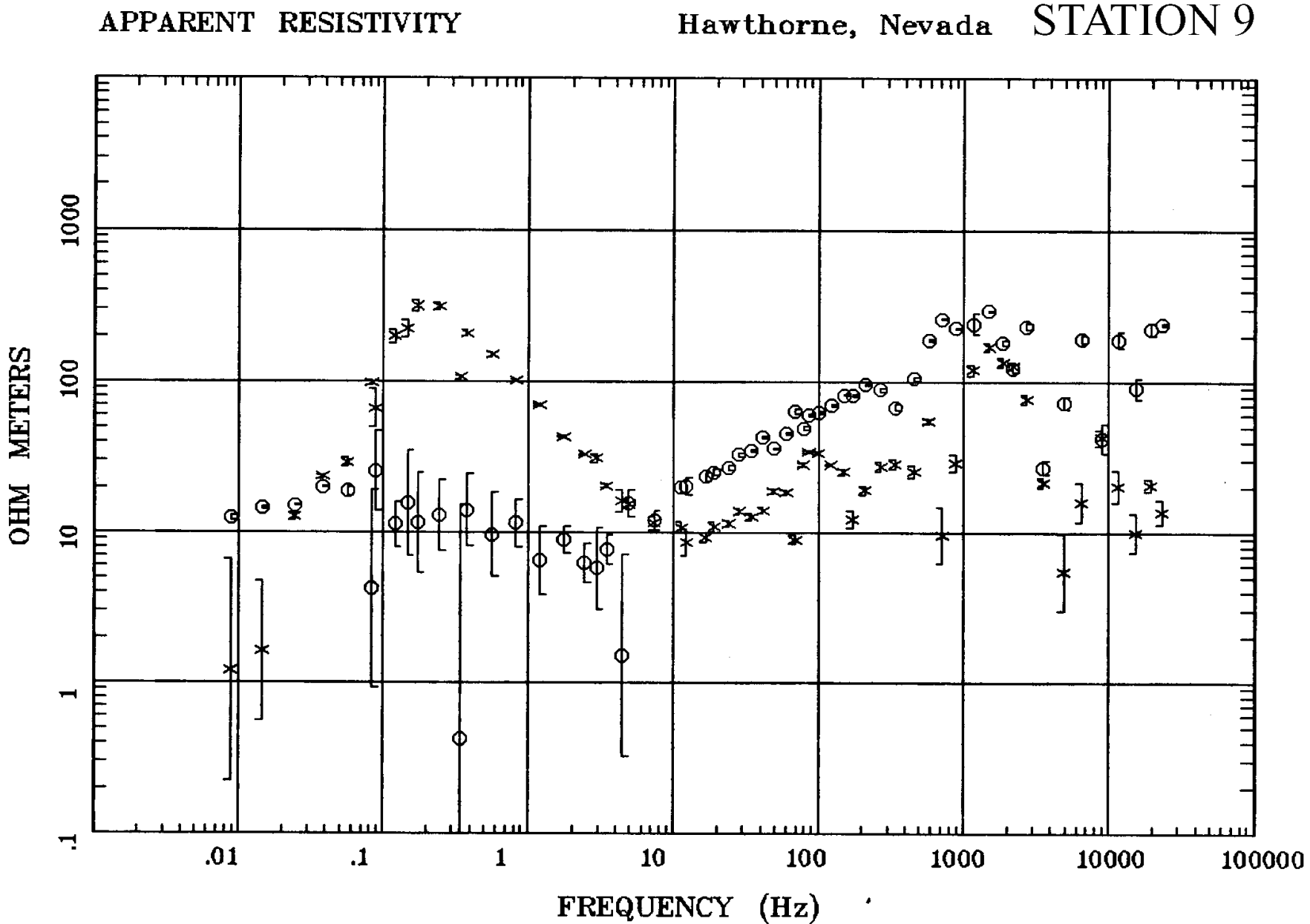

Client:

Remote: none

Acquired: 14:4 oct 10, 2001 Survey Co:USGS
Rotation:

Filename: ab9.avg

Channels: Ch1 Ch2 Ch3 Ch4 Ch5 Ch3 Ch4

Plotted: 14:16 Nov 16, 2001

< EMI - ElectroMagnetic Instruments > 


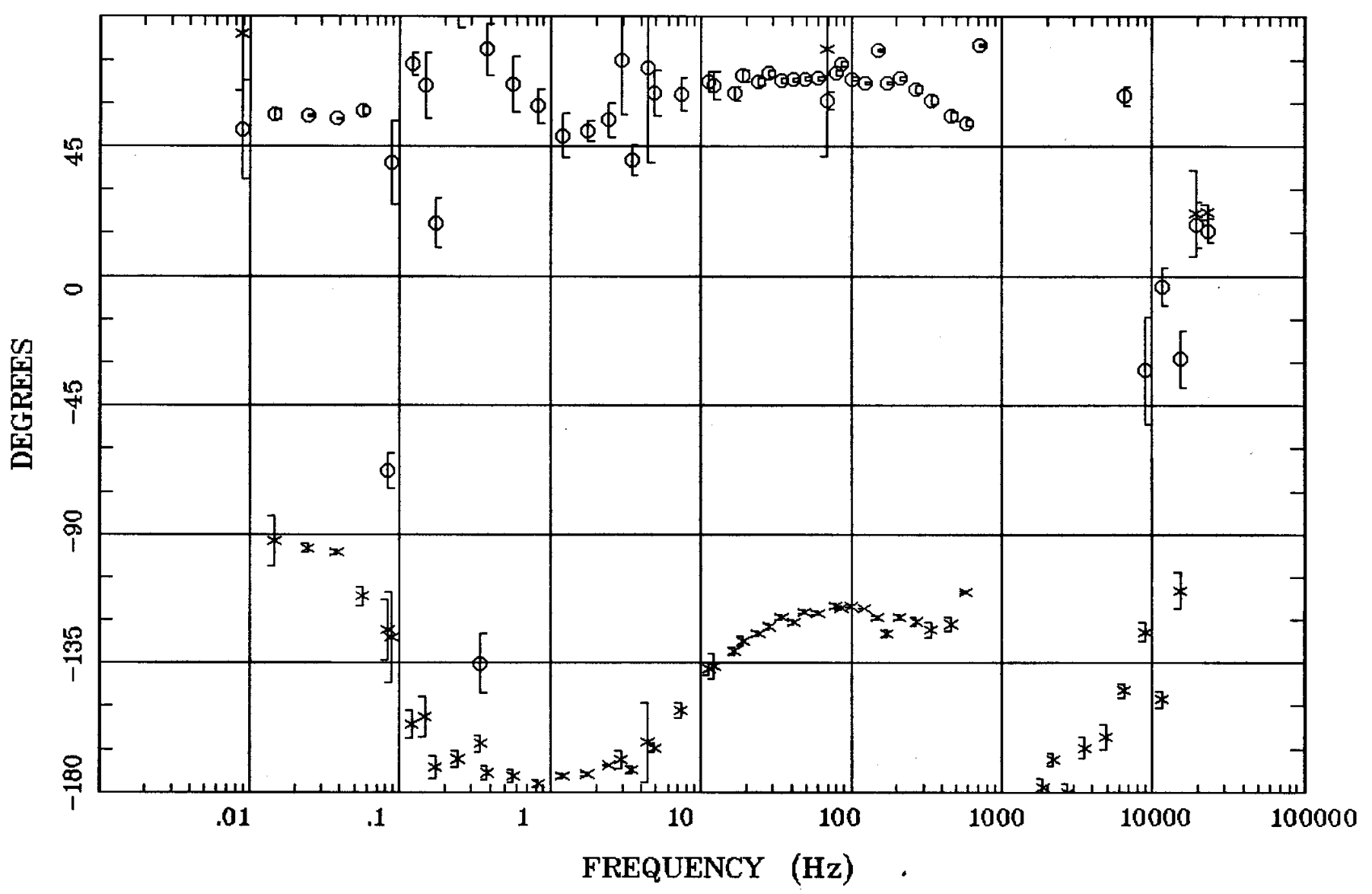

Client:

Remote: none

Acquired: 14:4 Oct 10, 2001 Survey Co:USGS
Rotation:

Filename: ab9.avg

Channels: Ch1 Ch2 Ch3 Ch4 Ch5 Ch3 Ch4

Plotted: 14:16 Nov 16, 2001

< EMI - ElectroMagnetic Instruments > 


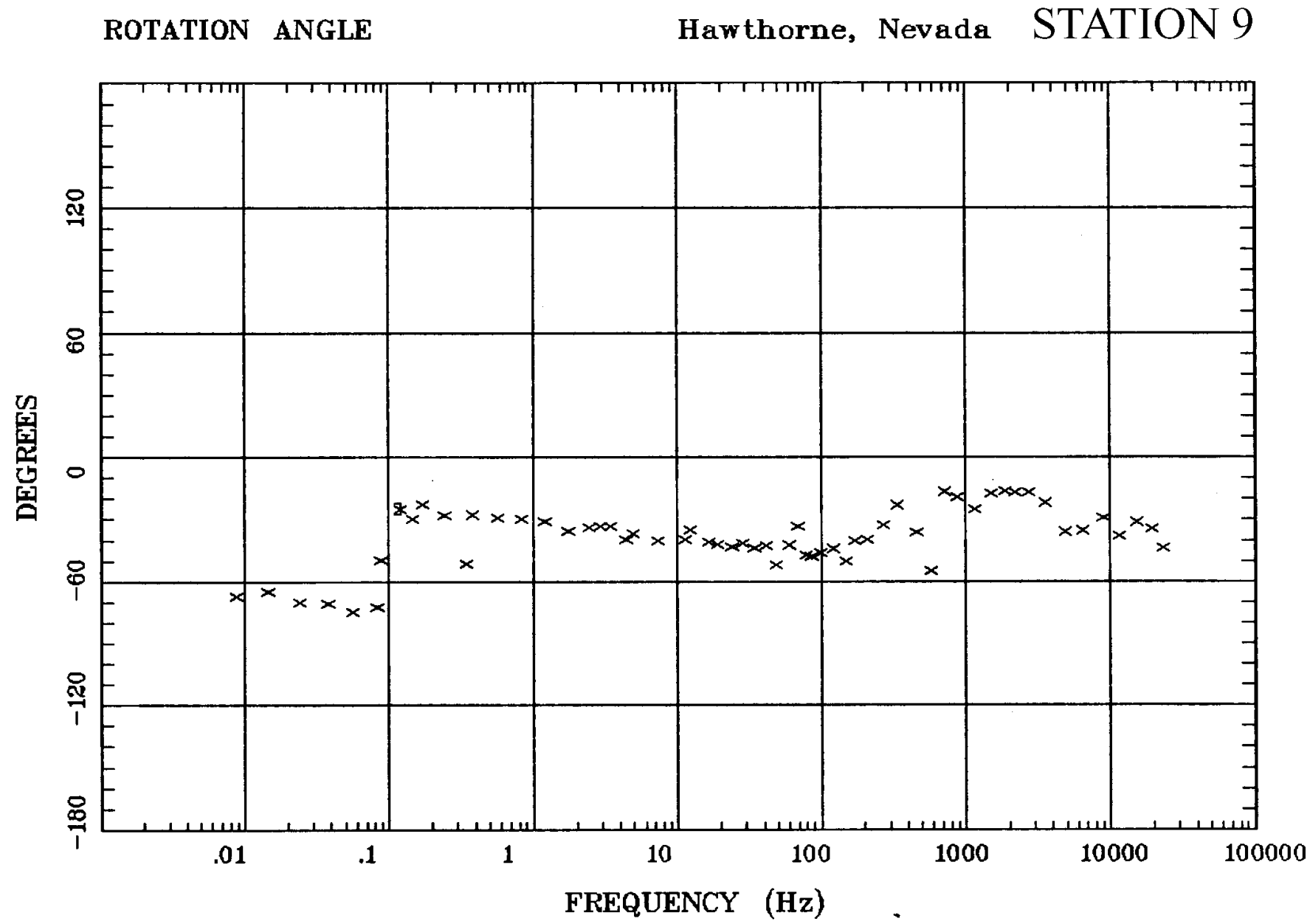

Client:

Remote: none

Acquired: 14:4 oct 10, 2001 Survey Co:USGS
Rotation:

Filename: ab9.avg

Channels: Ch1 Ch2 Ch3 Ch4 Ch5 Ch3 Ch4

Plotted: 14:16 Nov 16, 2001

< EMI - ElectroMagnetic Instruments > 


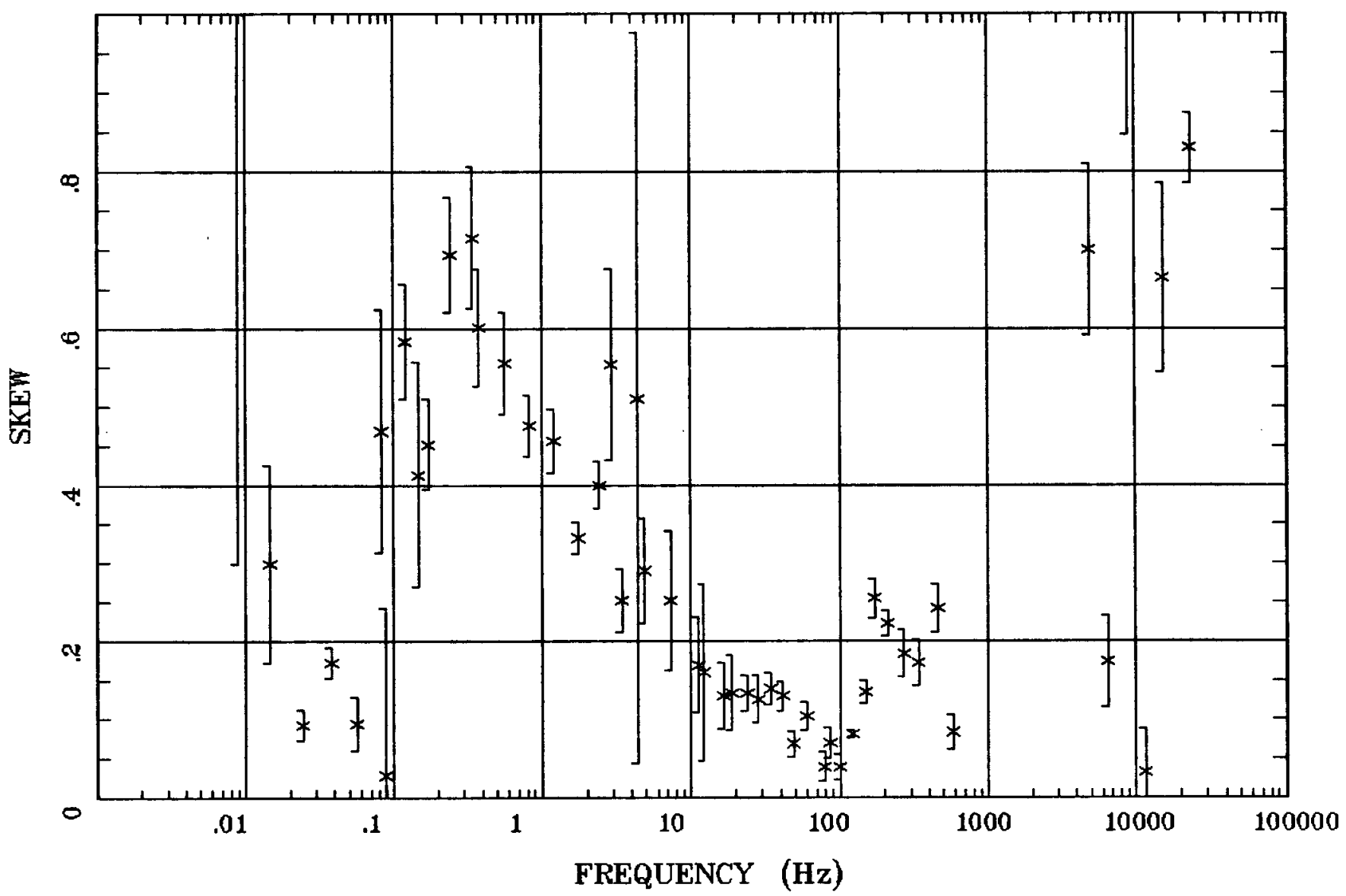

Client:

Remote: none

Acquired: 14:4 Oct 10, 2001 Survey Co:USGS
Rotation: .

Filename: ab9.avg

Channels: Ch1 Ch2 Ch3 Ch4 Ch5 Ch3 Ch4 Plotted: 14:16 Nov 16, 2001

< EMI - ElectroMagnetic Instruments > 


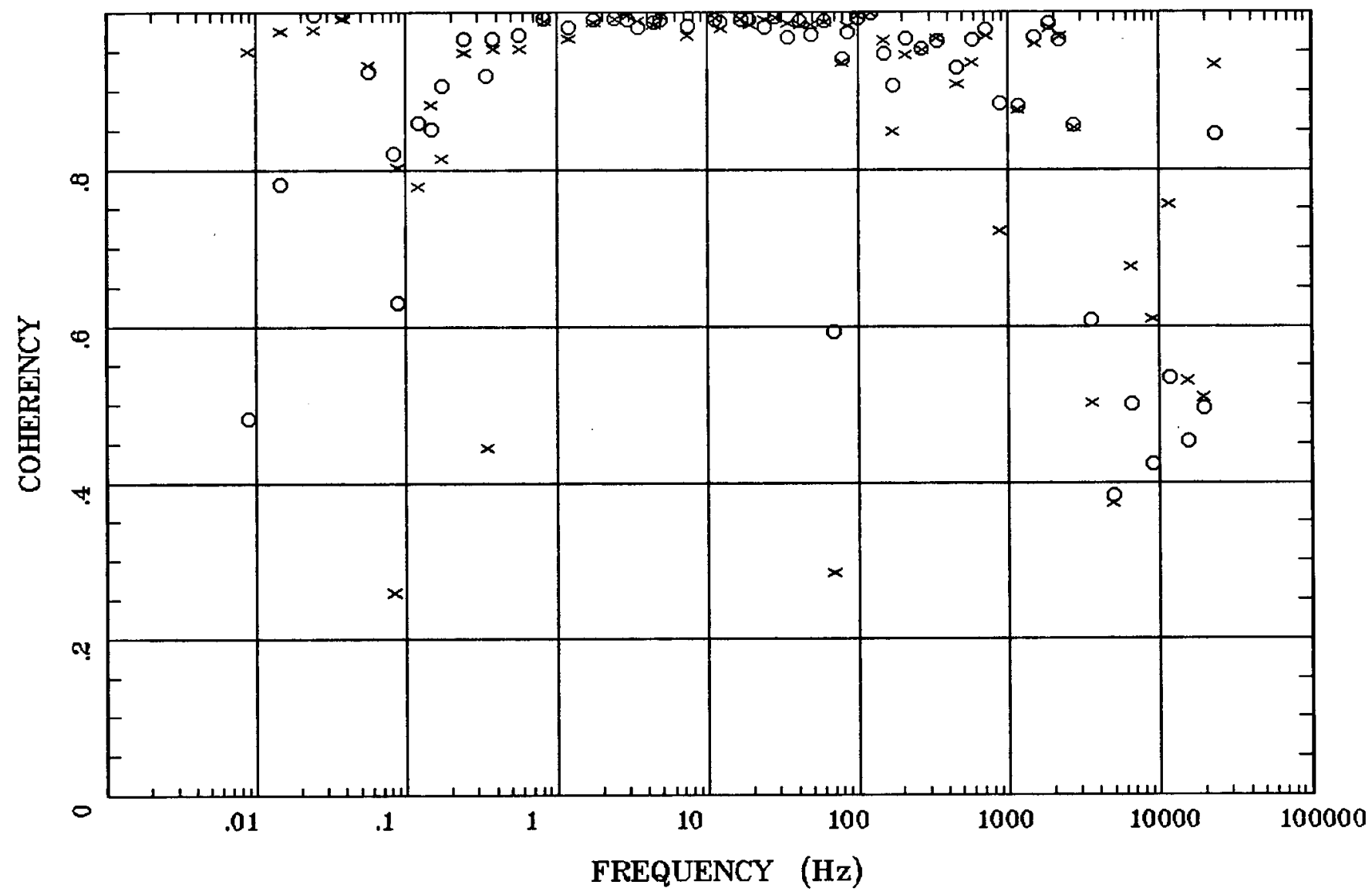

Client:

Remote: none

Acquired: 14:4 oct 10, 2001

Survey Co:USGS
Rotation:

Filename: ab9.avg

Channels: Ch1 Ch2 Ch3 Ch4 Ch5 Ch3 Ch4

Plotted: 14:16 Nov 16, 2001

< EMI - ElectroMagnetic Instruments > 


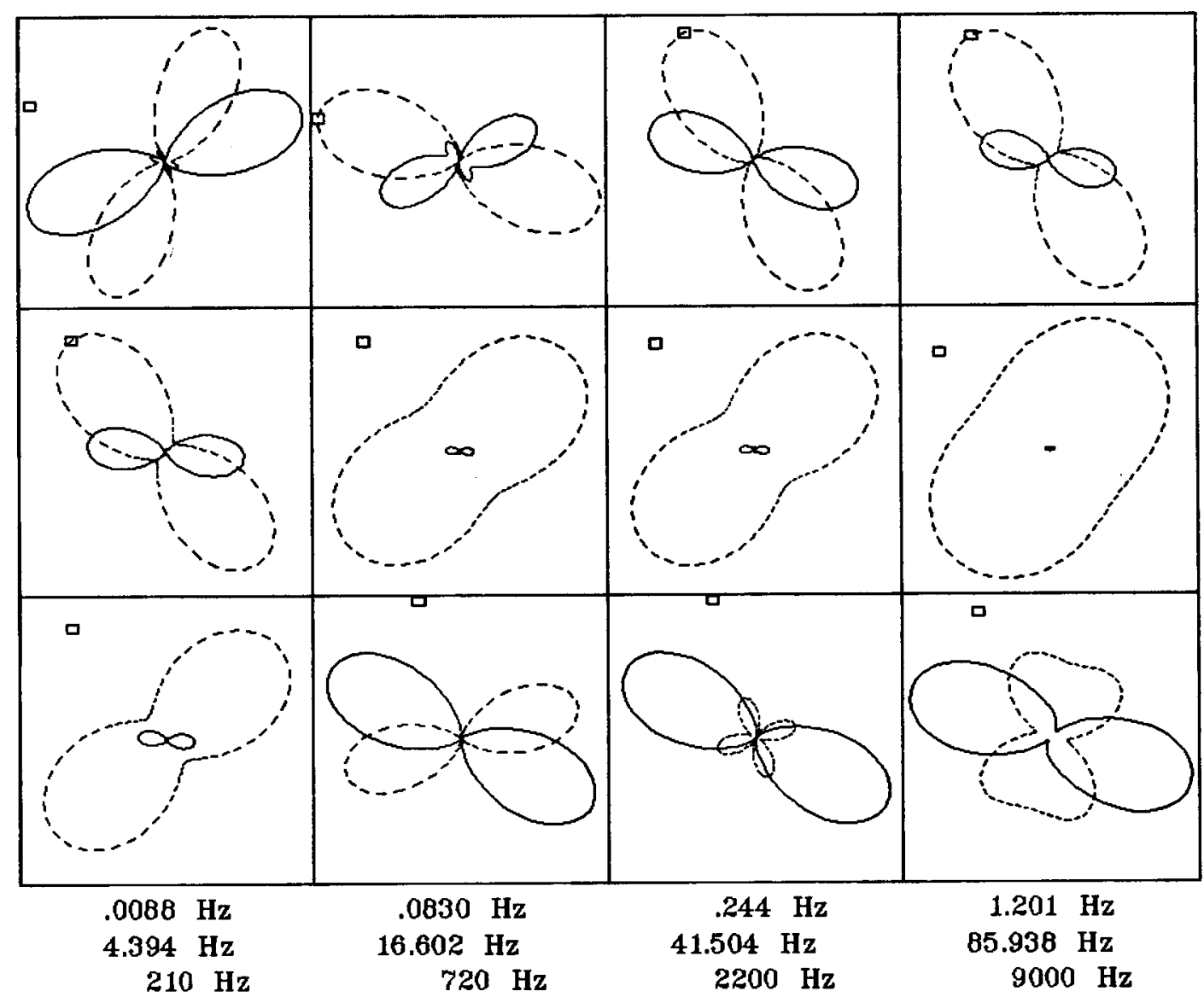

Client:

Remote: none

Acquired: 14:4 Oct 10, 2001 Survey Co:USGS
Rotation:

Filename: ab9.avg

Channels: Ch1 Ch2 Ch3 Ch4 Ch5 Ch3 Ch4

Plotted: 14:16 Nov 16, 2001

< EMI - ElectroMagnetic Instruments > 


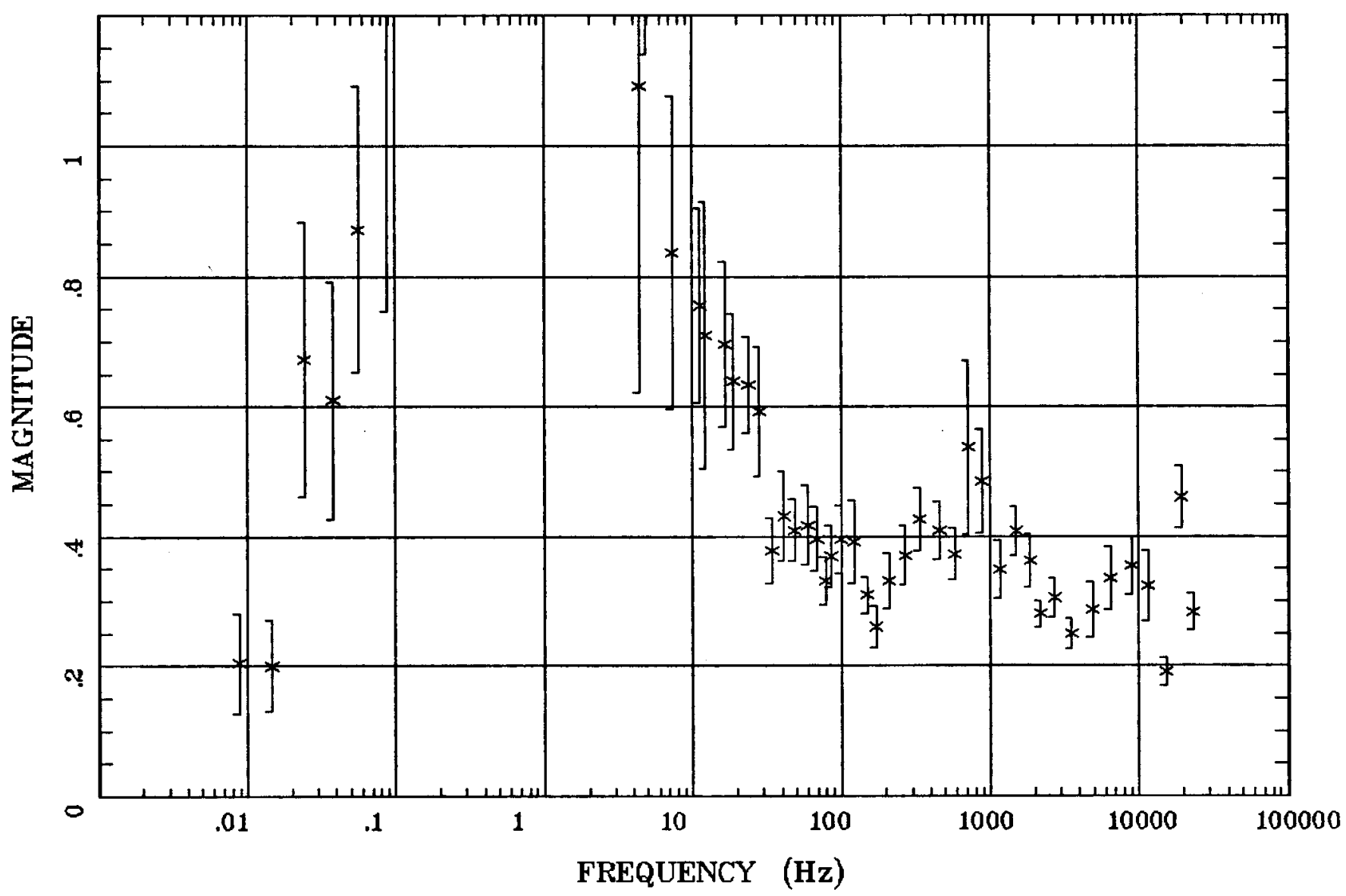

Client:

Remote: none

Acquired: 14:4 Oct 10, 2001 Survey Co:USGS
Rotation:

Filename: ab9.avg

Channels: Ch1 Ch2 Ch3 Ch4 Ch5 Ch3 Ch4

Plotted: 14:16 Nov 16, 2001

< EMI - ElectroMagnetic Instruments > 


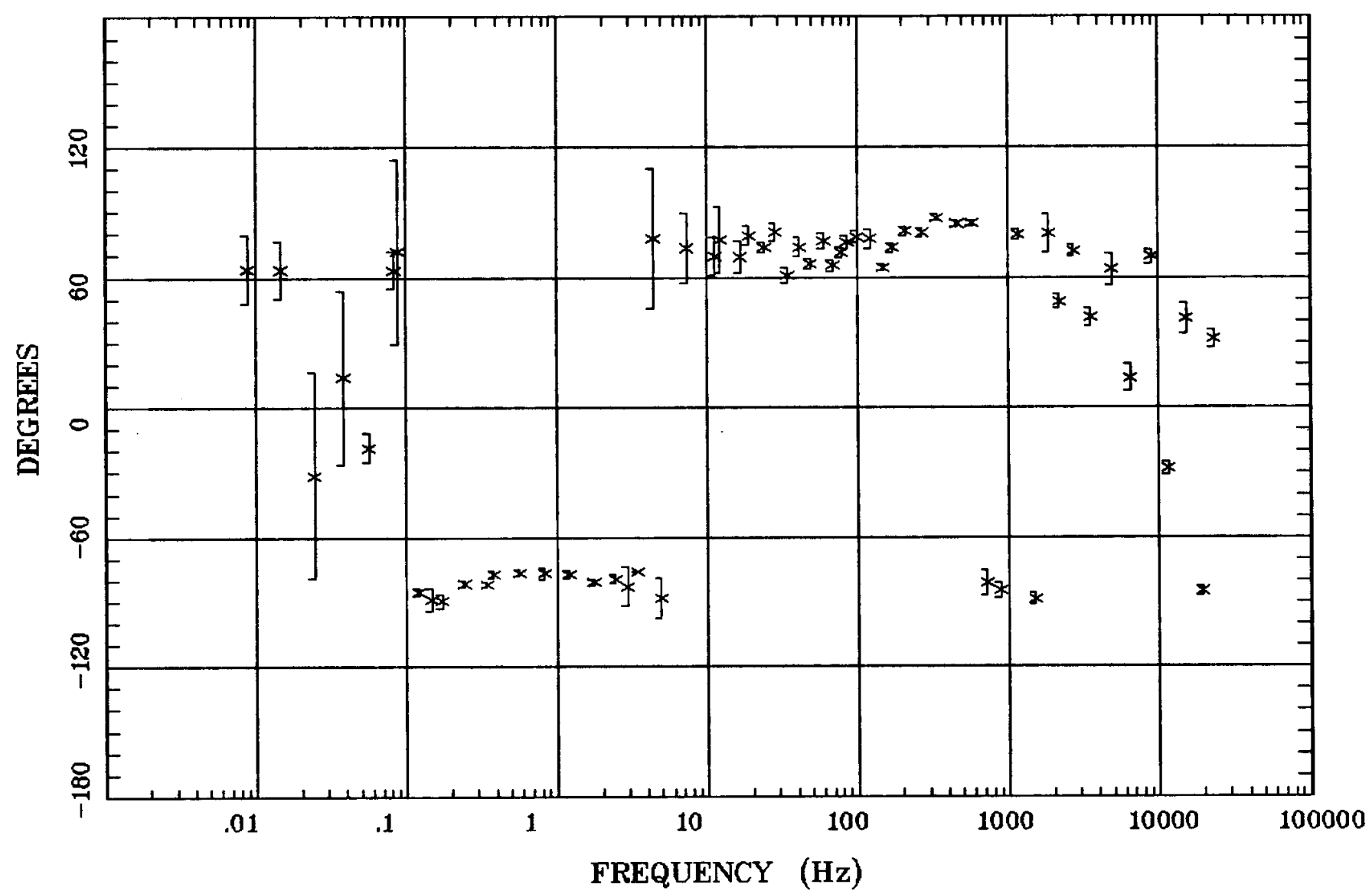

Client:

Remote: none

Acquired: 14:4 oct 10, 2001

Survey Co:USGS

Rotation:

Filename: ab9.avg

Channels: Ch1 Ch2 Ch3 Ch4 Ch5 Ch3 Ch4

Plotted: 14:16 Nov 16, 2001

< EMI - ElectroMagnetic Instruments > 
HzHx.x Coh HzHy.o

Hawthorne, Nevada STATION 9

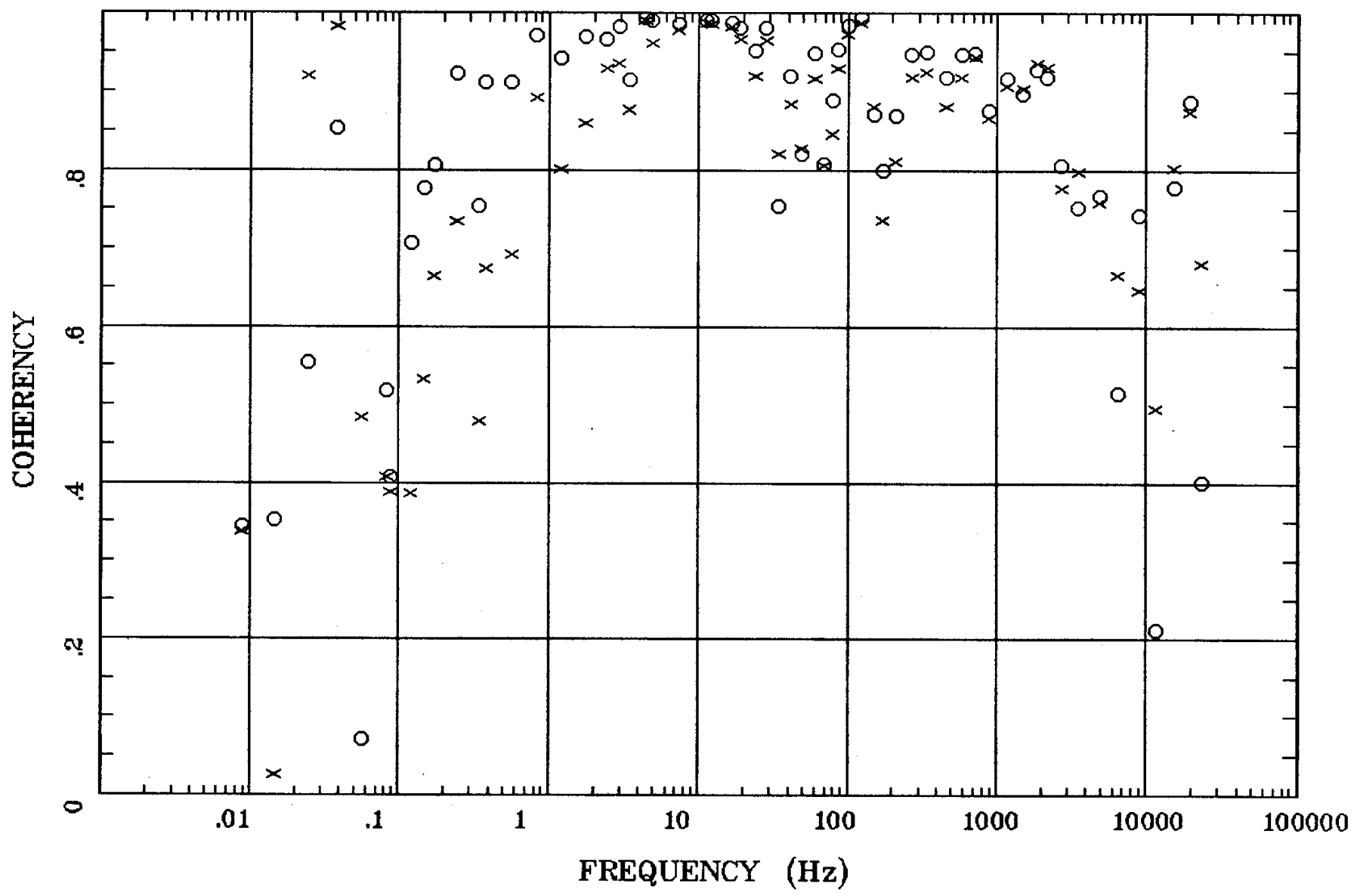

Client:

Remote: none

Acquired: 14:4 oct 10, 2001

Survey Co:USGS

\section{Rotation:}

Filename: ab9.avg

Channels: Ch1 Ch2 Ch3 Ch4 Ch5 Ch3 Ch4 Platted: 14:16 Nov 16, 2001

< EMI - ElectroMagnetic Instruments > 